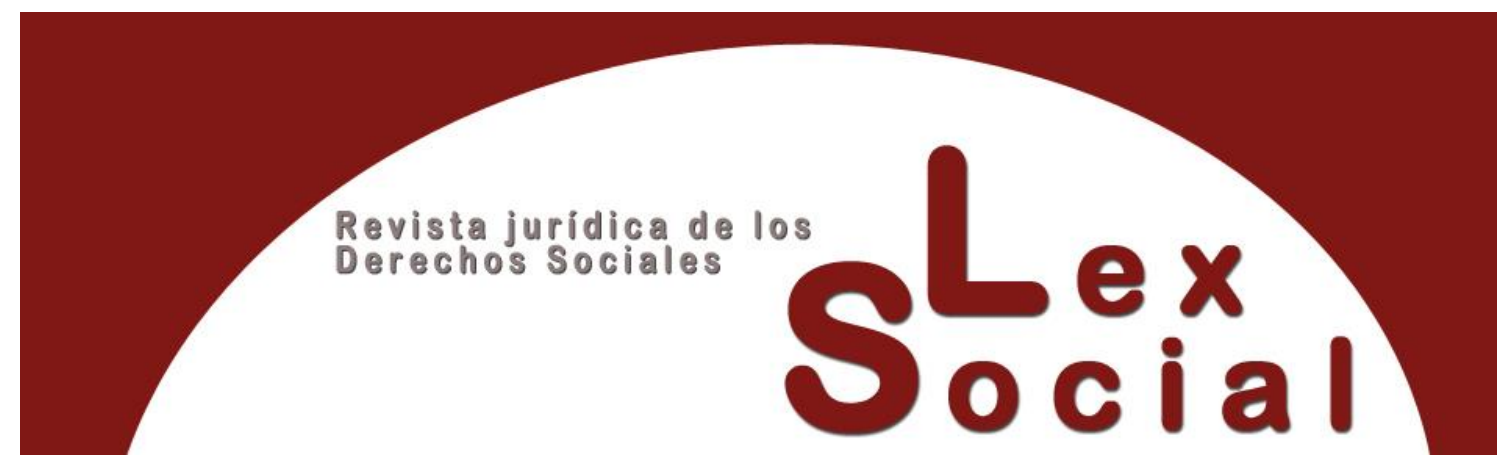

\title{
LOS CUIDADOS A LAS PERSONAS MAYORES: ASPECTOS ORGANIZATIVOS, SUBJETIVOS Y ASISTENCIALES DE LOS DENOMINADOS "SERVICIOS PÚBLICOS DE PROXIMIDAD"1
}

\section{CARE FOR THE OLDER PERSONS: ORGANIC, SUBJECTIVE AND ASSISTANCE ASPECTS OF THOSE DEFINED AS "PUBLIC SERVICES OF PROXIMITY"}

\author{
SUSANA RODRÍGUEZ ESCANCIANO \\ Catedrática de Derecho del Trabajo y de la Seguridad Social. \\ Universidad de León \\ http://orcid.org/0000-0001-5910-2982
}

Cómo citar este trabajo: Rodríguez Escanciano, S. (2021). Los cuidados a las personas mayores: aspectos organizativos, subjetivos y asistenciales de los denominados "servicios públicos de proximidad". Lex Social: Revista De Derechos Sociales, 11 (2), 662-728. https://doi.org/10.46661/lexnova.5965

\begin{abstract}
RESUMEN
Teniendo en cuenta que la longevidad conlleva una declinación de facultades físicas y mentales en una relación directamente ascendente, es necesario que los poderes públicos diseñen acciones dirigidas a proporcionar bienestar y dignidad en la vejez mediante la ayuda o atención de otra persona para la realización de las actividades básicas de la vida diaria. Pieza clave en este sistema de cuidados ha de ser la libertad de elección de los usuarios, que mayoritariamente manifiestan una clara voluntad de permanecer en sus domicilios, de manera que el Estado de Bienestar debe de proporcionar los servicios pertinentes a tal fin, al tiempo que debe procurar la
\end{abstract}

\footnotetext{
${ }^{1}$ Investigación realizada en el marco del Proyecto de Investigación LE013P20 de la Junta de Castilla y León "La prestación de servicios socio-sanitarios en el ámbito rural de Castilla y León: apostando por un bienestar integral".
}

\section{(cc) EY-NC-SA}


profesionalización de los empleados en tal sector de la actividad mejorando sus condiciones de trabajo.

Palabras Clave: sobre-envejecimiento, dependencia, mujer, ayuda a domicilio, cuidados no profesionales

\begin{abstract}
Considering that ageing leads to a decrease in physical and mental faculties in a directly ascending relationship, is necessary for the government to design actions aimed at providing wellbeing and dignity in old age through the help or care of another person to carry out the basic activities of daily living. A central element in this care system must be the freedom of choice of users, who for the most part express a clear desire to stay in their own homes, so that the Welfare State must provide the necessary services for this purpose, while at the same time providing for the professionalization of those employed in this sector of care activity by upgrading their working conditions.
\end{abstract}

KEYWORDS: over-ageing, dependency, woman, home help, non-professional care

SUMARIO

I. Necesidades de una población sobre-envejecida. La implicación de los poderes públicos

II. Cuidados de larga duración: la mujer como protagonista

III. El diseño de la Ley 39/2006, de 14 de diciembre, de Dependencia: servicios y prestaciones

IV. Heterogeneidad de agentes intervinientes en la red de servicios sociales públicos

1. Comunidades Autónomas

2. Administraciones Locales

3. Colaboración público-privada: posibilidades

3.1. El contrato administrativo de servicios

\title{
3.2. El tercer sector
}

3.2.1. Criterios de desempate entre licitadores a favor de entidades sin ánimo de lucro

\subsubsection{Contratos reservados y excluidos}

3.3. La técnica del concierto 


\subsection{Sistema de acreditación}

$V$. Los cuidados en el propio hogar como preferencia mayoritaria en la senescencia

1. El modelo de atención centrada en la persona

1.1. Salubridad, confortabilidad y conectividad de la vivienda como premisas para la dispensa de un servicio de teleasistencia avanzada

\subsection{El componente humano de los cuidados en el lugar de residencia}

\subsubsection{Ayuda a domicilio}

\subsubsection{Empleadas de hogar}

\subsubsection{Cuidadoras informales}

1.2.4. La asistencia personal: la apuesta por una regulación ad hoc

1.3. La doble jornada: la simultánea condición de trabajadoras y cuidadoras

\section{Conclusión: el respeto del derecho a decidir}

Bibliografía

"Cuenta tu jardín por las flores no por las hojas caídas"

(Trazos en el corazón Roger Patrón Luján)

\section{Necesidades de una población sobre-envejecida. La implicación de los poderes públicos}

Sin duda, la reducción de los índices de penosidad y peligrosidad en el trabajo fruto de los progresos tecnológicos, la calidad de la alimentación, el avance de la medicina y la innovación farmacéutica, han provocado que, en la última centuria, la expectativa de vida se haya visto incrementada en más de cuarenta años. Nuestro país da sobradas muestras de la llegada de un número cuantitativamente ascendente de personas a edades no sólo avanzadas sino muy avanzadas ("envejecimiento del envejecimiento" o "sobreenvejecimiento" $)^{2}$, no en vano un porcentaje nada desdeñable del 6,1 por 100 de la población son mayores de 80 años $^{3}$. Es más, las proyecciones poblacionales apuntan a que en el año 2065 las personas octogenarias van a representar el 18,1 por 100 de la

2 PÉREZ DÍAZ, J. y ABELLÁN GARCÍA, A.: "Envejecimiento demográfico y vejez en España", Panorama Social, núm. 28, 2018, pp. 30 y 31 ó ANAUT-BRAVO, S.: "Servicios sociales: definición en el marco del Estado de Bienestar", en VV.AA (ANAUT-BRAVO, S., Coord.): El sistema de servicios sociales en España, Aranzadi, Pamplona, 2019, p.54.

${ }^{3}$ Según los datos estadísticos definitivos del Padrón Continuo (INE), publicados el 27 de diciembre de 2019, hay en España 9.057.193 personas mayores de 65 años, un 19,3\% sobre el total de una población de 47.026.208 personas. La misma fuente destaca que sigue aumentando la proporción de centenarios que ascienden a 16.303 . 
población mayor ${ }^{4}$. Ahora bien, con ser estos datos positivos desde un punto de vista cuantitativo, la importancia de este grupo no radica solamente en su elevado montante, sino que ello va acompañado del surgimiento de nuevas carencias y necesidades que se deben cubrir a través de varios frentes.

En primer lugar, las personas ancianas deben recibir unos ingresos económicos dignos, sustitutivos de las rentas de trabajo, a cargo del sistema público de Seguridad Social, que articula, bajo los parámetros del art. $41 \mathrm{CE}$, una pensión de jubilación, configurada desde un doble punto de vista: de un lado, como prestación económica de carácter vitalicio asociada a la finalización de la carrera profesional por razón de la edad, basada en técnicas "aseguratorias" (requisitos de afiliación, alta y cotización) y "contributivas" (reconocimiento y cálculo de las prestaciones en función de las cotizaciones acreditadas) ${ }^{5}$; de otro, a través de un auxilio no contributivo para aquellos sujetos que no hubieran cotizado o no lo hubieran hecho durante un plazo suficiente ${ }^{6}$, financiado vía impuestos, limitado en su ámbito de aplicación a los ciudadanos sin recursos mayores de sesenta y cinco años, que carezcan de ingresos, teniendo en cuenta las percepciones individuales y de la unidad familiar ${ }^{7}$, al amparo de la Ley 26/1990, de 20 de diciembre ${ }^{8}$.

En segundo término, las personas mayores deben contar con un adecuado entramado de atención sanitaria y farmacéutica a través de los servicios públicos de salud, no en vano la edad avanzada está asociada, con un paralelismo exacto, a una mayor probabilidad de desarrollar dificultades de movilidad y enfermedades crónicas: hipertensión, afectaciones coronarias, diabetes, tumores, artritis, reumatismo, artrosis, colesterol, cataratas, demencia, parkinson, incontinencias esfinterianas, osteoporosis, enfisema, fatiga,

\footnotetext{
${ }^{4}$ DE VICENTE PACHÉS, F.: "Servicios sociales, envejecimiento activo y aprendizaje a lo largo de la vida", en VV.AA.: Por una pensión de jubilación, adecuada, segura y sostenible, Tomo II. III Congreso Internacional y XVI Congreso Nacional de la Asociación Española de Salud y Seguridad Social, Laborum, Murcia, 2019, p. 308.

5 MARTÍN VALVERDE, A.: "Asistencia social: propuesta de reconstrucción de un concepto constitucional", en VV.AA (MONEREO PEREZ, J.L.; MOLINA NAVARRETE, C. y MORENO VIDA, M.N., Coords.): La Seguridad Social a la luz de sus reformas pasadas, presentes o futuras. Homenaje al Profesor José Vida Soria con motivo de la jubilación, Comares, Granada, 2008, p. 1130.

${ }^{6}$ SALVADOR PÉREZ, F.: "La nueva pensión no contributiva de jubilación: objeto de la protección y régimen jurídico" (I), Actualidad Laboral, núm. 7, 1992, p. 110.

${ }^{7}$ No en vano las necesidades del interesado pueden llegar a ser menores o, incluso, desaparecer viviendo con otras personas que haciéndolo en solitario o con individuos sin ingresos. Por unidad familiar se entiende la unidad de convivencia y de dependencia económica con el beneficiario, considerando tal los casos de convivencia por razón de matrimonio o parentesco por consanguinidad hasta el segundo grado, tomando como fórmula para calcular el límite de recursos la equivalencia a la cuantía, en cómputo anual, de la pensión, más el resultado de multiplicar el 70 por 100 de dicha cifra por el número de convivientes menos uno, quedando mejorado este límite en 2,5 veces cuando dicha unidad familiar esté integrada por ascendientes o descendientes de primer grado (art. 363.2 y 4 LGSS). BARRIOS BAUDOR, G.L.; SEMPERE NAVARRO, A.V. y MEGINO FERNÁNDEZ, D.: “Art. 369", en VV.AA (SEMPERE NAVARRO, A.V. y BARRIOS BAUDOR, G.L., Dirs.): Comentarios a la Ley General de la Seguridad Social, Aranzadi, Pamplona, 2017, pp. 290 y ss.

${ }^{8}$ LÓPEZ CUMBRE, L.: "La pensión de jubilación", en VV.AA.: Derecho de la Seguridad Social, Tirant Lo Blanch, Valencia, 1997, p. 434.
} 
depresión o ansiedad, entre otras ${ }^{9}$. La cartera de servicios comunes del Sistema Nacional de Salud se recoge en el Real Decreto 1030/2006, de 15 de septiembre, que incluye prestaciones de salud pública, atención primaria, atención especializada, urgencias, dispensa farmacológica, ortoprotésica, dietética y de transporte sanitario ${ }^{10}$.

En tercer lugar, deben disponer de recursos técnicos de carácter público para gestionar su propia vida cotidiana en los aspectos más básicos y habituales, pues la longevidad conlleva una declinación de facultades físicas y mentales en una relación directamente ascendente, ya que el volumen de sujetos con limitaciones de su capacidad funcional aumenta significativamente en los grupos de edad superiores, sobre todo a partir de los 80 años ("cuarta edad") 11 . Siguiendo a la OMS, el envejecimiento puede definirse como la consecuencia de un proceso de acumulación de una gran variedad de daños moleculares y celulares a lo largo del tiempo que provoca un descenso gradual de las habilidades corporales y emocionales ${ }^{12}$. A pesar de la variabilidad individual, derivada de predisposiciones genéticas y de historia vital, la literatura científica ha constatado que la senectud provoca una disminución de las destrezas psicosomáticas que limita la adaptación del organismo al medio y su posibilidad de respuesta a las distintas exigencias. Como con acierto se ha dicho, dependencia no está ligada necesariamente a gran edad, pero es en ella donde tiene su principal manifestación ${ }^{13}$ ante "la pérdida de autonomía física, mental, intelectual o sensorial" ${ }^{14}$.

En fin, los tres pilares mencionados (monetario, sanitario y asistencial) deben estar perfectamente ensamblados ${ }^{15}$, convenientemente dotados y suficientemente financiados,

\footnotetext{
${ }^{9}$ RUBIO RUBIO, L. y DUMITRACHE, C.G.: "Salud y tercera edad", en VV.AA (MONEREO PÉREZ, J.L.; MALDONADO MOLINA, J.A. y RUBIO HERRERA, R., Dirs.): Prevención y protección de la dependencia: un enfoque transdisciplinar, Comares, Granada, 2014, pp. 103 y ss.

10 DÍAZ AZNARTE, M.T.: "El sistema nacional de salud y las carteras de servicios común y complementarias: una visión crítica de la descentralización territorial en materia de asistencia sanitaria", en VV.AA (MORENO VIDA, M.N. y DÍAZ AZNARTE, M.T, Dir.): La protección social de la salud en el marco del Estado de bienestar: una visión nacional y europea, Comares, Granada, 2019, pp. 119 y ss.

${ }^{11}$ VADILLO RUÍZ, J.J.: "Respuestas a los nuevos retos de envejecimiento, protección a la salud y cuidados: la perspectiva médica", en VV.AA.: Por una pensión de jubilación, adecuada, segura y sostenible, III Congreso Internacional y XVI Congreso Nacional de la Asociación Española de Salud y Seguridad Social, Laborum, Murcia, 2019, p. 64.

12 OMS: Envejecimiento y salud. Nota descriptiva núm. 404, septiembre 2015, http://apps.who.int/iris/bitstream/10665/186466/1/9789240694873_spa.pdf?ua=1

${ }^{13}$ MALDONADO MOLINA, J.A.: El seguro de dependencia. Presente y proyecciones de futuro, Tirant Lo Blanch, Valencia, 2003, p. 14.

${ }^{14}$ BAYLOS GRAU, A.: "A propósito del envejecimiento", Revista de Derecho Social, núm. 87, 2019, p. 15.

${ }^{15}$ Manifestación señera de esta imbricación puede encontrarse en el art. 14 de la Ley 16/2003, de 28 de mayo, de Cohesión y Calidad del Sistema Nacional de Salud, que comprende, bajo la denominación de prestación sociosanitaria, el conjunto de cuidados destinados a aquellos enfermos, generalmente crónicos, que por sus especiales características pueden beneficiarse de la actuación simultánea y sinérgica de los servicios sanitarios y sociales para aumentar su autonomía, paliar sus limitaciones o sufrimientos y facilitar su reinserción social. La atención sociosanitaria se lleva a cabo en los niveles de atención que cada Comunidad Autónoma determine y, en cualquier caso, aglutina: a) Los cuidados sanitarios de larga duración; b) La atención sanitaria a la convalecencia; c) La rehabilitación en pacientes con déficit funcional recuperable. MARTÍNEZ BARROSO, M.R.: "La atención a la dependencia en el mundo rural", en VV.AA
} 
sin que ninguno de ellos pueda considerarse prescincible o secundario ${ }^{16}$, tal y como exige el marco pautado por Naciones Unidas en la Agenda 2030, donde se encomienda a los distintos países realizar los esfuerzos pertinentes para garantizar el bienestar de las personas mayores, protegiendo sus derechos humanos, su seguridad económica, el acceso a la atención sanitaria, a las redes de apoyo formal e informal y al aprendizaje permanente ${ }^{17}$, objetivos reiterados en el Plan de Acción para la Implementación de la Agenda 2030 en España donde consta una apuesta clara a favor de la dignificación de las condiciones de vida en la tercera edad ${ }^{18}$.

\section{Cuidados de larga duración: la mujer como protagonista}

Como consecuencia del cambio abrupto en la estructura poblacional a consecuencia del aumento de la esperanza de vida, el número de personas en situación de dependencia ha empezado a experimentar un crecimiento exponencial, surgiendo nuevas necesidades de ayuda externa, derivadas de una serie de factores que combinan, de forma variable, severas disfunciones orgánicas y psicológicas, habitualmente resultado de graves enfermedades crónicas o trastornos incapacitantes, asociados a carencias diversas como la soledad, la falta de recursos materiales o las barreras arquitectónicas ${ }^{19}$.

La tutela de la senectud no debe quedar cubierta únicamente con el diseño de la pensión contributiva y no contributiva de jubilación dentro del ordenamiento de la Seguridad Social y por la atención sanitaria a través del sistema de salud; antes al contrario, a tal colectivo se debe destinar también otras prestaciones no económicas ${ }^{20}$, sino "técnicas" o "de hacer", dirigidas a proporcionar bienestar y calidad de vida a través de ayudas, atenciones y cuidados que auxilien sus deterioros físicos o cognitivos ${ }^{21}$.

(RODRÍGUEZ ESCANCIANO, S. y ÁLVAREZ CUESTA, H., Dirs.): La economía social como palanca para la sostenibilidad de los territorios rurales, Tirant Lo Blanch, Valencia, 2020 (en prensa).

${ }^{16}$ OBSERVATORIO ESTATAL DE LA DEPENDENCIA: XX Dictamen del Observatorio, Madrid (Asociación Estatal de Directoras y Gerentes en Servicios Sociales), 2020, p. 2, recuperado de https://dependencia.info/imagenes/xx-dictamen-observatorio-dependencia.pdf (15-01-2021).

17 BAVIERA PUIG, I.: "Desarrollo sostenible, transformación digital y atención a las personas: oportunidades y riesgos del envejecimiento demográfico", Adapt. Revista Internacional y Comparada de Relaciones Laborales y Derecho del Empleo, vol. 8, núm. 1, 2020, p. 153.

${ }^{18} \mathrm{http} / / /$ www.exteriores.gob.es/Portal/es/SalaDePrensa/Multimedia/Publicaciones/Documents/PLAN\%20 DE\%20ACCION\%20PARA\%20LA\%20IMPLEMENTACION\%20DE\%20LA\%20AGENDA\%202030.p df

${ }^{19}$ RUBIO HERRERA, R. y CASTELLÓN SÁNCHEZ DEL PINO, A.: "Las situaciones de dependencia desde una perspectiva socio-sanitaria", en VV.AA (MONEREO PÉREZ, J.L.; MALDONADO MOLINA, J.A. y RUBIO HERRERA, R., Dir.): Prevención y protección de la dependencia: un enfoque transdisciplinar, Comares, Granada, 2014, p. 14.

${ }^{20}$ VALDÉS DAL-RE, F.: "Una aproximación constitucional a los problemas competenciales de la Ley de Dependencia", Documentación Laboral, núm. 102, 2014, p. 18.

${ }^{21}$ ALEMÁN BRACHO, C. y ALONSO SECO, J.M.: "Los servicios sociales: sistema público de protección social", Revista Española de Derecho del Trabajo, núm. 151, 2011, p. 682 ó MOLINA GONZÁLEZPUMARIEGA, R.: "Los servicios del sistema para la autonomía y atención a la dependencia tras seis años de funcionamiento", en VV.AA (MOLERO MARAÑÓN, M.L., Coord.): Retos para una implantación efectiva del sistema para la autonomía y atención a la dependencia, Cinca, Madrid, 2012, p. 111. 
Es necesario, por tanto, un entramado público de atención in natura a la dependencia, que abandone el segundo plano que tradicionalmente había ocupado al pivotar sobre la caridad, la solidaridad de la beneficencia y el apoyo familiar intergeneracional, para pasar ahora a adquirir la cualidad de derecho de la ciudadanía ${ }^{22}$, de manera que el Estado del Bienestar tiene que evolucionar para involucrarse más decisivamente en impulsar e invertir en este sector de cuidados de las personas mayores, no en vano está llamado a convertirse en su cuarto pilar debiendo aspirar a proporcionar un catálogo acabado de derechos exigibles con mínimos óptimos e iguales en todo el territorio del Estado español ${ }^{23}$. Se trata de dar cumplimiento, así, a lo dispuesto en el art. 4 del Protocolo Adicional de 1988 a la Carta Social Europea de 1961 y en el art. 23 de la Carta Social Europea revisada de 1996 proporcionando un sistema de cuidados a largo plazo destinado a la pérdida de autonomía por causa de la edad avanzada, concebido como auténtica prerrogativa de los posibles beneficiarios condicionada únicamente al cumplimiento de los requisitos exigidos para su disfrute ${ }^{24}$. Sobre esta idea insiste el Pilar Europeo de Derechos Sociales, cuyo principio 18 establece que "toda persona tiene derecho a cuidados de larga duración asequibles y de buena calidad, en particular la asistencia a domicilio y los servicios domiciliarios" 25 .

En fin, dentro de este sistema las mujeres adquieren un extraordinario papel protagonista desde una doble perspectiva: de un lado, en cuanto personas potencialmente destinatarias de los cuidados, no en vano a partir de los 80 años hay más del doble de mujeres que de hombres $^{26}$; de otro, como principales prestadoras de los servicios en un sector intensivo en empleo donde la feminización del personal supera el 85 por $100^{27}$.

\footnotetext{
${ }^{22}$ MALDONADO MOLINA, J.A.: Génesis y evolución de la protección social por vejez en España, MTAS, Madrid, 2002, p. 24.

${ }^{23}$ ROQUETA BUJ, R.: "Principios básicos del sistema de protección social: el principio de igualdad territorial a debate", Documentación Laboral, núm. 102, 2014, vol.III, p. 34.

${ }^{24}$ CARRIL VÁZQUEZ, J.M.: "Argumentos de Derecho Internacional justificadores de que la legislación española tenga que adaptarse al envejecimiento de la población para proteger a las personas mayores con un sistema de atención (o de cuidados) a largo plazo", en VV.AA.: Estudios sobre Seguridad Social. Libro homenaje al profesor José Ignacio García Ninet, Atelier, Barcelona, 2017, pp. 127 y ss.

${ }^{25}$ ALONSO SECO, J.M.: "Las nuevas Leyes autonómicas de servicios sociales: hacia un reconocimiento progresivo de los servicios sociales como derechos subjetivos", Revista General de Derecho Administrativo, núm. 45, 2017, p. 2.

${ }^{26}$ Según los datos estadísticos facilitados por el IMPSERSO, el perfil de la persona beneficiaria de algún tipo de prestación asociada a la LD, coincide con el de una mujer española, mayor de 80 años, residente en una localidad de más de 50.000 habitantes, valorada en situación de gran dependencia, perceptora de una pensión de viudedad de la Seguridad Social, con una renta media situada entre uno y dos veces el IPREM y titular de un patrimonio inmobiliario, reducido mayoritariamente a su residencia habitual. https://www.imserso.es/InterPresent1/groups/imserso/documents/binario/im_061358.pdf

${ }^{27}$ CES: Informe 3/2020. El sistema de promoción de la autonomía personal y atención a las personas en situación de dependencia, CES, Madrid, 2021, pp. 12-13.
} 


\section{El diseño de la Ley 39/2006, de 14 de diciembre, de Dependencia: servicios y prestaciones}

La dispensa de cuidados de larga duración a la población de edad avanzada exige una respuesta firme por parte de los poderes públicos, que se ha pretendido llevar a cabo a través de la Ley 39/2006, de 14 de diciembre, de Promoción de la Autonomía Personal y Atención a la Situación de Dependencia (LD). Cierto es que esta Ley no tiene como destinatarios exclusivos a las personas mayores, si bien en la mayor parte de los casos se aplica para este colectivo, de manera que son las personas de más de 80 años quienes reciben la mayor parte de las atenciones ${ }^{28}$. El reconocimiento de la situación se efectuará, previa tramitación de un procedimiento a instancia de la persona que puede ser afectada o de quien ostente su representación, mediante resolución expedida por la Administración Autonómica de residencia del solicitante y tendrá validez para todo el territorio del Estado (art. 28) ${ }^{29}$, previa valoración por los correspondientes órganos técnicos de la Comunidad Autónoma, que se ocuparán de medir el grado de afectación aplicando un baremo estandarizado regulado con carácter general para todo el ámbito geográfico nacional en el Real Decreto 174/2011, de 11 de febrero, a partir del cual se obtendrá un resultado ubicado en las posibilidades de una cuádruple clasificación ${ }^{30}$ :

a) Sin grado: cuando el afectado no consigue alcanzar una valoración mínima, careciendo de la condición de dependiente.

b) Grado I: Dependencia moderada: cuando la persona necesita ayuda para realizar varias actividades básicas de la vida ordinaria, al menos una vez al día o presenta necesidades de apoyo intermitente o limitado para su autonomía personal.

c) Grado II: Dependencia severa: cuando la persona necesita ayuda para realizar varias actividades básicas de la vida diaria dos o tres veces al día pero no quiere el apoyo permanente de un cuidador, o tiene necesidades de auxilio externo para su autonomía personal.

d) Grado III: Gran dependencia: cuando la persona necesita ayuda para realizar varias actividades básicas de la vida diaria repetidas veces al día y, por su pérdida total de autonomía física, mental, intelectual o sensorial, demanda el apoyo indispensable y

\footnotetext{
${ }^{28}$ La mayor parte de la población beneficiaria, el 72 por 100, se encuentra en el tramo de edad superior a los 65 años, y el 54 por 100 ha alcanzado ya los 80 años. CES: Informe 3/2020. El sistema de promoción de la autonomía personal y atención a las personas en situación de dependencia, cit., p. 39.

${ }^{29}$ HERAS HERNÁNDEZ, M.L.: "Beneficiarios directos e indirectos de la protección social de la dependencia", en VV.AA (MOLERO MARAÑÓN, M.L., Coord.): Retos para una implantación efectiva del sistema para la autonomía y atención a la dependencia, Cinca, Madrid, 2012, p. 29 ó DURÁN BERNARDINO, M.: "La distribución constitucional y legal de competencias en el modelo de protección social a la dependencia", Aranzadi Social, núm. 8, 2013 (BIB 2013/2373).

30 BARRIOS BAUDOR, G.L.: "Avances y disfunciones en el procedimiento de reconocimiento de la dependencia: la valoración de la dependencia", Documentación Laboral, núm. 102, 2014, Vol. III, pp. 93 y ss. ó MARTÍN-SERRANO JIMÉNEZ, E.: El principio de cooperación como solución del Estado Autonómico. Una propuesta para la reforma (constitucional o no) del sistema público de protección social en España, Comares, Granada, 2018, p. 208.
} 
continuo de otra persona, o tiene necesidades de apoyo generalizado para su autonomía personal.

Como fácilmente puede apreciarse, la intensidad requerida de auxilio externo (personal y/o material según los casos) es el elemento clave para la inclusión de las personas dependientes en uno u otro nivel ${ }^{31}$. Dos referentes adicionales inciden en la conclusión a alcanzar. Por un lado, la autonomía personal, establecida en función de la mayor o menor necesidad de dicho apoyo por su carácter intermitente o limitado, extenso o generalizado. Por otro, la realización de las actividades básicas de la vida diaria cifrada por dos parámetros cumulativos: el temporal, delimitado por la referencia a la jornada diaria, y el personal, relacionado con la intervención, mayor o menor, de una tercera persona (cuidador, profesional o no ${ }^{32}$. De este modo, según el apoyo requerido sea ocasional, más o menos continuo o permanente en el día y según exija o no la presencia constante, indispensable y continua de un cuidador, así será también el grado reconocido. Todo ello, claro está, por referencia siempre a la realización de varias (dos o más y no sólo una) actividades básicas de la vida diaria, definidas como "las tareas más elementales de la persona, que le permiten desenvolverse con un mínimo de autonomía e independencia, tales como: el cuidado personal, las actividades domésticas básicas, la movilidad esencial, reconocer personas y objetos, orientarse, entender y ejecutar órdenes o tareas sencillas" $(\text { art. } 2.3 \mathrm{LD})^{33}$.

La resolución adoptada no sólo va a reconocer el grado de afectación, sino también los servicios y prestaciones más adecuados a su situación personal, concretados en el programa individual de atención ${ }^{34}$ (con sus respectivas intensidad, extensión y duración) "con la participación, previa consulta y, en su caso, elección entre las alternativas propuestas por parte del beneficiario y, en su caso, de su familia o entidades tutelares que le representen" (art. 29.1 de la LD)] ${ }^{35}$ :

1.- Teleasistencia, que facilita la puesta en contacto mediante el uso de tecnologías de la comunicación y de la información, proporcionando a través de un dispositivo

\footnotetext{
${ }^{31}$ A 31 de diciembre de 2019, han sido 1.385.037 las personas valoradas como dependientes, de las cuales en Grado I han sido ubicadas 467.298 (26,93\%); en el Grado II, 515.590 (29,71\%) y en el Grado III, 402.149 $(23,17 \%)$.

https://www.directoressociales.com/images/documentos/dictamenes/XX_Dictamen/INFO\%20GLOBAL \%20XX\%20DICTAMEN\%203-3-20_compressed.pdf

${ }^{32}$ SANZ MERINO, A.R.: Manual básico del sistema de Seguridad Social, La Ley, Madrid, 2010, p. 1170.

${ }^{33}$ BARRIOS BAUDOR, G.: "La dependencia y su valoración", en VV.AA (MOLERO MARAÑÓN, M.L.,

Coord.): Retos para una implantación efectiva del Sistema para la Autonomía y Atención a la Dependencia, Cinca, Madrid, 2012, p. 39.

${ }^{34}$ LLANO SÁNCHEZ, M.: "El marco procedimental del sistema de atención a la dependencia: balance crítico de los desarrollos normativos y de la práctica administrativa", Documentación Laboral, núm. 102, 2014, vol. III, p. 140 ó MOLERO MARAÑÓN, M.L.: Bases, evolución y retos de la Ley de Dependencia a los diez años de su aprobación, Bomarzo, Albacete, 2017, p. 23.

${ }^{35}$ GARCÍA NINET, J.I.; DE VICENTE PACHÉS, F. y GARRIGUES GIMÉNEZ, A.: "Configuración técnica de los servicios sociales y régimen jurídico", en VV.AA (MONEREO PÉREZ, J.L.; MOLINA NAVARRETE, C. y MORENO VIDA, M.N., Coords.): La Seguridad Social a la luz de sus reformas pasadas, presentes y futuras, Comares, Granada, 2008, p. 1163.
} 
respuesta profesional inmediata ante situaciones de emergencia, de inseguridad, soledad o aislamiento, lo cual evita o retrasa el internamiento en un centro residencial ${ }^{36}$.

2.- Ayuda a domicilio, constituida por el conjunto de actuaciones llevadas a cabo en la vivienda de las personas necesitadas con el fin de atender sus necesidades de la vida diaria, así como domésticas o del hogar, esto es, limpieza, lavado o cocina, ligadas estas últimas a su atención personal.

3.- Centro de día y de noche, el cual ofrece una atención integral durante el período diurno o nocturno con el objetivo de mejorar o mantener el nivel más óptimo posible de autonomía personal, apoyando a las familias o cuidadores. Dentro de este canal, se reconoce un servicio de manutención y restauración a los usuarios, se prestan atenciones $\mathrm{y}$ ayudas personales, se hace un seguimiento y tratamiento de la salud, se realizan actividades de prevención y promoción de hábitos saludables, de rehabilitación, mantenimiento y terapéuticas, se proporcionan eventos socioculturales y se ofrece orientación a la familia, transporte adaptado y asistencia durante el transporte diario ${ }^{37}$.

4.- Internamiento residencial, que ofrece servicios continuados de carácter personal y sanitario, prestados en centros habilitados al efecto y dotados con mecanismos necesarios para atender las distintas intensidades de cuidados requeridos en función de las circunstancias personales.

5.- Junto a los anteriores, cabe aludir también a los servicios planificados ex ante, esto es, para evitar situaciones de dependencia, cuyo objeto es "prevenir la aparición o el agravamiento de enfermedades o discapacidades y sus secuelas mediante el desarrollo coordinado entre los servicios sociales y de salud de actuaciones de promoción de condiciones de vida saludables, programas específicos de carácter preventivo y de rehabilitación dirigidos a las personas mayores y personas discapacitadas y a quienes se ven afectados por procesos de hospitalización completos" (art. $21 \mathrm{LD}$ ). E, igualmente, los de promoción de la autonomía personal, cuya finalidad es "desarrollar y mantener la capacidad personal de controlar, afrontar y tomar decisiones acerca de cómo vivir de acuerdo con las normas y preferencias propias y facilitar la ejecución de las actividades básicas de la vida diaria”, incluyendo "asesoramiento, orientación, asistencia y formación en tecnologías de apoyo y adaptaciones que contribuyan a facilitar la realización de las actividades de la vida diaria, los de habilitación, los de terapia ocupacional así como cualesquiera otros programas de intervención que se establezcan con la misma finalidad" (art. 6 Real Decreto 1051/2013).

\footnotetext{
${ }^{36}$ Resolución de 15 de enero de 2018, de la Secretaría de Estado de Servicios Sociales e Igualdad, por la que se publica el Acuerdo del Consejo Territorial de Servicios Sociales y del Sistema para la Autonomía y Atención a la Dependencia, sobre determinación del contenido del servicio de teleasistencia básica y avanzada. RODRÍGUEZ MARTÍN-RETORTILLO, M.C.: "Los contratos de teleasistencia en la doctrina de los Tribunales administrativos de contratación", Anuario de la Facultad de Derecho de la Universidad de La Coruña, núm. 23, 2019, pp. 339 y ss.

37 DURÁN BERNARDINO, M.: "La evolución de la acción protectora de las prestaciones de servicios. Impacto de las últimas reformas”, en VV.AA (MOLERO MARAÑÓN, M.L., Dir.): Dependencia (long term care) y empleo en el Estado del Bienestar, Aranzadi, Pamplona, 2017, pp. 219.
} 
Por su parte, tres son las prestaciones económicas fijadas con carácter secundario, bien al quedar supeditadas a la imposibilidad de atención mediante el catálogo de servicios, como sucede con la ayuda económica vinculada al servicio que sufraga parcialmente su adquisición en el mercado recurriendo a entidades privadas (art. 17), bien por estar concebidas de forma excepcional como se produce con la subvención para cuidados en el entorno familiar (art. 18), o bien por venir restringido su campo de actuación a la contratación de una persona sin atribución clara de funciones como sucede con el auxilio de asistencia personal (art. 19) ${ }^{38}$.

Como ya consta, dicha doble alternativa (servicios o prestaciones) no implica que la opción por una u otra se establezca de forma indiferenciada o neutra ${ }^{39}$. Por el contrario, la ordenación legal establece una relación de jerarquía entre ambos canales que se resuelve de forma decidida a favor de los primeros frente a las segundas (art. 14.2 LD). Con ello, el legislador ha buscado que sea el sistema púbico el que asuma la obligación de dispensa directa de la atención requerida por las personas dependientes a través de un conjunto de infraestructuras y equipamientos profesionalizados, de carácter público o, en su caso, concertado, capaz de cubrir las necesidades de las personas mayores, lo que implica una apuesta de política legislativa abiertamente rupturista con la tradición de cuidados familiares, fundamentalmente a cargo de mujeres ${ }^{40}$.

\section{Heterogeneidad de agentes intervinientes en la red de servicios sociales públicos}

La LD pretende la regulación de las condiciones básicas que garanticen la igualdad en el ejercicio del derecho subjetivo de ciudadanía a la promoción de la autonomía personal y atención a las personas en situación de dependencia, con la garantía por la Administración General del Estado de un contenido mínimo común de derechos para todos los ciudadanos en cualquier parte del territorio español ${ }^{41}$, acompañado de una herramienta fundamental, auténtica "llave" 42 , cual es el baremo de valoración que es homogéneo para todo el territorio nacional ${ }^{43}$, respetando, al tiempo, la legítima capacidad de intervención de las

\footnotetext{
${ }^{38}$ MOLINA GONZÁLEZ-PUMARIEGA, R.: "Los servicios del Sistema para la Autonomía y Atención a la Dependencia tras seis años de funcionamiento", en VV.AA (MOLERO MARAÑÓN, Ma.L., Coord.): Retos para una implantación efectiva del Sistema para la Autonomía y Atención a la Dependencia, Cinca, Madrid, 2013, p. 111.

39 MARTÍN-SERRANO JIMÉNEZ, E.: El principio de cooperación como solución del Estado Autonómico. Una propuesta para la reforma (constitucional o no) del sistema público de protección social en España, Comares, Granada, 2018, p. 68.

${ }^{40}$ CAVAS MARTÍNEZ, F.: "La apuesta por el catálogo de servicios en el sistema de atención y protección de la dependencia", Documentación Laboral, núm. 102, 2014, pp. 145-146.

${ }^{41}$ GARCÍA NINET, J.I.; DE VICENTE PACHÉS, F. y GARRIGUES GIMÉNEZ, A.: “Configuración técnica de los servicios sociales y régimen jurídico", en VV.AA (MONEREO PÉREZ, J.L.; MOLINA NAVARRETE, C. y MORENO VIDA, M.N., Coords.): La Seguridad Social a la luz de sus reformas pasadas, presentes y futuras, Comares, Granada, 2008, p. 1177.

42 MERCADER UGUINA, J.R.: "Titularidad, valoración y reconocimiento de las situaciones de dependencia", Temas Laborales, núm. 89, 2007, p. 162.

43 BARRIOS BAUDOR, G.: "La dependencia y su valoración”, en VV.AA (MOLERO MARAÑÓN, $\mathrm{M}^{\mathrm{a}}$.L., Coord.): Retos para una implantación efectiva del Sistema para la Autonomía y Atención a la Dependencia, Cinca, Madrid, 2013, p. 43.
} 
Comunidades Autónomas y manteniendo inmodificada la titularidad de la red de servicios sociales de las respectivas Autonomías ${ }^{44}$.

\section{Comunidades Autónomas}

En el momento de establecer la distribución de cometidos entre el poder central y las Autonomías, el art. 148.1.20 $\mathrm{CE}$ opta por otorgar competencia exclusiva a estas últimas en materia de asistencia social de conformidad con sus Estatutos ${ }^{45}$, razón por la cual los distintos entes territoriales autonómicos han procedido a articular su propia red de servicios sociales ${ }^{46}$. En concreto, los "mayores" (o "tercera edad") aparecen mencionados expresamente en doce Estatutos de autonomía distintos: Aragón, Islas Baleares, Cantabria, Castilla y León, Castilla-La Mancha, Comunidad Valenciana, Extremadura, Madrid, Murcia, Navarra, País Vasco y la Rioja ${ }^{47}$.

Las pautas que el propio texto constitucional ofrece como guía en el actuar de las Comunidades Autónomas se recogen en el art. 50 CE, que se refiere precisamente a los servicios sociales haciendo expresa referencia a las personas de la tercera edad, adoptando una premisa destinada a perseguir un concepto amplio de "bienestar" 48 y por atender desde un punto de vista objetivo a demandas muy variadas ("salud, vivienda, cultura y ocio" $^{49}$, en lo que se ha venido a calificar como "un plus a la mera suficiencia

\footnotetext{
${ }^{44}$ RODRÍGUEZ ESCANCIANO, S.: "Los cuidados en la vejez como servicio social público esencial: hacia una cobertura integral", Revista General de Derecho del Trabajo y de la Seguridad Social, núm. 57, 2020, pp. 99 y ss.

${ }^{45}$ Art. 10 del Estatuto de Autonomía del País Vasco aprobado por Ley Orgánica 3/1979; art. 27 del Estatuto de Autonomía de Galicia aprobado por Ley Orgánica 1/1981; art. 19 del Estatuto de Autonomía del Principado de Asturias, aprobado por Ley Orgánica 7/1981; art. 26 del Estatuto de Autonomía de Cantabria, aprobado por Ley Orgánica 8/1981; art. 8 del Estatuto de Autonomía de La Rioja, aprobado por Ley Orgánica 3/1982; art. 12 del Estatuto de Autonomía de la Región de Murcia, aprobado por Ley Orgánica 4/1982; art. 49 del Estatuto de Autonomía de la Comunidad Valenciana, aprobado por Ley Orgánica 5/1982: art. 31 del Estatuto de Autonomía de Castilla-La Mancha, aprobado por Ley Orgánica 9/1982; art. 30 del Estatuto de Autonomía de Canarias, aprobado por Ley Orgánica 10/1982; art. 44 de la Ley de Reintegración y amejoramiento del Régimen Foral Navarro, aprobada por Ley Orgánica 13/1982; art. 28 del Estatuto de Autonomía de la Comunidad de Madrid, aprobado por Ley Orgánica 3/1983; art. 30 del Estatuto de Autonomía de las Islas Baleares, aprobado por Ley Orgánica 1/2007; art. 166 del Estatuto de Autonomía de Cataluña, aprobado por Ley Orgánica 6/2006; art. 61 del Estatuto de Autonomía de Andalucía, aprobado por Ley Orgánica 2/2007; art. 71 del Estatuto de Autonomía de Aragón, aprobado por Ley Orgánica 5/2007; art. 71 del Estatuto de Autonomía de Castilla y León, aprobado por Ley Orgánica 14/2007 y art. 9 del Estatuto de Autonomía de Extremadura, aprobado por Ley Orgánica 1/2011. TRILLO GARCÍA, A.R.: "Art. 62”, en VV.AA (SEMPERE NAVARRO, A.V. y BARRIOS BAUDOR, G.L., Dirs.): Comentarios a la ley General de la Seguridad Social, Volumen I, Aranzadi, Pamplona, 2017, p. 493.

46 DE VICENTE PACHES, F.: Asistencia social y servicios sociales. Régimen de distribución de competencias, Secretaría General del Senado, Madrid, 2003, pp. 99 y ss.

${ }^{47}$ FERNANDEZ ORRICO, F.J.: “Art. 53”, en VV.AA (SEMPERE NAVARRO, A.V., Dir.): Comentarios a la Ley General de Seguridad Social, Laborum, Murcia, 2003, p. 261.

48 BAYLOS GRAU, A.: "Protección jurídica de las personas mayores. Tutela del empleo y del envejecimiento activo", en VV.AA.: Por una pensión de jubilación, adecuada, segura y sostenible, III Congreso Internacional y XVI Congreso Nacional de la Asociación Española de Salud y Seguridad Social, Laborum, Murcia, 2019, p. 13.

49 MARTÍN VALVERDE, A.: "Asistencia social: propuesta de reconstrucción de un concepto constitucional", Anuario de la Facultad de Derecho de la Universidad de Oviedo, núm. 2, 2017, p. 1150.
} 
económica" ${ }^{, 50}$.

Desde tal atalaya, las Autonomías han articulado tanto en los planos normativo como en el ejecutivo una serie varia de acciones "técnicas" o "de hacer" 51 tendentes al bienestar las personas de edad avanzada ${ }^{52}$ destinando ayudas, atenciones y cuidados ${ }^{53}$ a tal fin. En este entramado en el que se engarza la LD, que, con fundamento constitucional en el art. 149.1.1 ${ }^{\mathrm{a}} \mathrm{CE}^{54}$, pretende atender las necesidades de cuidado como cuarto pilar del Estado de Bienestar ${ }^{55}$.

La LD da cumplimiento, por tanto, al principio de cooperación interadministrativa, creando un mecanismo de protección integrado, a su vez, por tres elementos de distinta naturaleza: 1) una red de servicios sociales; 2) una organización administrativa para la gestión y coordinación de la acción protectora; y 3) un soporte financiero para sufragar tanto los servicios y prestaciones dispensados como el aparato administrativo que gestiona y coordina su implementación ${ }^{56}$. En suma, al nivel mínimo de protección garantizado directamente por la Administración General del Estado, se añade, por una parte, un segundo nivel a través de la cooperación entre tal Administración y las Comunidades Autónomas, mediante convenios entre ambas, y, por otra, un posible tercer nivel adicional, que podrá ser desarrollado por las Comunidades Autónomas que lo estimen conveniente. Tanto el nivel acordado como el adicional son niveles "contingentes", pues requieren la inexcusable colaboración o intervención de las Autonomías territoriales ${ }^{57}$. Los entes autonómicos asumen, pues, una intervención esencial en orden a la planificación, ordenación y gestión en su propio territorio de la LD. Como con acierto se ha dicho, la actual configuración de los servicios sociales a nivel

\footnotetext{
${ }^{50}$ Citando a FIGUERUELO BURRIEZA, A., DE LORENZO, R.: 'Los servicios sociales en la Constitución Española", Revista General de Derecho Administrativo, núm. 52, 2019, p. 2.

${ }^{51}$ VALDÉS DAL-RE, F.: "Una aproximación constitucional a los problemas competenciales de la Ley de Dependencia”, Documentación Laboral, núm. 102, 2014, p. 18.

${ }^{52}$ GARCÉS SANAGUSTÍN, A.: La acción social: delimitación conceptual y régimen jurídico, Diputación General de Aragón, Zaragoza, 1988, pp. 91 y ss.

53 DE VICENTE PACHES, F.: "Asistencia social y servicios sociales: régimen de distribución de competencias”, Tribuna Social, núm. 138, 2002, pp. 9 y ss. Precisamente, las primeras manifestaciones autonómicas en materia de servicios sociales se centraron en las personas mayores, pues desde los años ochenta han diseñado planes ad hoc destinados a este colectivo, pudiendo mencionar a título ejemplificativo, el Plan Gerontológico Regional de Extremadura, el Plan de las Personas Mayores de Madrid, el Plan Integral de Personas Mayores de Navarra o el Plan para las Personas Mayores de Castilla y León. TERRÓN SANTOS, D.: "Políticas de dependencia en el Estado de las Autonomías", Revista Noticias de la Unión Europea, núm. 303, 2010, p. 49.

${ }^{54}$ STCo 18/2016, de 4 de febrero.

${ }^{55}$ DE LA VILLA GIL, L.E.: “Asistencia social y crisis económica”, Revista Universitaria de Ciencias del Trabajo, núm. 15, 2014, p. 206.

56 MARTÍN VALVERDE, A.: “Asistencia social: propuesta de reconstrucción de un concepto constitucional”, en VV.AA (MONEREO PEREZ, J.L.; MOLINA NAVARRETE, C. y MORENO VIDA, M.N., Coords.): La Seguridad Social a la luz de sus reformas pasadas, presentes o futuras. Homenaje al Profesor José Vida Soria con motivo de la jubilación, Comares, Granada, 2008, p. 1150.

57 CAVAS MARTÍNEZ, F.: “Aspectos fundamentales de la Ley de promoción de la autonomía personal y atención a las personas en situación de dependencia”, Aranzadi Social, núm. 13, 2006, p. 17.
} 
autonómico es de carácter dual, donde sus modelos preexistentes conviven, de manera legítima, con los resultantes de la $\mathrm{LD}^{58}$.

Como fácilmente puede comprobarse, a través de la LD el legislador rehusó ofrecer una regulación completa y cerrada, abriendo en cambio la puerta a que las normas autonómicas pudieran contar con un amplio margen de maniobra a la hora de configurar el Sistema para la Autonomía y Atención a la Dependencia (SAAD) en sus respectivos territorios (a partir, obvio es, del mínimo de protección reconocido). De ahí que la publicación de la disposición estatal acarreara un intenso proceso de actualización a nivel regional, dando lugar a una abundante legislación autonómica, más allá de una mera puesta al día ${ }^{59}$.

A modo de ejemplo, cabe hacer referencia a las Leyes 27/2007, de 27 de mayo, de derechos y Servicios Sociales de Cantabria (BOE núm. 94, de 19 de abril); 4/2009, de 11 de junio, de Servicios Sociales de Islas Baleares (BOE núm. 163, de 7 de julio); 12/2007, de 11 de octubre, de Servicios Sociales de Cataluña (BOE núm. 266, de 6 de noviembre); 13/2008, de 3 de diciembre, de servicios sociales de Galicia (BOE núm. 15, de 17 de enero de 2009); Ley 12/2008, de 5 de diciembre, de Servicios Sociales del País Vasco (BOE núm. 246, de 24 de diciembre); 5/2009, de 30 de junio, de Servicios Sociales de Aragón (BOE núm. 201, de 20 de agosto); Ley 7/2009, de 22 de diciembre, de Servicios Sociales de la Rioja (BOE núm. 14, de 16 de enero de 2010); 27/2010, de 16 de diciembre, de Servicios Sociales de Castilla-La Mancha (BOE núm. 38, de 14 de febrero de 2011); 16/2010, de 20 de diciembre, de servicios sociales de Castilla y León (BOE núm. 7, de 8 de enero de 2011); 14/2015, de 9 de abril, de Servicios Sociales de Extremadura (BOE núm. 108, de 6 de mayo); 9/2016, de 27 de diciembre, de Servicios Sociales de Andalucía (BOE núm. 18, de 21 de enero de 2017); 3/2019, de 18 de febrero, de servicios sociales inclusivos de la Comunitat Valenciana (BOE núm. 61, de 12 de marzo); o 16/2019, de 2 de mayo, de Servicios Sociales de Canarias (BOE núm. 141, de 13 de junio) ${ }^{60}$.

\section{Administraciones Locales}

Pese al rol preponderante de las Autonomías, tampoco cabe olvidar el papel asumido por las Corporaciones Locales en la implementación del sistema de servicios sociales en

\footnotetext{
58 AGRA VIFORCOS, B. y MEGINO FERNÁNDEZ, D.: "Los cuidados a la vejez en el entorno rural: aistencia y el domicilio y teleasistencia”, en VV.AA (RODRÍGUEZ ESCANCIANO, S. y ÁLVAREZ CUESTA, H., Dirs.): La economía social como palanca para la sostenibilidad de los territorios rurales, Tirant Lo Blanch, Valencia, 2020 (en prensa).

${ }^{59}$ Con anterioridad a la LD que mantienen su vigencia, cabe mencionar las Leyes 1/2003, de 24 de febrero, de Servicios Sociales de Asturias (BOE núm. 86, de 10 de abril de 2003); 3/2003, de 10 de abril, del Sistema de Servicios Sociales de la Región de Murcia (BOE núm. 99, de 2 de mayo de 2003); 11/2003, de 27 de marzo (BOE núm. 88, de 14 de abril de 2003) ó 15/2006, de 14 de diciembre, de Servicios Sociales de la Comunidad Formal de Navarra (BOE núm. 152, de 20 de diciembre de 2006)

${ }^{60}$ TRILLO GARCÍA, A.R.: “Art. 63”, en VV.AA (SEMPERE NAVARRO, A.V. y BARRIOS BAUDOR, G.L., Dirs.): Comentarios a la Ley General de la Seguridad Social, Volumen I, Aranzadi, Pamplona, 2018, p. 495.
} 
relación con las personas mayores ${ }^{61}$.

Cierto es que esta materia ha sido tradicionalmente, desde los inicios del Estado contemporáneo, una cuestión típica de las competencias municipales, e históricamente a lo largo del siglo XIX y en los inicios ya del siglo XX siempre se ha señalado que una de las funciones básicas de los Ayuntamientos era atender a las necesidades de salubridad y de comodidad de los pueblos, los hospitales, hospicios, casas de caridad y de beneficencia, conceptos básicos que hoy día están actualizados con los de servicios sociales, bienestar y atención social. No menos verdad resulta que estos servicios han pasado, como ya consta, en la actualidad a girar en la órbita competencial regulatoria de las Comunidades Autónomas. Ahora bien, este cambio no ha supuesto en la práctica una retirada de las Administraciones Locales en la dispensa de los servicios sociales como entes públicos más cercanos al ciudadano, que comparten con las Autonomías dicho cometido en la atención de las personas mayores ${ }^{62}$.

En efecto, todas las Comunidades Autónomas han asignado, a través de su legislación sectorial, competencias a los ayuntamientos en materia de servicios sociales. Incluso, algunos de los nuevos Estatutos de Autonomía, también llamados de segunda generación, otorgan expresamente facultades en materia de servicios sociales a los municipios. Sirvan de ejemplo los Estatutos de Autonomía andaluz (Ley Orgánica 2/2007, de 19 de marzo) y catalán (Ley Orgánica 6/2006, de 19 de julio). Mientras el primero dispone que los ayuntamientos tienen competencias propias sobre la gestión de los servicios sociales comunitarios, en los términos que determinen las leyes [art. 92.2.c)], el segundo establece que los gobiernos locales de Cataluña tienen, en todo caso, competencias propias, en los términos que determinen las leyes, sobre la regulación y la prestación de los servicios de atención a las personas, de los servicios sociales públicos de asistencia primaria y de fomento de las políticas de acogida de los inmigrantes [art. 84.2.m) $]^{63}$.

Asimismo, la Ley 7/1985, de 2 de abril, reguladora de las Bases de Régimen Local (LBRL), tras la reforma introducida por la Ley 27/2013, dedica varios preceptos a regular las posibilidades de actuación de los entes municipales en materia de servicios sociales, si bien bastante más limitadas en su extensión que en la versión original de la Ley antes de la citada modificación, a saber: En primer lugar, el art. 25.2 atribuye a los municipios, como competencias propias, en los términos de la legislación del Estado y de las Comunidades Autónomas, la "evaluación e información de situaciones de necesidad

\footnotetext{
${ }^{61}$ RODRÍGUEZ ESCANCIANO, S.: "La atención a las necesidades de las personas mayores desde los servicios sociales", en VV.AA.: Por una pensión de jubilación, adecuada, segura y sostenible, III Congreso Internacional y XVI Congreso Nacional de la Asociación Española de Salud y Seguridad Social, Vol. II, Laborum, Murcia, 2019, pp. 29 y ss.

${ }^{62}$ FONT I LLOVET, T.: "Gestión de servicios sociales en el ámbito local. Nuevos planteamientos sobre la ciudad y la contratación pública”, en VV.AA (TOLIVAR ALAS, L. y CUETO PÉREZ, M., Dirs.): La prestación de servicios sociosanitarios: nuevo marco de la contratación pública, Tirant Lo Blanch, Valencia, 2020, pp. 21 y ss.

${ }^{63}$ ARIAS MARTÍNEZ, M.A.: "Las competencias locales en materia de servicios sociales tras la aprobación de la Ley 27/2013, de 27 de diciembre, de racionalización y sostenibilidad de la Administración Local”, Revista de Administración Pública, núm. 194, 2014, p. 380.
} 
social y la atención inmediata a personas en situación o riesgo de exclusión social" ${ }^{\text {. }}$. En segundo término, el art. 26.1 aclara que los ayuntamientos son competentes para prestar una serie de servicios que el precepto determina en función del número de habitantes o población municipal, de manera que los de más de 20.000 habitantes tienen competencias destinadas a la "evaluación e información de situaciones de necesidad social y la atención inmediata a personas en situación o riesgo de exclusión social (en la redacción anterior se refería a la prestación de servicios sociales)" ${ }^{65}$. Por su parte, el art. 27.3 dispone que "con el objeto de evitar duplicidades administrativas, mejorar la transparencia de los servicios públicos y el servicio a la ciudadanía y, en general, contribuir a los procesos de racionalización administrativa, generando un ahorro neto de recursos, la Administración del Estado y las Administraciones de las Comunidades Autónomas podrán delegar, siguiendo criterios homogéneos, entre otras, las competencias relativas a servicios sociales"66. Todo ello sin olvidar que la Sentencia del Tribunal Constitucional 41/2016, de 3 de marzo, ha declarado contraria a la Norma Fundamental y nula la disposición transitoria segunda de la Ley 27/2013, que establecía cómo "con fecha 31 de diciembre de 2015, en los términos previstos en las normas reguladoras del sistema de financiación autonómica y de las Haciendas Locales, las Comunidades Autónomas asumirán la titularidad de las competencias que se preveían como propias del Municipio, relativas a la prestación de los servicios sociales y de promoción y reinserción social. Las Comunidades Autónomas asumirán la titularidad de estas competencias, con independencia de que su ejercicio se hubiese venido realizando por Municipios, Diputaciones Provinciales o entidades equivalentes, o cualquier otra Entidad Local". Esta previsión incorporaba una operación que significaba un desapoderamiento competencial de los municipios total y radical, que el Alto Intérprete de la Constitución viene a rechazar. La Sentencia del Tribunal Constitucional 41/2016 claramente establece que no podía haberse efectuado por la Ley estatal 27/2013 ese traslado competencial, ni la pérdida de intervención de los municipios en favor de las Autonomías, no en vano son estas últimas las que tienen que decidir la distribución competencial entre sus propios servicios y los servicios municipales, quedando anuladas esas disposiciones transitorias que eliminaban el aludido contenido competencial de los entes locales ${ }^{67}$. En suma, el Tribunal Constitucional recuerda al Estado que no disponía de título competencial alguno para alterar las leyes autonómicas de servicios sociales que atribuían a los municipios competencias propias sobre la materia. Será, por tanto, una opción política de cada

\footnotetext{
${ }^{64}$ DÍAZ LEMA, J.M.: "El Anteproyecto de Ley de racionalización y sostenibilidad de la Administración local: ¿cambio de rumbo en la Administración local española?”, en Anuario del Gobierno Local 2012, Madrid, Fundación Democracia y Gobierno Local, 2013, pp. 47y ss.

${ }^{65}$ VELASCO CABALLERO, F.: "Nuevo régimen de competencias municipales en el Anteproyecto de Racionalización y Sostenibilidad de la Administración Local”, Anuario de Derecho Municipal 2012, núm. 6, 2013, p. 39.

${ }^{66}$ ARIAS MARTÍNEZ, M.A.: "Las competencias locales en materia de servicios sociales tras la aprobación de la Ley 27/2013, de 27 de diciembre, de racionalización y sostenibilidad de la Administración Local", cit., p. 382.

${ }^{67}$ FONT I LLOVET, T.: "Gestión de servicios sociales en el ámbito local. Nuevos planteamientos sobre la ciudad y la contratación pública”, cit., pp. 21 y ss.
} 
Comunidad Autónoma atribuir más o menos competencias sobre servicios sociales a sus Ayuntamientos ${ }^{68}$.

En consecuencia, aun con algunas limitaciones derivadas de la nueva regulación incorporada con la reforma del régimen local de 2013 ${ }^{69}$, las Administraciones Locales todavía a día de hoy han podido seguir asumiendo quehaceres en materia de servicios sociales $^{70}$. Y ello porque el modelo diseñado por la Ley 27/2013 no llegó a articularse de forma plena, debido a la confluencia de dos circunstancias añadidas al citado pronunciamiento del Tribunal Constitucional. En primer lugar, tras la entrada en vigor de esta disposición legal numerosas Comunidades Autónomas siguieron reconociendo a sus municipios competencias en materia de asistencia social que van más allá de la evaluación e información de situaciones de necesidad, así como de la atención inmediata a personas en situación de riesgo de marginación social. En segundo lugar, el Ministerio de Hacienda pospuso la eficacia del nuevo modelo, puesto que lo vinculó a un renovado sistema de financiación autonómica y de las Haciendas Locales ${ }^{71}$.

Recientemente, el Tribunal Constitucional, en Sentencia 82/2020, de 15 de julio, ha avalado la posibilidad de que las Administraciones Locales sigan prestando servicios sociales al considerar que "sólo se podrá atribuir competencias locales específicas, o prohibir que éstas se desarrollen en el nivel local, cuando se tenga la competencia en la materia o sector de que se trate", de manera que "en materias de competencia autonómica (como sucede en servicios sociales), únicamente las Comunidades Autónomas (y no el Estado) pueden atribuir competencias locales o prohibir que el nivel local las desarrolle; sujetándose en todo caso a las exigencias derivadas de la Constitución". No sería constitucionalmente admisible que la Autonomía se desentendiera completamente de los costes de los nuevos servicios a prestar por las diputaciones provinciales a los pequeños

\footnotetext{
${ }^{68}$ GARRIDO JUNCAL, A.: Los servicios sociales en el siglo XXI. Nuevas tipologías y nuevas formas de prestación, Aranzadi, Pamplona, 2020, p. 23.

${ }^{69}$ Con anterioridad a la reforma de 2013, el art. 25.1 LBRL/1985 preveía que los municipios podían "promover toda clase de actividades y prestar cuantos servicios públicos contribuyeran a satisfacer las necesidades y aspiraciones de la comunidad vecinal". A lo que se sumaba el art. 28 que declaraba cómo estas entidades estaban facultadas para realizar actividades complementarias de las propias de otras Administraciones Públicas, lo que les permitía intervenir en el ámbito de la asistencia social, aunque no dispusieran de una habilitación legal en este sentido. Además, el art. 25.2 k) LBRL/1985 incluía "la prestación de los servicios sociales y de promoción y reinserción social", entre las materias sobre las que, "en todo caso", los municipios debían tener competencias. De acuerdo con ello, las Comunidades Autónomas, a través de sus Estatutos y normas de servicios sociales podrían atribuirles competencias de desarrollo del sistema de atención a situaciones de dependencia. Tampoco cabe olvidar que el art. $26.1 \mathrm{c}$ ) LBRL/1985 establecía que aquellos municipios que poseyeran una población superior a 20.000 habitantes tenían, "en todo caso", la obligación de "prestación de servicios sociales". SERRANO GARCÍA, M.J.: "La distribución constitucional de competencias en el ámbito de la dependencia”, en VV.AA (MOLERO MARAÑóN, M.L., Dir.): Dependencia (long term care) y empleo en el Estado de Bienestar, Aranzadi, Pamplona, 2017, p. 103.

${ }^{70}$ ZAMORA ROSELLÓ, M.R.: “Administración local y ciudadanía: pilares de las políticas públicas en materia de servicios sociales", Adapt, Revista Internacional y Comparada de Relaciones Laborales y Derecho del Empleo, vol. 7, núm. 4, 2019, p. 203.

71 SERRANO GARCÍA, M.J.: "La distribución constitucional de competencias en el ámbito de la dependencia”, cit., p. 105.
} 
municipios $^{72}$.

\section{Colaboración público-privada: posibilidades}

A la descoordinación geográfica fruto de la atención diversa por parte de las distintas Comunidades Autónomas y Entidades Locales, se une un dato preocupante adicional: durante los últimos años de crisis, los servicios sociales han estado sometidos a la doble presión derivada, por un lado, del crecimiento de la demanda ante el aumento de situaciones de vulnerabilidad especialmente manifiestas como consecuencia del envejecimiento de la población que exige, además, ayudas de larga duración, y, por otro, de la restricción de recursos derivada de las exigencias de contención del déficit público. Este doble cúmulo de factores confluye en un problema capital: la financiación.

Consciente de tal escollo, la propia LD confiere al espacio privado importantes referencias en su articulado. De entrada, la participación de la iniciativa privada en los servicios y prestaciones de promoción de la autonomía personal y atención a la situación de dependencia se establece como principio rector del sistema [art. $3 \mathrm{~m}$ ) $]^{73}$. Tal premisa implica la intervención privada en el marco protector de los cuidados de larga duración a través de varios mecanismos que ayuden a sufragar sus elevados costes:

En primer lugar, el art. 33 LD impone la obligación de todos los beneficiarios de contribuir económicamente al coste de los servicios recibidos en atención a dos criterios: el montante final del servicio y la capacidad económica del beneficiario ${ }^{74}$, teniendo en cuenta que, en todo caso, este copago tiene un impacto progresivo respecto de la renta y patrimonio de los usuarios ${ }^{75}$, sin que en ningún caso un ciudadano pueda verse privado del servicio por falta de recursos económicos suficientes ${ }^{76}$. Ahora bien, si las aportaciones al coste final de las prestaciones y servicios fueran tan elevadas que no compense al usuario de los servicios al implicar un endeudamiento futuro del patrimonio familiar, asistiremos a un SAAD destinado exclusivamente a personas carentes de recursos

\footnotetext{
72 ALEMAN BRACHO, C. y ALONSO SECO, J.M.: "Los sistemas de servicios sociales en las Leyes autonómicas de servicios sociales", cit., p. 977.

${ }^{73}$ MONEREO PÉREZ, J.L. y FERNÁNDEZ BERNAT, J.A.: "La iniciativa privada en la protección de la dependencia. Instrumentos e instituciones privadas de aseguramiento y asistencia", en VV.AA (MONEREO PÉREZ, J.L.; MALDONADO MOLINA, J.A. y RUBIO HERRERA, R., Dirs.): Prevención y protección de la dependencia: un enfoque transdisciplinar, Comares, Granada, 2014, p. 295.

${ }^{74}$ HERAS HERNÁNDEZ, M.M.: "Cambios sustanciales en la protección jurídico pública de la persona en situación de dependencia: la estrangulada voluntad del beneficiario y su familia y el alance de su contribución al sostenimiento del SAAD”, Documentación Laboral, núm. 102, 2014, Vol. III, p. 226.

${ }^{75}$ ROLDÁN AYUSO, S.: "La necesidad de un replanteamiento en la financiación de la dependencia. El endurecimiento del copago", en VV.AA (MOLERO MARAÑÓN, M.L., Dir.): Dependencia (long term care) y empleo en el Estado de Bienestar, Aranzadi, Pamplona, 2017, p. 200.

${ }^{76}$ NICOLÁS MARTÍNEZ, C. y RIQUELME PEREA, P.: “Análisis y retos del sistema de autonomía y atención a la dependencia”, en VV.AA (LÓPEZ ANIORTE, M.C. y GARCÍA ROMERO, B.: Envejecimiento, cuidados y dependencia: hacia una protección social con perspectiva de género, Aranzadi, Pamplona, 2020, p. 363. Por término medio, en el conjunto de España el copago de la teleasistencia asciende al 17 por 100, el de la ayuda a domicilio al 11,7 por 100, el de los centros de día públicos al 26.2 por 100, y al 22,1 por 100 en caso de los concertados, mientras que en las residencias el copago alcanza el 41,4 por 100 en las públicas y el 38,6 por 100 en las concertadas. CES: Informe 3/2020. El sistema de promoción de la autonomía personal y atención a las personas en situación de dependencia, cit., p. 169.
} 
económicos y sin familia, que puede poner en peligro la naturaleza universal de este derecho subjetivo, generando la desconfianza de los usuarios ${ }^{77}$, de manera que el juego del principio de proporcionalidad debe adquirir importancia capital.

En segundo lugar, la transferencia de la dispensa de las atenciones al tercer sector de la acción social ${ }^{78}$, integrado por organizaciones de carácter privado surgidas de la iniciativa ciudadana o social, bajo diferentes modalidades que responden a criterios de solidaridad, con fines de interés general y ausencia de ánimo de lucro, que impulsan el reconocimiento y el ejercicio de los derechos sociales ${ }^{79}$. Tal trasvase, fruto de un progresivo proceso de externalización de los servicios sociales, supone un ahorro importante en personal, pues evita el reclutamiento directo de efectivos por parte de las Administraciones Públicas y la convocatoria de procesos de selección de recursos humanos, así como en gastos destinados a la adquisición de equipamientos ${ }^{80}$.

En tercer lugar, con estos mismos objetivos, muchas veces se ha recurrido también a una delegación en el sector mercantil privado, dando por bueno el inherente ánimo de beneficio empresarial. Cabe mencionar, así, el recurso a contrataciones externas a través de la Ley 9/2017, de 8 de noviembre, de Contratos del Sector Público (LCSP), la actuación de los centros privados concertados [art. 6.2 y 16.1 LD] y, cómo no, la condición impuesta por el art. 17.1 LD referida a que no sea posible el acceso a un servicio público o concertado de atención y cuidado para el otorgamiento de una prestación económica vinculada al servicio ${ }^{81}$.

\subsection{El contrato administrativo de servicios}

La LCSP es la encargada de dar cobertura a las sinergias descentralizadoras a favor de la iniciativa privada a través de una serie de tipos contractuales, dentro de los cuales la gestión indirecta de los servicios sociales obtiene respuesta principal mediante el denominado contrato de servicios, "cuyo objeto son prestaciones de hacer consistentes en el desarrollo de una actividad o dirigidas a la obtención de un resultado distinto de una

\footnotetext{
77 HERAS HERNÁNDEZ, Ma ${ }^{\mathrm{a}}$.M.: "Políticas públicas para el fomento de la financiación privada de la dependencia", en VV.AA (MOLERO MARAÑÓN, Ma.L., Coord.): Retos para una implantación efectiva del Sistema para la Autonomía y Atención a la Dependencia, cit., p. 232.

78 TORRES FERNÁNDEZ, J.J.: "Administración contratante y contratistas de las Administraciones Públicas”, Revista Española de Control Exterior, 2007, pp. 85 y ss.

${ }^{79}$ GARCÍA NINET, J.I.; DE VICENTE PACHÉS, F. y GARRIGUES GIMÉNEZ, A.: “Configuración técnica de los servicios sociales y régimen jurídico", cit., p. 1164.

${ }^{80}$ GARCÍA BLASCO, J.: "La experiencia aplicativa de las nuevas vertientes de protección social", en VV.AA.: Estudios sobre Seguridad Social. Libro Homenaje al Profesor José Ignacio García Ninet, Atelier, Barcelona, 2017, p. 365.

${ }^{81}$ MONEREO PÉREZ, J.L. y FERNÁNDEZ BERNAT, J.A.: "La iniciativa privada en la protección de la dependencia. Instrumentos e instituciones privadas de aseguramiento y asistencia", en VV.AA (MONEREO PÉREZ, J.L.; MALDONADO MOLINA, J.A. y RUBIO HERRERA, R., Dirs.): Prevención y protección de la dependencia: un enfoque transdisciplinar, Comares, Granada, 2014, p. 295.
} 
obra o suministro, incluyendo aquellos en que el adjudicatario se obligue a ejecutar el servicio de forma sucesiva y por precio unitario" (art. 17 LCSP) ${ }^{82}$.

La disposición adicional $47^{\mathrm{a}}$ LCSP aclara que en los casos de servicios de contenido social, además de la aplicación de las disposiciones generales relativas al establecimiento de las prescripciones técnicas, de las condiciones mínimas de solvencia, de los criterios de adjudicación y de las condiciones especiales de ejecución, los órganos de contratación velarán en todas sus fases por la necesidad de garantizar la calidad, la continuidad, la accesibilidad, la asequibilidad, la disponibilidad y la exhaustividad de los servicios; las necesidades específicas de las distintas categorías de usuarios, incluidos los grupos desfavorecidos y vulnerables o la implicación de los usuarios de los servicios; y la innovación en la prestación. Asimismo, los criterios de adjudicación podrán ir referirlos a aspectos tales como: la experiencia del personal adscrito al contrato en la prestación de servicios dirigidos a sectores especialmente desfavorecidos o en la prestación de servicios de similar naturaleza; la reinversión de los beneficios obtenidos en la mejora de los servicios que presta; el establecimiento de mecanismos de participación de los usuarios y de información y orientación de los mismos. Por tanto, esta disposición adicional $47^{\mathrm{a}}$ LCSP permite introducir criterios de valoración de las ofertas que pongan el acento en conceptos técnicos y de calidad, atendiendo a cómo se viene desempeñando y cómo se debe llevar a cabo esa actividad.

Por su parte, el art. 312 LCSP recoge una serie de especialidades en los contratos de servicios que conllevan prestaciones directas a favor de la ciudadanía, contemplando de esta manera la obligación del adjudicatario de prestar el servicio con la continuidad convenida y garantizar a los particulares el derecho a utilizarlo en las condiciones que hayan sido establecidas, debiendo cuidar del buen orden del mismo; destacando que, en todo caso, la Administración conservará los poderes de policía necesarios para asegurar la buena marcha de los servicios ${ }^{83}$.

Es más, se establece un umbral, fijado en 750.000 euros, para los contratos que tengan por objeto los servicios sociales [art. 22.1 c) LCSP], dotando de gran flexibilidad a los contratos de menor cuantía ${ }^{84}$.

A su vez, el art. 167.f) LCSP recoge como supuesto de aplicación del procedimiento de licitación con negociación el caso de que se trate de contratos de servicios sociales personalísimos que tengan por una de sus características determinantes el arraigo de la persona en el entorno de atención social, siempre que el objeto del contrato consista en

${ }^{82}$ DOMÍNGUEZ MARTÍN, M.: "Los contratos de prestación de servicios a las personas. Repensando las formas de gestión de los servicios sanitarios públicos tras las Directivas de contratos de 2014 y la Ley 9/2017”, Revista General de Derecho Administrativo, núm. 50, 2019, pp. 7 y ss.

${ }^{83}$ CARRODEGUAS MÉNDEZ, R.: "Reflexión crítica sobre el 'outsourcing' de los servicios sociales dirigidos a nuestros mayores en tiempos de covid", El Consultor de los Ayuntamientos y de los Juzgados, $5349 / 2020$.

${ }^{84}$ BURILLO SÁNCHEZ, F.J.: "Las entidades de economía social como principales beneficiarias de la innovación social en la contratación pública", en VV.AA (GARCÍA ROMERO, B. y PARDO LÓPEZ, M.M, Dirs.): Innovación social en la contratación administrativa: las cláusulas sociales, Aranzadi, Pamplona, 2018, p. 442. 
dotar de continuidad en la atención a las personas que ya eran beneficiarias. Esta hipóteiss puede ser aplicable a los contratos de contenido social que cumplan los dos requisitos siguientes: “a) Cuando para dar satisfacción a las necesidades del órgano de contratación resulte imprescindible que la prestación, tal y como se encuentra disponible en el mercado, sea objeto de un trabajo previo de diseño o de adaptación por parte de los licitadores. b) Cuando la prestación objeto del contrato incluya un proyecto o soluciones innovadoras".

En todo caso, para estos supuestos de gestión indirecta a favor de empresas mercantiles, la LCSP exige que se garantice el respeto a las condiciones laborales incluidas en los convenios colectivos aplicables durante toda la ejecución del contrato [art. $35 \mathrm{n}$ )], especialmente en lo que afecta al capítulo de retribuciones en la cuantía establecida en el pacto sectorial, tal y como requiere el art. 122.2, referido a las exigencias de los pliegos de cláusulas particulares, idea repetida en el art. 201.2 que alude al cumplimiento de los convenios sectoriales y territoriales aplicables como condición de ejecución del contrato. Asimismo, en aras a velar por la estabilidad en el empleo y corregir las elevadas tasas de temporalidad en el sector, es necesario no perder de vista lo dispuesto en el art. 71 del Convenio Colectivo marco estatal de servicios de atención a las personas dependientes y desarrollo de la promoción de la autonomía personal, que se encarga de establecer la obligación de subrogación de la empresa entrante respecto del personal de la empresa saliente en los supuestos de sucesión de contratas siempre que se acredite una antigüedad de tres meses ${ }^{85}$, previsión que se aplica también cuando se produce un cambio en la adjudicación de un contrato del sector público a la luz del art. 130 LCSP.

\subsection{El tercer sector}

Las entidades filantrópicas ocupan un lugar muy relevante en la dispensa de servicios socio-asistenciales, contando con un marcado componente de subvención y auxilio público, quedando convertidas en verdaderos coadyuvantes de los poderes gubernativos $^{86}$. La propia Ley 43/2015, de 9 de octubre, del Tercer Sector de Acción Social, tiene como objetivo principal reforzar la capacidad de estas entidades, "con fines de interés general y ausencia de ánimo de lucro", como interlocutores ante la Administración respecto de las políticas públicas sociales, así como definir las medidas de fomento que los poderes públicos podrán adoptar en su beneficio (art. 1).

\subsubsection{Criterios de desempate entre licitadores a favor de entidades sin ánimo de lucro}

El art. 147 LCSP introduce una habilitación o autorización a los órganos de contratación de las Administraciones públicas para señalar en los pliegos de cláusulas administrativas particulares la preferencia en la adjudicación de los contratos (con exclusión del resto de

85 BARRIOS BAUDOR, G.L.: "Modalidades contractuales en el sector de la dependencia: una aproximación al tema a propósito del VI Convenio Colectivo marco Estatal", en VV.AA (MOLERO MARAÑÓN, M.L., Dir.): Dependencia (long term care) y empleo en el Estado de Bienestar, Aranzadi, Pamplona, 2017, p. 393.

${ }^{86}$ HERRERA GÓMEZ, M.: El tercer sector en los sistemas de bienestar, Tirant Lo Blanch, Valencia, 1998, pp. 33 y ss. 
los concurrentes al proceso de selección de contratistas) en los supuestos de empate a favor de aquellas proposiciones presentadas por determinados sujetos que reúnan unas cualidades subjetivas determinadas ${ }^{87}$.

Tratándose de establecer criterios específicos para dirimir la paridad entre las ofertas más meritorias, una vez realizada la valoración correspondiente, el precepto mencionado exige además que dichos parámetros sean debidamente publicitados y estén vinculados al objeto del contrato, que la documentación acreditativa sea aportada en el momento en que se produzca el empate, y no con carácter previo, así como que los licitadores queden encuadrados en una serie de grupos, entre los que se encuentran las entidades filantrópicas ${ }^{88}$. Así, la tercera mención del art. 147 LCSP va referida, en la adjudicación de los contratos relativos a prestaciones de carácter social o asistencial, a las proposiciones presentadas por entidades sin ánimo de lucro ${ }^{89}$, que deben venir revestidas, además, de personalidad jurídica y dotadas de una determinada organización; tal exigencia ha de quedar cumplida por cualesquiera de las formas de personificación previstas en el ordenamiento jurídico, constituyendo, además, su inscripción en el registro una exigencia también esencial para la obtención de la prebenda establecida en la LCSP. Además, el patrimonio de la entidad non profit ha de hallarse destinado a la realización de fines de interés general, lo cual viene a suponer en la práctica su intervención como coadyuvantes de las Administraciones públicas ${ }^{90}$, no en vano estas entidades, como personas jurídico-privadas que son, no tienen la consideración de poderes administrativos, en cuanto no están dotadas de imperium o soberanía, pero en tanto en cuanto es precisamente a las organizaciones públicas a quienes se impone como obligación el logro del interés general, la intervención de las entidades sin ánimo de lucro en este campo a través del sistema de contratación administrativa va a quedar limitado a colaborar en la satisfacción pública de las demandas sociales referidas fundamentalmente a aquellos aspectos relacionados con los derechos de tercera generación o fundados en la solidaridad (paz, protección del medio ambiente, desarrollo o servicios culturales, de ocio o, por lo que aquí interesa, sociales).

87 LÓPEZ-VEIGA BREA, J.: "Novedades relacionadas con la contratación pública socialmente responsable. Especial referencia a la discapacidad en el texto refundido de la Ley de Contratos del Sector Público en España", en VV.AA: Contratación, ordenación del territorio y buena administración, Diputación, La Coruña, 2018, pp. 305 y ss.

88 RODRÍGUEZ ESCANCIANO, S.: "La vis expansiva de las cláusulas sociales en el sistema de contratación pública: un cauce para el fomento del empleo de los colectivos más desfavorecidos permitido por el Derecho Comunitario", en VV.AA.: Los mercados laborales y las políticas sociales en Europa, Vol. II, XX Congreso Nacional de Derecho del Trabajo y de la Seguridad Social, MTSS, Madrid, 2010, pp. 749 y ss.

${ }^{89}$ CHINCHILLA MARÍN, C.: "La nueva Ley de Contratos del Sector Público: ámbito de aplicación y otras cuestiones novedosas", Revista Vasca de Administración Pública, núm. 79, 2007, pp. 41 y ss.

${ }^{90}$ ESTEBAN LEGARRETA, R.: "El voluntariado corporativo en el marco de la responsabilidad social empresarial. Nuevas cuestiones sobre las fronteras entre la actividad voluntaria y el contrato de trabajo", Derecho de las Relaciones Laborales, núm. 1, 2017, pp. 29 y ss. ó DE NIEVES NIETO, N.: "Voluntariado y empleo en el tercer sector", Revista del Ministerio de Trabajo e Inmigración, núm. 33, 2001, pp. 279 y ss. 
De todas formas, es necesario distinguir el fin, que necesariamente tiene que ser general, y la realización de dicha finalidad, pues, al concertarse, in casu, con determinadas entidades no lucrativas, siempre acabará beneficiando en último término a personas determinadas (dependientes, in casu). Es más, para la aplicación de la preferencia en la adjudicación es necesario también que los fines de la entidad tengan relación directa con el objeto del contrato. Tomando en consideración que en este caso dicha prioridad sólo es aplicable a los vínculos contractuales relativos a prestaciones de carácter social o asistencial, resulta que los fines de estos sujetos han de tener, además de imbricación con el objeto del contrato, de nuevo, carácter social o asistencial ${ }^{91}$. Queda, por tanto, el círculo cerrado, máxime cuando en un proceso de licitación se desciende hasta valoraciones infinitesimales, razón por la cual es difícil que sea pertinente dirimir un empate.

\subsubsection{Contratos reservados y excluidos}

Teniendo en cuenta que los servicios sociales se pueden incluir en la categoría de servicios de interés general no económico, su prestación puede quedar al margen de las normas sobre mercado interior de libertad de establecimiento y libertad de prestación que marcan los procesos de licitación en el sector público. Bajo tal premisa, la jurisprudencia comunitaria ha admitido la adjudicación directa cuando ésta se efectúa con entidades sin ánimo de lucro, siempre y cuando "no obtengan ningún beneficio de sus prestaciones (independientemente del reembolso de los costes variables, fijos y permanentes necesarios para la prestación de los servicios), ni proporcionen ningún beneficio a sus miembros"92. Además de estos sujetos y bajo estas mismas pautas, también asumen un papel importante las entidades encuadradas dentro del marco de la economía social, esto es, las cooperativas, las mutualidades, las fundaciones y las asociaciones que lleven a cabo actividad económica, las sociedades laborales, las empresas de inserción, los centros especiales de empleo, las cofradías de pescadores, las sociedades agrarias de transformación y las entidades singulares creadas por normas específicas que se rijan por los principios de primacía de las personas y del fin social sobre el capital, aplicación de los resultados obtenidos principalmente en función del trabajo aportado y servicio o actividad realizada por las socias y socios o por sus miembros al fin social objeto de la entidad, promoción de la solidaridad interna y con la sociedad, e independencia respecto a los poderes públicos (arts. 4 y 5 Ley 5/2011, de 29 de marzo, de Economía Social).

Esta doble realidad (entidades non profit y de economía social) es tomada en consideración por la LCSP en dos pasajes dignos de mención:

De un lado, el art. 99.4 habilita a los órganos de contratación de los poderes adjudicadores a reservar a determinadas organizaciones el derecho a participar en los procedimientos de

\footnotetext{
${ }^{91}$ MARTÍNEZ FONS, D.: "La contratación pública como instrumento de la política de empleo y la libre competencia", en VV.AA.: Los mercados laborales y las políticas sociales en Europa, XX Congreso Nacional de Derecho del Trabajo y de la Seguridad Social, Vol. II, MTSS, Madrid, 2010, pp. 649 y ss. 92 SSTJUE de 13 de diciembre de 2014, caso Rossa Italiana y otros, C-113/13, y de 28 de enero de 2016, caso Costa, C-50/14 . Por extenso, GIMENO FELIÚ, J.M.: "Las condiciones sociales en la contratación pública: posibilidades y límites”, Anuario del Gobierno Local, núm. 1, 2017, pp. 241 y ss.
} 
licitación de los contratos de servicios de carácter cultural, de salud y, por lo que aquí interesa, social ${ }^{93}$, siempre y cuando cumplan los siguientes requisitos marcados por la disposición adicional $48^{\mathrm{a}}$ : a) Que su objetivo sea la realización de una misión de servicio público vinculada a la prestación de los servicios mencionados. b) Que los beneficios se reinviertan con el fin de alcanzar el objetivo de la organización; o en caso de que se distribuyan o redistribuyan beneficios, la distribución o redistribución deberá realizarse con arreglo a criterios de participación. c) Que las estructuras de dirección o propiedad de la organización que ejecute el contrato se basen en la propiedad de los empleados, o en principios de participación, o exijan la participación activa de los empleados, los usuarios o las partes interesadas. d) Que el poder adjudicador no haya adjudicado a la organización un contrato para los servicios en cuestión con arreglo al presente artículo en los tres años precedentes. e) La duración máxima del contrato que se adjudique no excederá de tres años. f) En el anuncio que sirva de medio de convocatoria de la licitación se dará publicidad a esta reserva ${ }^{94}$.

El tipo de contratos de servicios que facultativamente se puede reservar a las citadas entidades de economía social destinadas a la prestación de servicios sociales están perfectamente delimitados e incluso numerados en el Anexo IV LCSP, en referencia a los contratos de servicios sociales (código CPV 85320000-8); servicios de asistencia social sin alojamiento (código CPV 85312000-9); servicios de asistencia social y servicios conexos (código CPV 85300000-2) y servicios de asistencia social (código CPV 85310000-5), quedando fuera de la reserva, entre otros, los servicios de asistencia social con alojamiento (código CPV 85311000-2) ${ }^{95}$.

De otro, teniendo en cuenta la naturaleza jurídica de los servicios sociales, no puede extrañar que el legislador permita también mantenerlos alejados de la lógica contractual, de manera que no sea necesario seguir los cauces de la LCSP quedando exceptuados de las reglas de concurrencia competitiva y posibilitándose su prestación a través de medios no contractuales ${ }^{96}$. Así, el art. 6.1 LCSP regula la figura del convenio como técnica excluida del ámbito de aplicación de esta Ley siempre y cuando se den tres requisitos: a) Las entidades intervinientes no han de tener vocación de mercado; b) El texto del acuerdo establezca o desarrolle una cooperación entre las entidades participantes con la finalidad de garantizar que los servicios públicos que les incumben se prestan de modo que se logren los objetivos que tienen en común; c) El desarrollo de la cooperación se guíe

\footnotetext{
${ }^{93}$ MENDOZA JIMÉNEZ, J.; ROMÁN CERVANTES, C.A. y HERNÁNDEZ LÓPEZ, M.: “Los contratos reservados: una herramienta para el fortalecimiento de las entidades sociales", Ciriec: Revista Jurídica de Economía Social y Cooperativa, núm 83, 2018, pp. 295-332.

94 DÍEZ SASTRE, S.: "Las cláusulas sociales en la contratación pública", Anuario de la Facultad de Derecho de la Universidad Autónoma de Madrid, núm. 21, 2017, pp. 195 y ss.

95 CARRODEGUAS MÉNDEZ, R.: "Reflexión crítica sobre el 'outsourcing' de los servicios sociales dirigidos a nuestros mayores en tiempos de covid", cit.

${ }^{96}$ FORTES MARTÍN, A.: "El nuevo contrato de servicios que conlleva prestaciones directas a favor de la ciudadanía ¿consolidación o disrupción del contrato de servicios públicos?”, Revista General de Derecho Administrativo, núm. 52, 2019, pp. 10 y ss.
} 
únicamente por consideraciones relacionadas con el interés público ${ }^{97}$. Se sigue, pues, la argumentación del Tribunal de Justicia de la Unión Europea que admite la posibilidad de que una normativa nacional habilite la adjudicación directa, sin forma alguna de publicidad, a asociaciones de voluntariado, siempre que el marco legal y convencional en el que se desarrolla la actividad de esos organismos contribuya realmente a una finalidad social y a la prosecución de objetivos de solidaridad y eficacia presupuestaria, sin que puedan obtener ningún beneficio de sus prestaciones independientemente del reembolso de los costes variables, fijos y permanentes necesarios para prestarlas, ni proporcionen ningún rédito a sus miembros ${ }^{98}$.

\subsection{La técnica del concierto}

El art 11.6 LCSP excluye, como novedad, del ámbito de aplicación de la LCSP la prestación de servicios sociales "por entidades privadas" que quedan "homologadas" para dispensar ciertas funciones asistenciales del entorno público, quedando admitida, por tanto, la persecución de lucro mercantil, "siempre que esta se realice sin necesidad de celebrar contratos públicos, a través, entre otros medios, de la simple financiación de estos servicios o la concesión de licencias o autorizaciones a todas las entidades que cumplan las condiciones previamente fijadas por el poder adjudicador, sin límites ni cuotas, y que dicho sistema garantice una publicidad suficiente y se ajuste a los principios de transparencia y no discriminación".

Lo determinante para que opere el concierto es que todos los operadores puedan concurrir en condiciones de transparencia (publicidad) e igualdad de trato $\mathrm{y}$, además, que la admisión o selección se sustente en la apreciación de la aptitud de los operadores (experiencia, cualificación o medios de que disponen) y no en criterios de adjudicación (valoración, competición o comparación entre ofertas) ${ }^{99}$. Por tanto, a la luz del citado art. 11.6 LCSP, no existe ninguna obligación de acudir a un contrato público para gestionar servicios sociales ${ }^{100}$.

Bajo tal premisa, la disposición adicional 49a LCSP permite que "las Comunidades Autónomas, en el ejercicio de las competencias que tienen atribuidas, legislen articulando instrumentos no contractuales para la prestación de servicios públicos destinados a satisfacer necesidades de carácter social" "101, tarea llevada a cabo por todas las autonomías bajo los estándares propios del casuismo pero bajo un denominador común, que entiende que estamos ante una figura alternativa a la gestión directa o indirecta de los servicios

\footnotetext{
${ }^{97}$ FERNÁNDEZ ACEVEDO, R.: "Negocios y contratos excluidos", en VV.AA.: Estudio sistemático de la Ley de Contratos del Sector Público, Aranzadi, Pamplona, 2018, pp. 294 y ss.

98 STJUE 28 enero 2016, asunto Costa y otros, C-50/14. Por extenso, GIMENO FELIÚ, J.M.: "La colaboración público-privada en el ámbito de los servicios sociales y sanitarios dirigidos a personas. Condicionantes europeos y constitucionales", Revista Aragonesa de Administración Pública, núm. 52, 2018, pp. 25 y ss.

${ }^{99}$ STJUE 1 marzo 2018, asunto Tirkkonen, C-9/17

${ }^{100}$ Informe 52/18 Junta Consultiva de Contratación Pública del Estado.

${ }^{101}$ VILLALTA REIXACH, M.: "Los convenios administrativos a la luz de la nueva Ley de Contratos del Sector Público", en VV.AA.: Estudio sistemático de la Ley de Contratos del Sector Público, Aranzadi, Pamplona, 2018, pp. 325 y ss.
} 
públicos no económicos en el ámbito de los servicios a las personas ${ }^{102}$. De esta forma, la acción concertada en la prestación de servicios sociales es una opción organizativa, un convenio que dispone de un régimen jurídico especial, pues exige previsión legal expresa (en este caso autonómica) sobre sus modalidades, alcance y sistema retributivo ${ }^{103}$, no en vano está configurado con carácter subsidiario, precedido de un estudio de viabilidad, una justificación de la necesidad basada en la insuficiencia de medios públicos disponibles y un intento de optimizar los recursos públicos existentes contribuyendo realmente a una finalidad social y a la persecución de objetivos de solidaridad ${ }^{104}$. Como es lógico, los centros que opten por esta vía deberán disponer de autorización administrativa e inscripción en el registro oficial ad hoc, una vez superado un proceso de acreditación sustentado en estándares de calidad previamente establecidos por la Administración, quedando sujetos a una serie de obligaciones de gestión, un elenco de condiciones técnicas y económicas y un estricto control, debiendo respetar la equivalencia de prestación de la cartera de servicios ${ }^{105}$.

Esta ordenación está literalmente tomada de la regulación de los llamados "contratos a las personas" incluida en las Directivas de contratación (Considerando 54 Directiva 2014/23, Considerando 114 Directiva 2014/24 y Considerando 120 Directiva 2014/25) ${ }^{106}$. A tenor de la normativa comunitaria y de la previsión contenida en el art. 11.6 LCSP, la prestación de los servicios sociales se puede llevar a cabo a través de fórmulas no contractuales, siempre que quede garantizado que todos los operadores o prestadores que cumplan los requisitos puedan acceder a este régimen, prestar los servicios y, en su caso, obtener la financiación que se haya fijado, bien de la Administración, bien del usuario $^{107}$. La propia LD permite avalar esta conclusión cuando prevé que la red de centros estará formada por los centros públicos de las Comunidades Autónomas, de las Corporaciones Locales o de referencia estatal, así como los privados concertados debidamente acreditados (art. 16.1 LD), de manera que no se impide la participación de la iniciativa comercial en sentido estricto del término.

\footnotetext{
102 DOMÍNGUEZ MARTÍN, M.: "La acción concertada de los servicios a las personas en la Ley de Contratos del Sector Público y en la legislación autonómica”, en VV.AA (TOLIVAR ALAS, L., Dir.): $L a$ prestación de servicios socio sanitarios, Valencia, Tirant Lo Blanch, 2020, pp. 54 y ss.

${ }^{103}$ RODRÍGUEZ BEAS, M.: "El encaje de las reglas de mercado en la gestión de los servicios sociales y sanitarios", en VV.AA (FONS I FERNÁNDEZ, M.V., Ed.): La protección jurídica de la atención a las personas en materia de servicios sociales. Una perspectiva multidisciplinar, Atelier, Barcelona, 2020, p. 241.

${ }^{104}$ CUETO PÉREZ, M.: "Incertidumbre en las modalidades de gestión de servicios socio-sanitarios tras la LCSP”, en VV.AA (TOLIVAR ALAS, L. y CUETO PÉREZ, M., Dirs.): La prestación de servicios socio sanitarios, Tirant Lo Blanch, Valencia, 2020, pp. 139 y ss.

105 GIMENO FELIÚ, J.M.: La Ley de Contratos de Sector Público 9/2017. Sus principales novedades, los problemas interpretativos y las posibles soluciones, Aranzadi, Pamplona, 2019, p. 155.

106 BERNAL BLAY, M.A.: "La contratación de servicios a personas", en VV.AA.: Tratado de Contratos del Sector Público, vol. 3, Tirant Lo Blanch, Valencia, 2018, pp. 2864 y ss.

107 STJUE de 1 de marzo de 2018, C-9/17. DOMÍNGUEZ MARTÍN, M.: "Los contratos de prestación de servicios a las personas. Repensando las formas de gestión de los servicios sanitarios públicos tras las Directivas de contratos de 2014 y la Ley 9/2017”, cit, pp. 10 y ss.
} 
Como pautas comunes de la variada legislación autonómica sobre la materia, cabe destacar que la selección de las entidades para el establecimiento de conciertos se realizará a través de la valoración de la entidad basada no sólo en el cumplimiento de unos requisitos mínimos relativos a las condiciones de infraestructura o de ratios y titulación del personal, sino también en criterios sociales, de calidad, experiencia, evaluación de las personas usuarias, promoción de la igualdad de género, cumplimiento de la normativa laboral, menor diferencia retributiva del personal respecto a la misma categoría profesional en la Administración Autonómica, trabajo en red con otras entidades sociales o trayectoria acreditada en la materia ${ }^{108}$. Igualmente se asignarán conciertos en relación con la adecuación del recurso o servicio concertado a las características y necesidades de la persona que vaya a ser beneficiaria: atención personalizada, arraigo en el entorno, elección del destinatario o continuidad en la atención ${ }^{109}$. Si bien algunas Comunidades Autónomas permiten únicamente concertar con entidades sin ánimo de lucro, al entender que los servicios sociales no son de interés económico (Aragón, Asturias, Extremadura, Navarra o Valencia), otras sin embargo incorporan esta posibilidad a entidades con ánimo de beneficio (Andalucía, Galicia, Islas Baleares o Murcia) ${ }^{110}$.

A diferencia de la contratación pública, a través del concierto, el proveedor actúa en nombre propio y tiene autonomía en la prestación del servicio, es decir, puede llevarlo a cabo de la manera que considere más conveniente siempre y cuando respete los requisitos establecidos por la Administración. Se establece, de esta forma, un régimen especial de atención a los ciudadanos, desvinculado de la idea del contrato administrativo, a través de la fórmula de la acción concertada, que si bien no puede amparar situaciones que comporten una "privatización" del modelo, ni, por supuesto, que se pueda "abrir un mercado" en fraude de ley ${ }^{111}$, lo cierto es que en la práctica queda expedito el camino para reducir la calidad en las prestaciones de los servicios y para empeorar las condiciones laborales de los trabajadores en aras a conseguir un mayor beneficio empresarial, debiendo adquirir un papel sustancial el riguroso ejercicio de controles e inspecciones de las circunstancias en las que se dispensan los cuidados.

\subsection{Sistema de acreditación}

Tal y como se puede deducir de los epígrafes anteriores, en la dispensa del servicio, conviven empresas con ánimo de lucro de mayor y menor envergadura junto a entidades filantrópicas del denominado tercer sector o del sector de la economía social, manifestando intereses distintos $\mathrm{y}$, a veces, contrapuestos en la definición de las

\footnotetext{
${ }^{108}$ GARRIDO JUNCAL, A.: Los servicios sociales en el siglo XXI. Nuevas tipologías y nuevas formas de prestación, Aranzadi, Pamplona, 2020, p. 271.

109 CERMI: "Los aspectos sociales en la contratación pública", enero 2018, https://www.cermi.es/sites/default/files/docs/basicas/guia\%20CERMI.pdf

110 CARRODEGUAS MÉNDEZ, R.: "Reflexión crítica sobre el `outsourcing' de los servicios sociales dirigidos a nuestros mayores en tiempos de covid", cit.

111 GIMENO FELIÚ, J.M.: La Ley de Contratos de Sector Público 9/2017. Sus principales novedades, los problemas interpretativos y las posibles soluciones, Aranzadi, Pamplona, 2018, p. 155.
} 
condiciones básicas en la prestación de los servicios catalogados. Buena muestra de lo cual puede encontrase en la sola mención de las organizaciones empresariales implantadas en este sector: AESTE (Asociación de Empresas de Servicios para la Dependencia), que agrupa a grandes corporaciones; FED (Federación Empresarial de la Dependencia), que integra a empresas de menor entidad; y LARES (Federación de residencias y servicios de atención a los mayores del sector solidario), cuyo nombre es ilustrativo de la cualidad de sus miembros ${ }^{112}$.

La propia LD establece un endeble mecanismo, la denominada acreditación, acompañada de serias fugas, en aras a conseguir la calidad de los servicios dispensados por entidades privadas con o sin ánimo de lucro que como postulado teórico clave establece el art. 3 j), si bien queda en entredicho en su materialización práctica, pues es patente la vaguedad de los términos que utiliza el art. 35, remitiendo, sin pautas previas, la fijación de los estándares mínimos a observar por los centros, servicios y entidades que quieran obtener la acreditación para funcionar como tales, al Consejo Territorial del Sistema para la Autonomía y Atención a la Dependencia. Este órgano, adscrito al Ministerio de Derechos Sociales y Agenda 2030 y constituido por la persona titular de dicho Ministerio, que ostentará su presidencia, así como por los Consejeros competentes en materia de servicios sociales y de dependencia de cada una de las Comunidades Autónomas, ha adoptado un Acuerdo de fecha 27 de noviembre de 2008, modificado en sucesivas ocasiones (Acuerdos de 7 de octubre de 2015, de 19 de octubre de 2017 y de 20 de marzo de 2020, este último para atender la situación excepcional provocada por el covid-19), en el que se fijan unos criterios comunes, a desarrollar por cada una de las Comunidades Autónomas, en los que se tiene en cuenta de forma harto genérica el número de plazas, la intensidad en la prestación, la tipología de recursos y los servicios que deben ofrecer, haciendo referencia a dos extremos fundamentales: a) Recursos materiales y equipamientos que garanticen la prestación del servicio adaptada a las necesidades de las personas en situación de dependencia, a las intensidades, a la seguridad y a la accesibilidad. b) Recursos humanos que garanticen la adecuada prestación del servicio, tanto en número de profesionales, como en su formación, cualificación y actualización para el desempeño del puesto de trabajo ${ }^{113}$.

\footnotetext{
112 ESCUDERO RODRÍGUEZ, R.: "El empleo en el sector de la dependencia", Documentación Laboral, núm. 102, 2014, p. 69.

${ }^{113}$ Resolución de 23 de marzo de 2020 (BOE, 25 de marzo de 2020) de la Secretaría de Estado de Derechos Sociales da publicidad al Acuerdo del Consejo Territorial de Servicios Sociales que modifica el Acuerdo de 27 de noviembre de 2008, en virtud del cual se rebajan ciertas exigencias ante la expansión de la pandemia por covid-19. Así: "Cuando se acredite la no existencia de demandantes de empleo con las titulaciones especificas necesarias en la zona donde esté ubicado, bien el centro o institución social o bien donde se preste el servicio de asistencia personal o las labores de auxiliar de ayuda a domicilio, podrán desempeñar estas funciones personas que tengan alguna de las titulaciones exigidas para cualquiera de ellas. Si tampoco hubiera disponibilidad de demandantes de empleo con ninguna de las titulaciones antes señaladas, podrán desempeñar estas funciones personas que, careciendo de titulación, preferentemente, tengan experiencia en cuidado y atención de personas dependientes, debiendo las entidades prestadoras de servicios garantizar la supervisión y formación práctica en el puesto de trabajo para mejorar sus competencias profesionales. Este régimen excepcional estará vigente por un plazo inicial de tres meses a partir de su publicación, pudiendo ser prorrogado por nuevo acuerdo del Consejo Territorial por sucesivos
} 
Son, pues, las Comunidades Autónomas las que concretan estos timoratos mínimos (estructurales, funcionales y recursos humanos disponibles) dando muestras de una gran dispersión material y diversidad procedimental ${ }^{114}$, manifestada en ritmos y dinámicas muy dispares, que necesitan una seria labor de armonización, en la que deviene imprescindible apostar por una revisión al alza de las ratios de personal de atención directa para mejorar la calidad asistencial, mejorar la cualificación de los trabajadores, incrementar las inspecciones y controles diseñando planes específicos y guías de buenas prácticas, así como implementar una atención médica y de enfermería más amplia y extensa en los centros residenciales ${ }^{115}$.

Ante la tradicional ausencia de una consistente red asistencial de carácter público en el ámbito de la protección a la vejez, la propia Ley 39/2006 optó por el predominio absoluto de la contratación o concertación de los distintos servicios garantizados legalmente ${ }^{116}$, con el resultado de una clara descompensación a favor de la acción concertada y el exponencial crecimiento de la oferta privada lucrativa y no lucrativa, sin que haya sido acompañada de una mayor implicación de las Administraciones autonómicas en cuanto a su cohesión y ordenación, provocando cierta falta de control e incluso cierto deterioro en los estándares de calidad como consecuencia de la obtención de precios bajos en los conciertos y concesiones ${ }^{117}$, que la covid-19 se ha encargado de poner de manifiesto de manera destacada. También se ha echado en falta la coordinación general desde el IMSERSO y el establecimiento de unos estándares irreductibles variables en función de las circunstancias de cada momento.

Es necesario, por ende, terminar con el repliegue en la implicación de las Administraciones y con la relajación de las supervisiones y el cierto grado de tolerancia en las exigencias de calidad a cambio de un abaratamiento en los costes que se han puesto de manifiesto en los últimos años y que la expansión de la infección por la covid-19 se ha encargado de hacer visible de una forma muy clara ${ }^{118}$. En tanto en cuanto no se está privatizando porque no se transfiere a un sujeto privado la titularidad o la responsabilidad

periodos de tres meses o inferiores en función de las necesidades organizativas y asistenciales derivadas de la evolución de la situación sanitaria".

${ }^{114}$ Entre las más recientes, cabe mencionar el Decreto 126/2019, de 30 de julio, de centros residenciales para personas mayores en el ámbito del País Vasco. También, en Cantabria, la Orden UMA/11/2019, de 14 de marzo, por la que se regulan los requisitos materiales y funcionales de los centros de servicios sociales especializados, y la Orden UMA/12/2019, de 14 de marzo, por la que se establecen los criterios y se regula el procedimiento para la acreditación de centros de servicios sociales destinados a la atención a personas en situación de dependencia.

${ }^{115}$ DEFENSOR DEL PUEBLO: Separata sobre atención a las personas mayores. Centros residenciales en el Informe anual de 2019. https://www.defensordelpueblo.es/wpcontent/uploads/2020/05/Separata_personas_mayores_centros_resid enciales.pdf

116 ESCUDERO RODRÍGUEZ, R.: "El empleo en el sector de la dependencia", Documentación Laboral, núm. 102, 2014, p. 69.

${ }^{117}$ CAVAS MARTÍNEZ, F.: "La apuesta por el catálogo de servicios en el sistema de atención y protección a la dependencia", cit., p. 147.

118 MOLERO MARAÑÓN, M.L.: Bases, evolución y retos de la Ley de Dependencia a los diez años de su aprobación, cit., p. 36. 
en la prestación de un servicio, que no pasa al mercado sino que sigue en manos de la Administración ${ }^{119}$, esta debe ejercer sus potestades de inspección.

\section{Los cuidados en el propio hogar como preferencia mayoritaria en la senescencia}

Tomando en consideración los variados perfiles que presentan las personas de edad avanzada, sus pluripatologías y su entorno vital, es necesario ofrecer una amplia variabilidad en la oferta y multitud de combinaciones en función de las particularidades de los beneficiarios, dando cobertura a una vasta gama de situaciones entre quienes tienen graves mermas en su autonomía física, mental, intelectual o sensorial y quienes padecen menos limitaciones, distinguiendo entre quienes requieren una atención institucionalizada y quienes padecen grados de dependencia más bajos, que deben poder optar por la permanencia en el domicilio, recibiendo una atención integral en tal entorno a través de un acabado sistema de servicios de proximidad ${ }^{120}$, contando con la oportuna "coordinación de las administraciones de servicios sociales y sanitaria"121.

Entre las posibilidades que otorga la LD, es la del cuidado en el propio hogar la que ocupa la posición prioritaria, atendiendo al índice cuantitativo de las preferencias manifestadas por los dependientes, que se ha incrementado sustancialmente con el miedo al contagio tras la expansión de la pandemia por la covid-19 $9^{122}$. Ninguna objeción merece la siguiente afirmación: el internamiento del sujeto no siempre es la mejor opción.

\section{El modelo de atención centrada en la persona}

El respeto a la dignidad en situación de dependencia implica que se cuente con la voluntad del afectado en la toma de decisiones sobre su vida personal, superando un mero planteamiento formal "pro-activo de intervención" 123 formulado a través de un más bien simbólico mecanismo de consulta preceptiva pero no vinculante que conlleva, en muchas ocasiones, una sobreprotección basada en erróneos estereotipos que asocian a la edad con la falta de capacidad volitiva ${ }^{124} \mathrm{y}$, en otras, un reconocimiento de la modalidad concreta de atención concedida en función de la disponibilidad real con la que cuenten los servicios

119 LAGUNA DE PAZ, J.C.: "Regulación, externalización de actividades administrativas y autorregulación”, Revista de Administración Pública, núm. 185, 2011, p. 99.

${ }^{120}$ MOLERO MARAÑÓN, M.L.: "El espacio de las prestaciones económicas en la protección social de las personas dependientes: una reflexión sobre el sistema de cuidados deseable", Documentación Laboral, núm. 102, 2014, vol. III, p. 178.

121 PROCURADOR DEL COMÚN DE CASTILLA Y LEÓN: Resolución 13/11/2020, Atención y cuidados en las residencias de Castilla y León ante la pandemia ocasionada por la Covid-19 https://www.procuradordelcomun.org/archivos/resoluciones/1_1609317758.pdf

122 CES: Informe 3/2020. El sistema de promoción de la autonomía personal y atención a las personas en situación de dependencia, cit., p. 137.

${ }^{123}$ LLANO SÁNCHEZ, M.: "El marco procedimental del sistema de atención a la dependencia: balance crítico de los desarrollos normativos y de la práctica administrativa", Documentación Laboral, núm. 102, Vol. III, 2014, p. 127.

${ }^{124}$ CABEZAS CASADO, J.L. y GONZÁLEZ MALDONADO, M.C.: "La importancia de la participación en la tercera edad", en VV.AA (MONEREO PÉREZ, J.L.; MALDONADO MOLINA, J.A. y RUBIO HERRERA, R., Dir.): Prevención y protección de la dependencia: un enfoque transdisciplinar, Comares, Granada, 2018, p. 329. 
sociales autonómicos, sin tener en cuenta las preferencias y necesidades específicas de la persona dependiente ${ }^{125}$. Es necesario, por ende, apostar por un verdadero "Modelo de Atención Integral Centrada en la Persona (AICP)" en el que se garantice una libertad absoluta de elección ${ }^{126}$.

Como ha señalado la Sociedad Española de Geriatría y Gerontología, los cuidados no solo deben llevarse a cabo en residencias, máxime teniendo en cuenta que el 99 por 100 de las personas mayores prefieren quedarse en su hogar ${ }^{127}$. Dicho en otros términos, entre la población mayor está extendido el deseo de "envejecer en su propia casa y en su entorno habitual, el que ha ocupado generalmente a lo largo de su vida y compartido con los miembros de su familia"128.

La atención de esta manifestación exige tomar en consideración las circunstancias singulares de cada persona, muy particularmente su mayor o menor deterioro cognitivo y funcional, su biografía (el medio en que ha vivido, las relaciones interpersonales que ha tenido, la profesión que ha ejercido...) y los factores ambientales en los que va a desarrollar su existencia vital (el emplazamiento, la habitabilidad y conectividad de su vivienda) ${ }^{129}$.

\subsection{Salubridad, confortabilidad y conectividad de la vivienda como premisas para la dispensa de un servicio de teleasistencia avanzada}

La permanencia de la persona dependiente en su domicilio requiere, como premisa básica de partida, disponer de una vivienda digna, pues, en muchas ocasiones, las condiciones de habitabilidad, sobre todo en las zonas rurales y en barrios urbanos deprimidos, son pésimas al tratarse de construcciones antiguas y muy poco cuidadas por sus propietarios, normalmente de edad avanzada. Por un lado, las características de la vivienda en términos de accesibilidad y habitabilidad son fundamentales para determinar la viabilidad de los cuidados. Por otro lado, las condiciones del domicilio del anciano como espacio de trabajo son muy importantes en términos de salud laboral y prevención de riesgos laborales de los profesionales asistentes. Ambas cuestiones son de especial relevancia si se pretende

\footnotetext{
${ }^{125}$ DE LAS HERAS HERNÁNDEZ, M.M.: "Cambios sustanciales en la protección jurídico-pública de la persona en situación de dependencia: la estrangulada voluntad del beneficiario y de su familia y el alcance de su contribución al sostenimiento del SAAD”, Documentación Laboral, núm. 102, 2014, Vol. III, p. 221. ${ }^{126}$ RODRÍGUEZ RODRÍGUEZ, P.: "La atención integral centrada en la persona (Principios y criterios que fundamentan un modelo de intervención en discapacidad, envejecimiento y dependencia)", Informes Portal Mayores, núm. 106, 2010, pp. 1-17.

127 https://www.segg.es/actualidad-segg/2021/02/01/la-segg-plantea-la-transformacion-social-delenvejecimiento-en-el-senado

128 ROJO-PÉREZ, F. y FERNÁNDEZ-MAYORALAS, G.: "La calidad de vida en la población mayor", Panorama Social, núm. 28, 2018, p. 68.

${ }^{129}$ CABEZAS CASADO, J.L. y GONZÁLEZ MALDONADO, M.C.: "La importancia de la participación en la tercera edad", en VV.AA (MONEREO PÉREZ, J.L.; MALDONADO MOLINA, J.A. y RUBIO HERRERA, R., Dir.): Prevención y protección de la dependencia: un enfoque transdisciplinar, Comares, Granada, 2018, p. 329.
} 
impulsar el servicio de ayuda a domicilio, de teleasistencia o dar sentido a la prestación económica para cuidados en el entorno familiar ${ }^{130}$.

La permanencia en la vivienda de la persona dependiente demanda contar con domicilios remodelados, dotados de condiciones óptimas de confortabilidad, carentes de barreras arquitectónicas y respetuosos con el medio ambiente, ubicados, al tiempo, en asentamientos pertechados de servicios telemáticos, educativos, sanitarios y de transporte colectivo $^{131}$. Las viviendas deben de adaptarse, por ende, en aras a conseguir los imperativos de dignidad vital y eficiencia energética, contando con una suficiente ventilación, una correcta iluminación, un adecuado confort término, unas fáciles condiciones de accesibilidad, un óptimo saneamiento y una pertinente implementación de medidas de higienización respecto del tratamiento de aguas residuales ${ }^{132}$, exigiendo la pertinente dotación de recursos públicos para el desarrollo de políticas destinadas al denominado "urbanismo social".

Cuando está bien planificado, el urbanismo comprende cometidos tan variados como pueden ser la conservación de los conjuntos históricos y culturales, la reparación y renovación del parque de viviendas cuando existan situaciones de insuficiencia o degradación de los requisitos básicos de funcionalidad, salubridad y habitabilidad, la superación de la pobreza energética, la eliminación de barreras arquitectónicas, el progreso de la calidad de vida de los ciudadanos en todos los lugares incluidos los más alejados, así como la aplicación de las tecnologías de la información y comunicación en los entornos habitados para conseguir la mejora del transporte, la movilidad, la seguridad ciudadana, el desarrollo del teletrabajo y el suministro y consumo de energía y agua ${ }^{133}$. Estos exigentes postulados se englobaban bajo el concepto de "smart city"134, en su pretensión de posibilitar la "consecución de la calidad de vida de la ciudadanía"135.

Este nuevo enfoque del urbanismo, centrado en la regeneración, rehabilitación y renovación de las zonas habitadas, va a permitir incentivar la coyuntura económica, impulsar el desarrollo del empleo diseñando emplazamientos cohesionados y viviendas

\footnotetext{
${ }^{130}$ CES: Informe 3/2020. El sistema de promoción de la autonomía personal y atención a las personas en situación de dependencia, cit., p. 141.

${ }^{131}$ MIÑARRO YANINI, M.: "Innovación tecnológica, organización del trabajo y sostenibilidad ambiental: ¿es el teletrabajo una forma de empleo verde?", Revista Trabajo y Seguridad Social (Centro de Estudios Financieros), núm. 454, 2021, p. 15.

${ }^{132}$ GÓMEZ JIMÉNEZ, M.L.: "Vivienda domótica adaptada a la emergencia sanitaria: ideas preliminares, retos y propuestas normativas para la sociedad post covid-19”, Revista de Derecho Urbanístico y medio ambiente, núm- 337-338, p. 346.

${ }^{133}$ Departamento de Asuntos Económicos y Sociales. División de la Población. La situación demográfica en el mundo 2014. Informe conciso, Naciones Unidas, Nueva York, 2014, ST/ESA/SER.A/354, p. 27.

134 VAN-HALEN RODRÍGUEZ, J., "Ciudades sostenibles: un reto inaplazable", Revista de Derecho Urbanístico y Medio Ambiente, núm. 300, 2015, p. 24. También, SANTIAGO IGLESIAS, D.: "Iniciativas para un futuro urbano sostenible: las Smart cities", en VV.AA (QUINTANA LÓPEZ, T., Dir.): Urbanismo sostenible. Rehabilitación, regeneración y renovación urbanas, Tirant Lo Blanch, Valencia, 2015, p. 702. ${ }^{135}$ FORTES MARTÍN, A.: "La movilidad urbana sostenible como fenómeno jurídico: El derecho de la movilidad sostenible", en VV.AA (FORTES MARTÍN, A., Dir.): Movilidad urbana sostenible y acción administrativa. Perspectiva social, estrategias jurídicas y políticas públicas de movilidad en el medio urbano, Aranzadi, Pamplona, 2019, p. 63.
} 
dignas y energéticamente más eficientes ${ }^{136}$ donde los ancianos puedan permanecer en condiciones dignas y recibir cuidados. Sobre estas consideraciones inciden la Estrategia Europea de descarbonización y el Pacto Verde Europeo ${ }^{137}$, así como su proyección en el Proyecto de Ley español de Cambio Climático y Transición Energética ${ }^{138}$.

Teniendo en cuenta que el parque inmobiliario español consta de 25 millones de viviendas: un 90\% de ellas construidas antes del último código técnico de la edificación, y un $60 \%$ antes de que existiera cualquier normativa de eficiencia energética, la Estrategia Española de Transición Justa ${ }^{139}$ recoge la necesidad de transformar este entramado, lo cual debe aprovecharse como una de las mayores oportunidades de empleo y de asentamiento de la población. No es ocioso recordar que a través de este nuevo modelo de urbanismo se va a redundar en la reducción de emisiones contaminantes, de gases de efecto invernadero o de producción de residuos, así como de los consumos de agua y energía, priorizando la utilización de materiales reutilizados o reciclados y de energías renovables frente a las fuentes de energía fósil ${ }^{140}$.

Este planteamiento exige un cambio estructural profundo a fin de garantizar la transición a un nuevo modelo urbanístico global, esto es, cohesionado y, simultáneamente, transversal en materia de eficiencia, tecnología, multifucionalidad, integración social y competitividad empresarial generadora de ocupaciones laborales en condiciones dignas no sólo en las ciudades sino también en las zonas rurales y un adecuado lugar para vivir y ser cuidados. Estas ideas han sido puestas de manifiesto en la Cumbre Mundial de Naciones Unidas celebrada en Nueva York entre el 25 y 27 de septiembre de 2015, con carácter previo a la celebración de la $70^{\mathrm{a}}$ Asamblea General, que concluye con la adopción de los Objetivos de Desarrollo Sostenible (ODS), entre los cuales se encuentra asegurar que "las ciudades y los asentamientos humanos sean inclusivos, seguros, resilientes y sostenibles"141.

Bajo tales postulados, la Unión Europea ha insistido en la importancia de incrementar la eficiencia energética precisamente en el sector de la construcción, dando buena muestra de esta línea de actuación la Directiva 2018/844 relativa a la eficiencia energética de los edificios. Teniendo presente que los edificios consumen el 40 por 100 de la energía y suponen el 36 por 100 de las emisiones de CO2 de la Unión Europea, esta Directiva persigue como objetivos la creación de edificios inteligentes que ayuden a mitigar la

${ }^{136}$ RODRÍGUEZ ESCANCIANO, S.: "Sostenibilidad laboral en el sector de la construcción: la estabilidad en el empleo como premisa", Temas Laborales, núm. 152, 2020, pp. 13 y ss.

${ }^{137}$ Comunicación de la Comisión al Parlamento Europeo, al Consejo Europeo, al Consejo, al Comité Económico y Social Europeo y al Comité de las Regiones: El Pacto Verde Europeo, Bruselas, 11.12.2019 $\operatorname{COM}(2019) 640$ final.

138 ÁLVAREZ CUESTA, H.: "Transición justa y lucha contra el cambio climático en el Pacto Verde europeo y en el Proyecto de Ley de Cambio Climático en España", Iuslabor, núm. 2, 2020, p. 5.

${ }^{139} \mathrm{https}: / /$ www.miteco.gob.es/images/es/documentoetj_tcm30-514300.pdf

${ }^{140}$ QUINTANA LÓPEZ, T.: "Hacia un modelo de urbanismo sostenible", en VV.AA (QUINTANA LÓPEZ, T., Dir.): Urbanismo sostenible. Rehabilitación, regeneración y renovación urbanas, Tirant Lo Blanch, Valencia, 2015, p. 17.

${ }^{141}$ RAMOS QUINTANA, M.I.: "El futuro del trabajo y las mutaciones del empleo", Trabajo y Derecho, núm. 11, 2015, pp. 11 y ss. 
pobreza energética y, en concreto, la planificación de un parque inmobiliario de emisiones bajas o nulas en la Unión Europea en el horizonte del año 2050, mediante la aplicación de hojas de rutas nacionales para la descarbonización de los edificios utilizando fuentes de energías renovables ${ }^{142}$. En concreto, la Directiva 2018/844 pretende acelerar la renovación rentable de los edificios existentes, más específicamente, introduce sistemas de control y automatización como alternativa a las inspecciones físicas, fomenta el despliegue de la infraestructura para e-mobility e introduce un indicador de inteligencia para evaluar la preparación tecnológica del inmueble. Para ello, entre las modificaciones introducidas, implementa una estrategia a largo plazo para apoyar la renovación de los edificios de los Estados Miembros, transformándolos en parques inmobiliarios con alta eficiencia energética y descarbonizados antes del citado año $2050^{143}$. En concreto, el Pacto Verde Europeo se refiere expresamente, entre sus líneas estratégicas, a "garantizar que los edificios sean más eficientes desde el punto de vista energético"144.

Sin duda, las zonas habitadas deben de garantizar el bienestar de sus habitantes, integrando los criterios de sostenibilidad en todos los ámbitos y niveles, con el objetivo de asegurar el bienestar ambiental y la cohesión social en las viejas edificaciones, y deben asimismo tener en cuenta la relación entre los diferentes elementos que las componen (infraestructuras, entorno natural, edificación y movilidad) como claves del desarrollo empresarial y para la permanencia en las viviendas en situaciones de dependencia. Se trata de aplicar el principio del desarrollo sostenible, poniendo el acento en la regeneración de los núcleos de población, con espacios públicos y dotaciones de servicios de calidad y unas condiciones ambientales que hagan espacios para vivir más y mejor, recibiendo cuidados cuando sea necesario ${ }^{145}$, todo ello previa dotación de un sistema de ayudas económicas para incorporar las mejores técnicas disponibles ${ }^{146}$, teniendo en cuenta la doble funcionalidad del domicilio, no por conocida menos digna de reiteración: por una parte, como soporte para la viabilidad del cuidado de las personas ancianos en el hogar; por otra, como espacio de trabajo para quienes se ocupan de dispensar los cuidados al objeto de garantizar una adecuada prevención de riesgos laborales ${ }^{147}$.

Es más, la adaptación del hogar donde se vayan a recibir los cuidados no sólo ha de garantizar la seguridad, comodidad y la supresión de barreras, sino la interactividad dinámica con el fin de permitir encuentros virtuales bidireccionales capaces de paliar la

\footnotetext{
${ }^{142}$ GARCÍA LUPIOLA, A.: "Normativa para el desarrollo sostenible: los paquetes legislativos 'economía circular' y ‘energía limpia'”, Revista General de Derecho Europeo, núm. 50, 2020, pp. 302 y ss.

${ }^{143}$ FERNÁNDEZ SCAGLIUSI, M.A.: "La integración ambiental en la contratación pública: el certificado de eficiencia energética de los edificios", Revista General de Derecho Administrativo, núm. 49, 2018, p. 7. ${ }^{144} \mathrm{https}$ ///ec.europa.eu/info/strategy/priorities-2019-2024/european-green-deal_es

145 MENÉNDEZ REXACH, A.: "Los objetivos económicos de la regulación del suelo (1956-2015)", Revista de Derecho Urbanístico y Medio Ambiente, núm. 311, 2017, p. 293 o SÁNCHEZ, V.: "Las implicaciones de la economía digital en el sector de la construcción”, Gaceta Sindical, núm. 27, 2016, p. 305.

146 ZAMORANO WISNES, J.: "El derecho a la ciudad sostenible", Revista de Estudios de la Administración Local y Autonómica, núm. 15, 2021, p. 101.

${ }^{147}$ CES: Informe 3/2020. El sistema de promoción de la autonomía personal y atención a las personas en situación de dependencia, cit., 2021, p. 115.
} 
sensación de soledad a través del servicio de teleasistencia. En su primera versión, la teleasistencia consistía en una simple telealarma destinada a ofrecer al anciano o dependiente que vivía solo (o se encontraba en tal situación en ese momento) una vía sencilla de comunicación en busca de auxilio en caso de emergencia (caída, malestar...), tanto en la vivienda como fuera de ella. Pulsando el botón de ayuda, el operador especialista avisaba a los familiares y a los servicios de emergencia y se activaba una comunicación con el afectado. Así, de forma expeditiva, servía al objetivo de detectar y prevenir situaciones de riesgo, activando una pronta respuesta. Pero en el momento presente la teleasistencia no puede consistir únicamente en la dotación de un dispositivo de seguridad de fácil manipulación y de una conexión telefónica, sino que es necesario aprovechar los avances de la ciencia para dispensar un servicio más completo con detección de movimiento, geolocalización dentro y fuera del domicilio (incluyendo el establecimiento de un área de seguridad superada la cual salta un aviso en la centralita), monitorización de constantes, convulsiones o enuresis, detección de riesgos o emergencias por incidencias (escapes de gas, de agua, de fuego y otras), detección de alteraciones en los hábitos o rutinas (que pueden alertar sobre circunstancias que requieran atención), incluidas posibles caídas, atención psicológica diaria, gestión de consultas médicas, tele-estimulación cognitiva, tele-rehabilitación física y funcional, seguimiento nutricional, auxilio en movimientos, soporte al tratamiento farmacológico o protocolos especiales (atención en situaciones de duelo o ante contingencias y grandes catástrofes o prevención del maltrato y del suicidio, por ejemplo). Todo ello exige traer a colación las dificultades planteadas cuando los usuarios son personas mayores de áreas rurales, donde confluyen cuatro elementos integrantes de la conocida como brecha digital: la carencia de recursos informáticos adaptados, la falta de habilidades digitales, la ausencia de conexión a internet en determinadas áreas geográficas y la ingente inversión necesaria para su óptimo funcionamiento (computación cuántica, inteligencia artificial, nanorobots, cyborgización, interfaces cerebro-ordenador, sensores, tricodificadores médicos, realidad virtual y aumentada o impresión en 3D) ${ }^{148}$. Para que este servicio sea operativo en cualquier parte del territorio español previamente debe garantizarse, como primer paso, el acceso a las infraestructuras digitales para el conjunto de los ciudadanos y no solo a aquellos que, por conocimientos informáticos o residir en una zona geográfica determinada dispongan de mayores oportunidades en la línea marcada por en la Agenda Digital 2025, a fin de lograr precisamente en esa anualidad una conectividad digital adecuada para toda la población, con una cobertura de $100 \mathrm{Mbp}^{149}$. Además, es necesario incorporar a los hogares instalaciones de cámaras y sensores y dotaciones de aparatos electrónicos e informáticos, adiestrando a los usuarios en su manejo cotidiano y convenciéndoles de su utilidad. Y, por último y no menos importante, debe implantarse

\footnotetext{
${ }^{148}$ AGRA VIFORCOS, B. y MEGINO FERNÁNDEZ, D.: ““'Los cuidados a la vejez en el entorno rural: aistencia y el domicilio y teleasistencia”, en VV.AA (RODRÍGUEZ ESCANCIANO, S. y ÁLVAREZ CUESTA, H., Dirs.): La economía social como palanca para la sostenibilidad de los territorios rurales, Tirant Lo Blanch, Valencia, 2020 (en prensa).

149 www.administracionelectronica.gob.es
} 
un modelo eficaz de coordinación entre profesionales de la salud, trabajadores sociales y servicios de emergencia.

\subsection{El componente humano de los cuidados en el lugar de residencia}

Las estadísticas se ocupan de demostrar que el cuidado de las personas que no pueden valerse por sí mismas es una tarea realizada principalmente por mujeres tanto si se trata de trabajos llevados a cabo de forma profesional como no profesional por parientes y allegados. Cierto es que una de las expectativas iniciales más interesantes generadas en torno a la Ley 39/2006 ha sido la creación de empleo asalariado en el ámbito de los servicios sociales relacionados con el sector de la dependencia, ya sea en la composición de los órganos de evaluación de la situación de dependencia, ya como técnico de atención en centros especializados (al amparo del Real Decreto 1593/2011, de 4 de noviembre) sobre el que aparentemente se erige un importante nicho de empleo emergente ${ }^{150}$. Pero la realidad se ha encargado de demostrar otro panorama de rostro muy distinto, con señera manifestación cuando las atenciones se desarrollan en el domicilio del anciano, pues son llevadas a cabo por un grupo no homogéneo de cuidadoras, unas asociadas a la LD y otras extramuros de esta disposición legal, con dos características básicas comunes: invisibilidad y precariedad.

Por un lado, se encuentra el cuidado gratuito que se manifiesta en su falta de reconocimiento como propia actividad laboral, llevado a cabo por asalariadas que, combinando el papel de trabajadoras del sector público o privado con el de cuidadoras, asumen dobles o triples jornadas, utilizando las escuetas medidas de interrupción, suspensión y flexibilización de jornada previstas en nuestro ordenamiento jurídico para salvaguardar la conciliación de la vida laboral y familiar. Por otro, se encuentra el trabajo de cuidado remunerado, en cuyo caso se concibe como empleo de escasa cualificación, de muy baja retribución, con cuantías inferiores a otros trabajos feminizados en la hostelería y el comercio, y con condiciones especialmente devaluadas, nutrido con las trabajadoras del servicio de ayuda a domicilio, normalmente asalariadas de empresas externalizadas en la dispensa de un servicio público, o, en muy pocos casos, de asistentes personales. Además, es menester mencionar a las empleadas de hogar, víctimas de un grave déficit en el concepto de trabajo decente. Sin olvidar tampoco a las denominadas "cuidadoras informales", dedicadas en exclusiva a dispensar atenciones a un familiar dependiente, que no solo renuncian a realizar una actividad retribuida fuera del hogar, sino que pierden toda expectativa laboral y prestacional futura.

La eficiencia de la asistencia a las personas ancianas en su propio domicilio se encuentra directamente condicionada por dos variables que operan a modo de desideratum: por una parte, la adecuación y suficiencia en la implementación de fondos públicos ordenados a proporcionar óptimos soportes técnicos e infraestructuras capaces de atender las circunstancias subjetivas de cada individuo; por otra, y no menos importante, la probidad

150 MARTÍNEZ BARROSO, M.R.: "La atención a la dependencia en el mundo rural", en VV.AA (RODRÍGUEZ ESCANCIANO, S. y ÁLVAREZ CUESTA, H., Dirs.): La economía social como palanca para la sostenibilidad de los territorios rurales, Tirant Lo Blanch, Valencia, 2020 (en prensa). 
de las condiciones de trabajo de los empleados en tal sector de la actividad. En suma, la calidad de las prestaciones del sistema es inseparable de la calidad del empleo ${ }^{151}$.

\subsubsection{Ayuda a domicilio}

Aunque "la ayuda a domicilio no es un programa nuevo"152, lo cierto es que la LD precipitó el incremento en el peso y la calidad, apostando por los cauces formales para su prestación ${ }^{153}$. Bajo el calificativo de Servicios de Ayuda a Domicilio (SAD) se engloba a todo un conjunto de recursos dirigidos a prestar apoyo y cuidados en su domicilio a las personas cuando, por cualquier circunstancia, dejan de ser autónomas para llevar a cabo las actividades básicas de la vida diaria. Se estima que un $95 \%$ de las personas mayores pueden ser atendidas en sus casas si reciben el oportuno apoyo, complementado, cuando proceda, con teleasistencia y centro de día. Esto haría que sólo un 5\% de la tercera edad acabe necesitando ingresar en una residencia geriátrica ${ }^{154}$.

El servicio de ayuda a domicilio es un cuidado formal individualizado en función de las circunstancias del usuario que responde al principio de permanencia del anciano en su vivienda, recibiendo atención personal para la realización de las actividades de la vida diaria y de las necesidades domésticas ${ }^{155}$. Su carácter preventivo y rehabilitador hace que, por un lado, intente prevenir situaciones carenciales que incrementen el riesgo de pérdida de independencia: crear hábitos saludables respecto a la higiene o a la alimentación; prevenir caídas o accidentes en el hogar mediante acondicionamientos de la vivienda y accesibilidad de enseres y aparatos (ayudas técnicas); reforzar los vínculos familiares y sociales. Por otro lado, pretende recuperar capacidades funcionales perdidas, mediante entrenamiento en habilidades para actividades de la vida diaria, tales como vestirse, andar, asearse, hacer las tareas domésticas, comer o acudir al servicio con regularidad. En fin, también se orienta al refuerzo de la capacidad de la persona mayor para su comunicación con el exterior, para la realización de actividades lúdicas y recreativas, etc ${ }^{156}$.

Pese a que este servicio es el más demandado por los ancianos, lo cierto es que va acompañado de un lado oscuro, cual es la dificultad de su implementación en muchas zonas rurales y la escasa intensidad horaria mensual en la atención dispensada a la luz del

\footnotetext{
${ }^{151}$ CES: Informe 3/2020. El sistema de promoción de la autonomía personal y atención a las personas en situación de dependencia, cit., p. 165.

152 ALONSO SECO, J. M. ${ }^{a}$ y GONZALO GONZÁLEZ, B.: La asistencia social y los servicios sociales en España, BOE, Madrid, 1997, pp. 235 y 236.

${ }^{153}$ AGRA VIFORCOS, B. y MEGINO FERNÁNDEZ, D.: "Los cuidados a la vejez en el entorno rural: aistencia y el domicilio y teleasistencia”, en VV.AA (RODRÍGUEZ ESCANCIANO, S. y ÁLVAREZ CUESTA, H., Dirs.): La economía social como palanca para la sostenibilidad de los territorios rurales, Tirant Lo Blanch, Valencia, 2020 (en prensa).

${ }^{154}$ PROCURADOR DEL COMÚN DE CASTILLA Y LEÓN: Resolución 13/12/2019. Ayuda a domicilio. https://www.procuradordelcomun.org/archivos/resoluciones/1_1579862792.pdf

${ }^{155}$ SANCHO CASTIELLO, M. y DÍAZ MARTÍN, R.: "Atención a las personas mayores en su entorno: teleasistencia, ayuda a domicilio y centros de día”, Sociedad y Utopía. Revista de Ciencias Sociales, núm. 30, 2007, p. 163.
}

156 PROCURADOR DEL COMÚN DE CASTILLA Y LEÓN: Resolución 13/12/20119. Ayuda a domicilio. https://www.procuradordelcomun.org/archivos/resoluciones/1_1579862792.pdf 
art. 8 Real Decreto 1051/2013: Para el Grado III, entre 46 y 70 horas mensuales; para el Grado II entre 21 y 45 horas y para el Grado I máximo 20 horas ${ }^{157}$. De media en España, la franja del servicio alcanza las 19,64 horas mensuales, de manera que, como es lógico, tal escueto parámetro exige una paralela atención extrasistemática encauzada a través de la familia ${ }^{158}$.

La permanencia de las personas ancianas en sus domicilios exige, pues, el incremento de las horas de atención y un esfuerzo económico importante para evitar interrupciones dada la escasez de profesionales, sometidos, por lo demás, a unas condiciones de trabajo precarias ${ }^{159}$. Asimismo, requiere la dotación de una serie completa de atenciones no disponibles en todas las Comunidades Autónomas que se pueden resumir en las siguientes ${ }^{160}$ :

1.- Servicio de terapia individual. Incluiría la estimulación, supervisión, apoyo y asistencia en las actividades de la vida diaria cotidiana: vestido, aseo, alimentación, deambulación, continencia y tareas domésticas.

2.- Servicio de atención doméstica. Abarcaría la limpieza básica del hogar, lavado, planchado y arreglo de ropa, así como la realización de compras.

3.- Servicio de acompañamiento dentro y fuera del hogar tanto para ofrecer apoyo a las personas mayores que viven solas como para proporcionar descanso y tiempo libre a las familias cuidadoras. En concreto, en este segundo aspecto, conllevaría la compañía en consultas sanitarias, paseos, compras o gestiones bancarias.

4.- Servicio de teleasistencia avanzada al que anteriormente se hizo referencia.

5.-Servicio de transporte accesible. Dirigido a facilitar desplazamientos fuera del hogar para la realización de gestiones y participación en actividades diversas.

6.- Servicio de comida a domicilio. Comprendería la preparación y entrega en domicilio de comida y cena diaria.

7.- Servicio de podología. Aglutinaría la atención podológica, bien dispensada en el propio domicilio, bien facilitando el desplazamiento en transporte accesible hasta el lugar de impartición del servicio.

\footnotetext{
${ }^{157}$ https://www.directoressociales.com/images/documentos/dictamenes/XX_Dictamen/INFO\%20GLOBA L\%20XX\%20DICTAMEN\%203-3-20_compressed.pdf

158 AGRA VIFORCOS, B. y MEGINO FERNÁNDEZ, D.: "Los cuidados a la vejez en el entorno rural: aistencia y el domicilio y teleasistencia”, en VV.AA (RODRÍGUEZ ESCANCIANO, S. y ÁLVAREZ CUESTA, H., Dirs.): La economía social como palanca para la sostenibilidad de los territorios rurales, Tirant Lo Blanch, Valencia, 2020 (en prensa).

${ }^{159}$ REVUELTA ALONSO, M.L.: "La ayuda a domicilio como servicio de proximidad en el contexto social actual”, Humanismo y Trabajo Social, Vol. 15, 2015, pp. 112 y ss.

${ }^{160}$ MARTÍNEZ RODRÍGUEZ, T. y DÍAZ PÉREZ, B.: "El desarrollo de nuevos servicios de proximidad para la atención de personas mayores que viven en zonas rurales". http://envejecimiento.csic.es/documentos/documentos/martinez-desarrollo-01.pdf 
8.-Otros servicios a domicilio: fisioterapia, atención psicológica, biblioteca, peluquería, lavandería... ${ }^{161}$.

Aun cuanto las trabajadoras ocupadas en esta actividad deben aportar formación (titulación de técnico Sociosanitario de Atención a personas Dependientes en el domicilio, auxiliar de ayuda a domicilio o de geriatría, auxiliar de enfermería o certificados de profesionalidad de la rama), sus remuneraciones son escasas (prácticamente coincidentes con el salario mínimo interprofesional), asumen una acumulación de tareas, que muchas veces exigen sobreesfuerzos físicos (encamados, personas obesas o con movilidad reducida), con escuetos márgenes temporales y muchas veces son reclutadas a tiempo parcial. Además, no cuentan con adecuados protocolos de evaluación de riesgos y deben de realizar varios desplazamientos entre domicilios, con la posibilidad de sufrir accidentes in itinere ${ }^{162}$.

Surge la duda, además, de si estas trabajadoras se benefician de la protección como accidente de trabajo (y no solo como situación asimilada al mismo) ante el contagio por el SARS-COV-2, mereciendo tal interrogante una respuesta positiva, siempre y cuando la dolencia se hubiera "contraído con causa exclusiva en la realización del trabajo" (art. 5 Real Decreto Ley 6/2020, en la redacción otorgada por el Real Decreto Ley 13/2020 y por el Real Decreto Ley 28/2020). Dando un paso más, cabe plantearse también si procedería la consideración de tal contingencia como enfermedad profesional, debiendo entender que así es efectivamente, pues la Orden TES/1180/2020, de 4 de diciembre, incluye expresamente el SARS-CoV-2 en el Real Decreto RD 664/1997, de 12 de mayo, como agente biológico, y la actividad de cuidado a domicilio aparece expresamente catalogada entre las que pueden generar enfermedad profesional ${ }^{163}$.

\subsection{2.- Empleadas de hogar}

Al margen de la LD queda la atención de las personas ancianas a través del servicio en el hogar familiar, pese a que en muchos casos ese es el objeto principal y determinante de la suscripción del contrato de trabajo bajo tal modalidad. En este caso, la prestación de servicios se encuadra dentro de una relación laboral especial que une al trabajador con el titular del hogar familiar, regulada por el Real Decreto 1620/2011, que, además de otras múltiples tareas como muestra de una polivalencia inusitada, incorpora en su ámbito de

\footnotetext{
${ }^{161}$ REVUELTA ALONSO, M.L.: "La ayuda a domicilio como servicio de proximidad en el contexto social actual", cit., pp. 112 y ss.

162 UGT: Trabajadoras del cuidado a domicilio. https://fespugtandalucia.org/images/FeSPUGTAndalucia/SSanidad_Sociosanitario_Dependencia/Imagenes/Guia_tra bajadoras_Ayuda_a_Domicilio.pdf

${ }^{163}$ LÓPEZ ANIORTE, M.C. y FERRANDO GARCÍA, M.C.: "Precariedad y desprotección social del trabajo de limpieza y cuidados ante la situación de crisis sanitaria provocada por la Covid-19", Adapt. Revista Internacional y Comparada de Relaciones Laborales y Derecho del Empleo, vol. 9, núm. 1, 2021, p. 19.
} 
aplicación "el cuidado o atención de los miembros de la familia o de las personas que forman parte del ámbito doméstico o familiar” (art. 1.4) ${ }^{164}$.

Pese a esta posibilidad, el propio Real Decreto 1620/2011 se encarga de trazar sus fronteras frente a la LD, excluyendo de su ámbito de aplicación: de un lado, "las relaciones de los cuidadores profesionales contratados por instituciones públicas o por entidades privadas, de acuerdo con la LD" [art. 2.1 c)]; de otro, "las relaciones de los cuidadores no profesionales consistentes en la atención prestada a personas en situación de dependencia en su domicilio, por personas de la familia o de su entorno, no vinculadas a un servicio de atención profesionalizada, de acuerdo con la LD" [art. 2.1 d) $]^{165}$.

Una aproximación al perfil real de quienes llevan a cabo trabajo en los hogares familiares dibuja un colectivo abrumadoramente feminizado, generalmente compuesto por trabajadoras extranjeras, cuyos ingresos están de manera fraudulenta por debajo del salario mínimo interprofesional en relación con las horas trabajadas, sin estar tuteladas por ningún convenio colectivo ni tampoco por la Ley 31/1995, de 8 de noviembre, de Prevención de Riesgos Laborales (LPRL), realizando, sin embargo, largas jornadas, además de un cometido de alta responsabilidad sobre todo si se atiende a una persona que no puede valerse por sí misma ${ }^{166}$.

Cierto es que el salario mínimo conlleva una garantía de ingresos para quien vive del trabajo asalariado, con particular incidencia para aquellos trabajadores que no disfrutan del manto protector de un convenio colectivo, tal y como sucede con las empleadas de hogar, donde su cuantía se fija en 7,43 euros/hora. Cierto es también que con la integración de estas trabajadoras en el régimen general a partir de 1 de enero de 2012, se introdujo un cambio significativo relacionado con la fórmula del cálculo de la base de cotización, que dejó de ser tarifada y única para ser sustituida por una lista o escala en función de los niveles salariales, de forma que, lógicamente, será más alta a medida que la retribución lo sea y que el tiempo de servicios prestados sea, igualmente, de mayor entidad $^{167}$. Junto a esta significativa novación, también se modificó la concepción de quiénes deberían de ser los sujetos obligados a cotizar, estableciéndose al efecto que, a partir de la fecha de integración de estos trabajadores en el régimen general mediante el mecanismo del sistema especial, dicha obligación debía ser siempre compartida entre el empleado y el titular del hogar ${ }^{168}$.

\footnotetext{
${ }^{164}$ MOLERO MARAÑÓN, M.L.: "Las trabajadoras del cuidado. Por un futuro de trabajo decente", Revista de Derecho Social, núm. 89, 2019, p. 55.

${ }^{165}$ ESCUDERO RODRÍGUEZ, R.: "La injustificable desconexión legal entre el trabajo de cuidados en el hogar familiar y la protección de la dependencia", en VV.AA (MOLERO MARAÑÓN, M.L., Dir.): Dependencia (long term care) y empleo en el Estado de Bienestar, Aranzadi, Pamplona, 2017, p. 334.

${ }_{166}$ MIÑARRO YANINI, M.: El trabajo al servicio del hogar familiar: análisis de su nueva regulación, Reus, Madrid, 2013, pp. 10-11.

${ }^{167}$ RUANO ALBERTOS, S.: "Integración del régimen especial de la Seguridad Social de los empleados de hogar en el régimen general de la Seguridad Social", Revista General de Derecho del Trabajo y de la Seguridad Social, núm. 29-30, 2012, p. 453.

${ }^{168}$ QUESADA SEGURA, R.: "De nuevo sobre el sistema especial de Seguridad Social de Personas Empleadas de Hogar. Puntos críticos", Revista de Derecho de la Seguridad Social, núm. 3, 2015, p. 69.
} 
Ahora bien, esta nueva regulación no ha evitado la existencia de amplias bolsas de fraude, pues, en el mejor de los casos, la cotización se realiza en el tramo mínimo con independencia de las horas realmente realizadas, sin dejar de reconocer que la mayoría de las situaciones caen directamente en la economía sumergida y sin olvidar la especialidad peyorativa que también se produce en relación con la ausencia de tutela por el FOGASA y con la protección por desempleo de la que también carecen ${ }^{169}$, sólo paliada en un porcentaje mínimo a raíz de la covid-19, donde el Real Decreto Ley 11/2020, de 31 de marzo, estableció un "subsidio extraordinario por falta de actividad" destinado tanto a las empleadas de hogar que hubieran dejado de prestar servicios "total o parcialmente, con carácter temporal", a fin de reducir el "riesgo de contagio", como a las que hubieran visto "extinguido su contrato de trabajo" por despido o por desistimiento del empleador (Resolución de 30 de abril de 2020) ${ }^{170}$. Muy criticable resulta, por lo demás, que el Estado Español siga sin ratificar el Convenio 189 de la OIT.

\subsection{3.- Cuidadoras informales}

Dentro del elenco de posibilidades que atribuye la LD para la atención de las personas mayores, es la prestación económica para cuidados en el entorno familiar y apoyo a cuidadores no profesionales una de las más utilizada ${ }^{171}$, pues los últimos datos publicados por el IMSERSO revelan que del conjunto de prestaciones del SAAD, un 31,57\% (en 2020) son de esta naturaleza, razón por la cual procede detener la atención en las exigencias subjetivas de quienes asumen el papel de "cuidadores no profesionales".

La LD define esta prestación como la atención dispensada a personas en situación de dependencia en su domicilio, por personas "de su familia o de su entorno" no vinculadas a un servicio de atención profesionalizado. Evidentemente maneja el legislador una noción ambigua que ha sido acotada por la normativa reglamentaria de desarrollo y da cabida tanto al cónyuge y parientes "por consanguinidad, afinidad o adopción, hasta el tercer grado de parentesco" y a "las parejas de hecho, tutores y personas designadas, administrativa o judicialmente, con funciones de acogimiento" (art. 12.2 Real Decreto 1051/2013), siempre que convivan en el mismo domicilio de la persona dependiente, esta esté siendo atendida por ellos y lo hayan hecho durante el período previo de un año a la fecha de presentación de la solicitud. Es más, se amplía el concepto de cuidador a personas que no sean familiares hasta el tercer grado, cuando la persona en situación de dependencia reconocida tenga su domicilio en un entorno caracterizado por insuficiencia de recursos públicos o privados acreditados, despoblación, o circunstancias geográficas o de otra naturaleza que impidan o dificulten otras modalidades de atención (incluida la atención mediante servicios a través de la prestación vinculada), en cuyo caso la

169 RODRÍGUEZ CARDO, I.A.: "El nuevo sistema especial de empleados de hogar: una revolución inconclusa", Nueva Revista Española de Derecho del Trabajo, núm. 158, 2013, p. 163.

${ }^{170}$ LOZANO LARES, F.: "Los déficits de protección social del trabajo femenino", Revista General de Derecho del Trabajo y Seguridad Social, núm. 58, 2021, p. 113.

${ }^{171}$ MOLERO MARAÑÓN, M.L.: "Un replanteamiento del modelo español de atención a la dependencia (long term care) en el contexto europeo", en MOLERO MARAÑÓN, M.L. (Dir.): Dependencia (long term care) y empleo en el Estado de Bienestar, Aranzadi, Pamplona, 2017, p. 67. 
Administración competente podrá excepcionalmente permitir la existencia de cuidados no profesionales por parte de una persona de su entorno que, aun no teniendo el grado de parentesco señalado, resida en el municipio de la persona dependiente o en uno vecino, y lo haya hecho durante el periodo previo de un año a la fecha de presentación de la solicitud. Cuando la persona tenga reconocida la situación de dependencia en grado III o II será necesaria la convivencia con la persona de su entorno, dada la necesidad de atención permanente y apoyo indispensable y continuo que requiere. Únicamente, si tiene reconocida la situación de dependencia en grado I, no será necesaria la convivencia en el domicilio de la persona dependiente ${ }^{172}$.

Tales exigencias confieren un rostro eminentemente femenino a quienes dispensan tales cuidados ${ }^{173}$, máxime cuando no se toman en consideración necesidades de formación de las propias cuidadoras, pese a la enorme responsabilidad asumida, pues deben controlar la ingesta de fármacos en usuarios polimedicados, actuar en situaciones de emergencia o llevar a cabo prácticas rehabilitadoras a menudo indispensables para el bienestar real de la persona en situación de dependencia ${ }^{174}$. Así, las mujeres que prestan cuidados no profesionales con cargo a la LD representan el $89 \%{ }^{175}$ siendo las hijas quienes se encargan mayoritariamente ${ }^{176}$, si bien cabe dar noticia de una tendencia que se manifiesta también al alza: es muy similar el porcentaje de personas cuidadoras de ambos sexos respecto de la pareja en edades avanzadas, coexistiendo en un mismo hogar cuidándose entre ellos ${ }^{177}$.

En cuanto a la dinámica objetiva de dicha prestación, cabe señalar que se reconoce legalmente a favor de la persona dependiente, y no del cuidador familiar, de manera que el perceptor es libre para proporcionar el destino que le parezca más oportuno al montante económico: contratar a personas que complementen la asistencia o cuidado del hogar, ahorrarlo o entregárselo al cuidador. En este último caso, el cuidador no profesional se convertiría en beneficiario indirecto o reflejo, si bien el auxilio monetario no puede servir como retribución a dicho sujeto, puesto que la vinculación entre dependiente y cuidador tiene carácter familiar sin que pueda mercantilizarse ${ }^{178}$. Como con acierto ha precisado la

172 MARTÍNEZ BARROSO, M.R.: "La atención a la dependencia en el mundo rural”, en VV.AA (RODRÍGUEZ ESCANCIANO, S. y ÁLVAREZ CUESTA, H., Dirs.): La economía social como palanca para la sostenibilidad de los territorios rurales, Tirant Lo Blanch, Valencia, 2020 (en prensa).

${ }^{173}$ FERNÁNDEZ COLLADOS, Ma.B.: "Los cuidados en el entorno familiar más de una década después: los vaivenes en su regulación, su aplicación por la doctrina judicial y sus efectos en materia de igualdad", Nueva Revista Española de Derecho del Trabajo, núm. 210, 2018, p. 12.

174 MARTÍNEZ BARROSO, M.R.: "La atención a la dependencia en el mundo rural", en VV.AA (RODRÍGUEZ ESCANCIANO, S. y ÁLVAREZ CUESTA, H., Dirs.): La economía social como palanca para la sostenibilidad de los territorios rurales, Tirant Lo Blanch, Valencia, 2020 (en prensa).

175 IMSERSO: Datos sobre cuidadores no profesionales a 31 de diciembre de 2020, 2020, recuperado de https://www.imserso.es/imserso_01/documentacion/estadisticas/info_d/estadisticas/est_inf/datos_estadisti cos_saad/index.htm (15-01-2021).

176 OBSERVATORIO ESTATAL DE LA DEPENDENCIA: XX Dictamen del Observatorio, Asociación Estatal de Directoras y Gerentes en Servicios Sociales, Madrid, 2020, p. 31.

${ }^{177}$ CES: Informe 3/2020. El sistema de promoción de la autonomía personal y atención a las personas en situación de dependencia, cit., p. 49.

${ }^{178}$ MOLERO MARAÑÓN, M.L.: "El espacio de las prestaciones económicas en la protección social de las personas dependientes: una reflexión sobre el sistema de cuidados deseable", Documentación Laboral, núm. 102, 2014, vol. III, p. 168. 
doctrina, la inexistente relación contractual entre el cuidador informal y la persona dependiente provoca que quien desempeña dicha tarea lo haga de manera "altruista por razón del vínculo de parentesco y afectivo" "179, razón por la cual es menester parar la atención también, siquiera brevemente, en el problema particular que ha venido planteando la situación en que se encontraban estos cuidadores (normalmente, como ya consta, mujeres vinculadas con el dependiente por lazos de parentesco o, excepcionalmente, mujeres del entorno), que se dedican en exclusiva a las tareas de cuidado $^{180}$, pues, en situaciones extremas, después de muchos años dedicados a atender a una persona dependiente, al cesar en esta tarea, se podían encontrar sin la posibilidad de ingresar en un trabajo, fuera por cuenta ajena o autónomo, o con tan corto período de cotizaciones que resultara imposible obtener pensiones de jubilación o de invalidez en su nivel contributivo por falta del período de carencia, e incluso en el nivel no contributivo si tenían algunas rentas o ingresos propios que superaran los mínimos establecidos ${ }^{181}$.

En el ordenamiento español, es sabido que, de conformidad con lo previsto en el art. 2.1 d) Real Decreto 1620/2011, quedan excluidos del marco de la relación laboral de carácter especial de empleados de hogar los cuidadores informales o del entorno de la persona dependiente que le prestan atención domiciliaria, pues la configuración no profesional de esta dispensa excluye la retribución (habida cuenta el destinatario del auxilio económico es el dependiente), no considerándose, por lo tanto, de carácter laboral ni, en consecuencia, dando lugar a relación de trabajo formal ${ }^{182}$, pese a que hasta el 15 de julio de 2012 -fecha de entrada en vigor del Real Decreto Ley 20/2012--, quedaba incluida, de forma obligatoria, en el régimen general de la Seguridad Social mediante un convenio especial $^{183}$. En efecto, el actualmente derogado Real Decreto 615/2007 dispuso la inclusión obligatoria de los cuidadores no profesionales en el campo de aplicación del régimen general de la Seguridad Social y en situación asimilada al alta, mediante la suscripción de un convenio especial cuyas cuotas eran pagadas con cargo a fondos públicos, en concreto, por el IMSERSO que firmaba al efecto el oportuno convenio con la Tesorería (art. 2.1). A lo que había que unir la cotización también por la Administración General del Estado en materia de formación mediante un tipo reducido (art. 4.4 y 5), incluyendo a los cuidadores no profesionales dentro de las acciones formativas de oferta

179 CRISTOBAL RONCERO, R.: "Los cuidadores familiares y su visualización”, en VV.AA (AESSS): Protección a la familia y Seguridad Social: Hacia un nuevo modelo de protección sociolaboral, II Congreso Internacional y XV Congreso Nacional de la Asociación Española de Salud y Seguridad Social, Vol. 1, Laborum, Murcia, 2018, p. 95.

180 SELMA PENALVA, A.: "La (des)protección social de los cuidadores no profesionales", Revista de Derecho Social y Empresa, núm. 10, 2019, p. 116.

${ }^{181}$ SÁNCHEZ-TERÁN HERNÁNDEZ, J.M.: "En las fronteras del contrato de trabajo: el cuidador no profesional de las personas en situación de dependencia”, Revista Trabajo y Seguridad Social (Centro Estudios Financieros), núm. 70, 2008, p. 38.

182 FERNÁNDEZ ORRICO, F.J.: "Prestación económica para cuidados en el entorno familiar y Seguridad Social de cuidadores no profesionales”, Revista Ministerio Trabajo y Asuntos Sociales, núm. 74, 2008, p. 97.

${ }^{183}$ MIÑARRO YANINI, M.: El trabajo al servicio del hogar familiar: análisis de su nueva regulación, Reus, Madrid, 2013, p. 19. 
dentro del subsistema de formación profesional para el empleo (disposición final $\left.3^{a}\right)^{184}$. Con este modelo, ni los cuidadores, ni tampoco las personas dependientes, tenían que participar económicamente en dichas cotizaciones ${ }^{185}$. Únicamente en aquellos casos en los que el cuidador decidiera elevar o mantener la base por encima de lo establecido con carácter ordinario (tope mínimo del régimen general), asumiría personalmente la diferencia ${ }^{186}$.

El descrito entramado de protección de Seguridad Social de los cuidadores no profesionales instaurado por el Real Decreto 615/2007 representó un indudable avance en la dignificación y reconocimiento de los cuidados al permitir el tránsito de una "situación de invisibilidad" a la definición de un "estatuto ocupacional mínimo"187. Sin embargo, el Real Decreto Ley 20/2012 dio un golpe de timón a la protección social de los cuidadores no profesionales desde el momento en que puso fin al pago por la Administración General del Estado de las cuotas del convenio especial con la Seguridad Social de tal colectivo y pasó a convertirlo en una posibilidad voluntaria para los referidos cuidadores, recayendo, en su caso y de modo exclusivo, el coste del mismo sobre ellos (disposición adicional $\left.8^{\mathrm{a}}\right)^{188}$. En paralelo, se suprimió también la cotización de la Administración General del Estado en materia de formación ${ }^{189}$. Desde este momento, el mecanismo del convenio especial pasa a ser de utilización voluntaria, debiendo ingresar el cuidador las cotizaciones a su exclusiva costa como si fuera un trabajador autónomo. Como era de esperar, el número de convenios especiales de cuidadores no profesionales de personas en situación de dependencia descendió drásticamente y de forma inmediata a la luz de esta previsión ${ }^{190}$. Afortunadamente, en virtud del Real Decreto Ley 6/2019, la Administración General del Estado se ha vuelto a hacer cargo de la cuota correspondiente a los convenios especiales en la Seguridad Social para estos cuidadores no profesionales, recuperando el régimen anterior a la reforma de 2012, lo cual resulta de interés para las mujeres aunque no soluciona del todo el problema.

El convenio especial se liga de forma inexorable con el reconocimiento y pago al dependiente de la prestación económica para cuidados en el entorno familiar, que implica la designación como persona cuidadora, con el fin de que en un futuro pueda acceder a las prestaciones por muerte y supervivencia, jubilación e incapacidad permanente,

${ }^{184}$ GONZÁLEZ ORTEGA, S.: "El cuidador no profesional de las personas en situación de dependencia de los mayores en la Ley 39/2006", Temas Laborales, núm. 89, 2007, pp. 297 y ss.

185 ROQUETA BUJ, R.: “Las prestaciones económicas”, en VV.AA (ROQUETA BUJ, R., Coord.): $L a$ protección de la dependencia, Tirant Lo Blanch, Valencia, 2007, p. 461.

${ }^{186}$ BARCELÓN COBEDO, S.: "Seguridad Social y prestaciones en favor de cuidadores no profesionales", en VV.AA (GONZÁLEZ ORTEGA, S., Dir.): La aplicación de la Ley de Dependencia en España, CES, Madrid, 2013, pp. 387 y ss.

${ }^{187}$ MOLINA NAVARRETE, C.: "El régimen cuasi-profesional de cuidados de las personas dependientes", Revista Trabajo y Seguridad Social (Centro Estudios Financieros), núm. 297, 2007, pp. 397 y ss.

${ }^{188}$ BARCELÓN COBEDO, S.: "Seguridad Social y prestaciones en favor de cuidadores no profesionales", cit., pp. 387 y ss.

189 FONTECHA LÓPEZ, A.: "Empleo y sistema para la autonomía y atención a la dependencia", Documentación Laboral, núm. 102, 2014, vol. III, p. 91.

190 DURÁN BERNARDINO, M.: "La prestación económica para cuidados en el entorno familiar y su carácter excepcional a la luz de las últimas reformas”, Temas Laborales, núm. 124, 2014, pp. 172-173. 
derivadas tanto de contingencias comunes como profesionales. No obstante, quedan extramuros de protección, tanto el desempleo como la incapacidad temporal, pese a que los problemas de salud son relativamente habituales ${ }^{191}$.

Lamentablemente, ni las rentas mínimas autonómicas, ni tampoco la nueva prestación social recientemente aprobada por el Real Decreto Ley 20/2020, de 29 de mayo, por el que se establece el ingreso mínimo vital, se ocupan de atender el déficit de ingresos de estas cuidadoras, pues se trata de prestaciones asistenciales condicionadas a la demostración del estado de necesidad y a una ineludible obligación de inserción laboral que difícilmente van a poder cumplir unas mujeres que han sido excluidas del mercado de trabajo precisamente por tener que dedicarse a los cuidados ${ }^{192}$.

A la vista de tal regulación, la conclusión se presenta obvia: no se puede seguir admitiendo un cuidado de 24 horas los 7 días de la semana, sin remuneración alguna, deviniendo necesario modificar la LD para crear una nueva categoría de "cuidadora asalariada" capaz de incluir a estas mujeres ${ }^{193}$, asociada al disfrute de una renta básica de carácter individual dotada de un importe digno, condicionada a la demostración de la imposibilidad de acceder al mercado de trabajo o de hacerlo en condiciones muy precarias, a consecuencia, precisamente, de la dedicación en exclusiva o de forma prioritaria al trabajo de cuidados no remunerados ${ }^{194}$. Muy importante es, asimismo, proporcionar a estas mujeres formación, apoyo psicológico y mecanismos de respiro, con el fin de que puedan contar con el tiempo de descanso necesario para reponer fuerzas físicas y mentales en una actividad harto extenuante.

\subsubsection{La asistencia personal: la apuesta por una regulación $\mathrm{ad}$ hoc}

A diferencia del cuidador no profesional, que queda excluido de la aplicación del Derecho del Trabajo, y del empleado de hogar, que queda sometido a una relación laboral especial, el asistente personal, al igual que el asistente a domicilio, está vinculado a la persona dependiente a través de una relación laboral ordinaria ${ }^{195}$, pero sin que nada impida recurrir a la contratación con persona jurídica que preste la asistencia movilizando personal propio $^{196}$. Sin negar la legalidad de esta segunda opción, no puede ignorarse que el asistente personal que atiende al dependiente a través de una empresa de servicios puede quedar colocado en la frágil frontera entre la subcontratación y la cesión ilegal de

${ }^{191}$ MOLERO MARAÑÓN, M.L.: "Las trabajadoras del cuidado: por un futuro de trabajo decente", Revista de Derecho Social, núm. 89, 2020, p. 52.

192 LOZANO LARES, F.: "Los déficits de protección social del trabajo femenino", Revista General de Derecho del Trabajo y Seguridad Social, núm. 58, 2021, p. 122.

${ }^{193}$ MOLERO MARAÑÓN, M.L.: "Las trabajadoras del cuidado: por un futuro de trabajo decente", Revista de Derecho Social, núm. 89, 2020, p. 56.

${ }^{194}$ LOZANO LARES, F.: "Los déficits de protección social del trabajo femenino", Revista General de Derecho del Trabajo y Seguridad Social, núm. 58, 2021, p. 122.

${ }^{195}$ POQUET CATALÁ, R.: "Covid-19, crisis sanitaria, económica y laboral: ¿hacia un trabajo decente en el trabajo doméstico?", Adapt. Revista Internacional y Comparada de Relaciones Laborales y Empleo, Vol. 9, núm. 1, 2021, p. 250.

${ }^{196}$ CAVAS MARTÍNEZ, F.: "Prestaciones del sistema", en VV.AA (MONTOYA MELGAR, A., Dir.): La protección de las personas dependientes. Comentario a la Ley 39/2006, de promoción de la autonomía personal y atención a las situaciones en situación de dependencia, Civitas, Madrid, 2007, p. 159. 
trabajadores ex art. 43 ET, y ello desde el momento en que la empresa empleadora debe organizar y supervisar el desarrollo del trabajo asalariado, al tiempo que es la persona dependiente (o su representante legal) quien ejerce el control sobre la calidad de los servicios que recibe y quien imparte las instrucciones sobre cómo llevarlos a cabo ${ }^{197}$.

Se trata de una persona que realiza o ayuda a realizar las tareas de la vida diaria de otra persona que por su situación de dependencia no puede encargarse por sí misma o tiene grandes dificultades, haciendo posible la vida independiente del beneficiario ${ }^{198}$. Aun cuando no cabe desconocer algunos rasgos positivos de esta prestación, como son su adecuación para cualquier grado de dependencia reconocido, la obligatoriedad de reclutar personal cualificado con el título de técnico en atención a personas en situación de dependencia y el hecho de garantizar el objetivo final cual es que la persona dependiente gane autonomía, lo cierto es que la falta de definición de cometidos que queda al libre albedrío de las partes hace que se recurra a esta figura con carácter marginal ${ }^{199}$.

Nuevas perspectivas abre el Acuerdo de la Mesa de Diálogo Social en Autonomía Personal y Dependencia de 18 de marzo de 2021, que prevé la aprobación de una regulación ad hoc de este cauce capaz de cubrir las carencias legales ${ }^{200}$.

\subsection{La doble jornada: la simultánea condición de trabajadoras y cuidadoras}

Al margen de la LD se encuentra el régimen no formal de cuidados por parte de quien mantiene su relación laboral en el mercado de trabajo ordinario y la compagina con la labor de atención al familiar dependiente. Teniendo en cuenta que el tiempo de vida doméstica penaliza a las mujeres trabajadoras ${ }^{201}$, la vertebración legal tradicional de las medidas de conciliación presentaban un marcado carácter femenino ${ }^{202}$, lo que enfatizaba estereotipos de género, al pivotar sobre la posibilidad de otorgar tiempo (ausencias al trabajo con graves secuelas en el mantenimiento de la actividad laboral y en la progresión profesional), de forma remunerada o no, para que la trabajadora, cuidadora clásica y tradicional de los menores, de los mayores, de los enfermos y de las personas con discapacidad, pudiera atender sus responsabilidades parentales, minorando el período

\footnotetext{
197 LLANO SÁNCHEZ, M.: "Los cuidados informales tras diez años de aplicación de la Ley de Dependencia: puntos críticos y algunas propuestas de mejora", en VV.AA (MOLERO MARAÑÓN, M.L., Dir.): Dependencia (Long term care) y empleo en el Estado del Bienestar, Aranzadi, Pamplona, 2017, p. 175.

${ }^{198}$ CES: Informe 3/2020. El sistema de promoción de la autonomía personal y atención a las personas en situación de dependencia, cit., p.143.

${ }^{199}$ MOLERO MARAÑÓN, M.L.: "El espacio de las prestaciones económicas en la protección social de las personas dependientes: una reflexión sobre el sistema de cuidados deseable", Temas Laborales, núm. 102, vol. III, 2014, p. 167 ó HUETI-GARCÍA, A.; CHAVERRI-CARVAJAL, A. y MORALES-ROMO, N.: "El sistema para la autonomía y atención a la dependencia en España (SAAD). Memoria de debilidades desde su implantación", Prisma Social, enero, 2021, p. 35.

${ }^{200}$ https://www.ccoo.es/22a776587b1bec1115ac2ab92fec53df000001.pdf

201 CASAS BAAMONDE, M.E.: "Soberanía sobre el tiempo de trabajo e igualdad de trato y de oportunidades de mujeres y hombres", Derecho de las Relaciones Laborales, núm. 3, 2019, p. 236.

202 BALLESTER PASTOR, M.A.: Retos y perspectivas de la discriminación laboral por razón de sexo, Tirant Lo Blanch, Valencia, 2016, p. 100.
} 
dedicado a sus actividades asalariadas ${ }^{203}$. Tal perspectiva ha provocado la desvinculación o expulsión total o parcial no deseada del entorno laboral y un denostado efecto boomerang en perjuicio de las mujeres al considerar muchos empresarios que se trataba de una mano de obra más cara o menos productiva ${ }^{204}$. Por citar algunos datos numéricos, en el año 2019, las mujeres que optaron por acogerse a una excedencia para cuidar a un familiar rozaban las 10.000 (9.789), frente a los varones que la solicitaron que, pese a incrementar cifras de años anteriores, no alcanzaban los 2.500 beneficiarios $(2.260)^{205}$. Además, todavía a día de hoy los hombres solo dedican de promedio diario 1 hora y 54 minutos al cuidado del hogar y familia (tareas asociadas tradicionalmente a los roles femeninos), mientras que las mujeres duplican esa cifra y asignan para la realización de las mismas 4 horas y 7 minutos ${ }^{206}$

El enfoque jurídico inicial tendente a establecer los denominados "derechos de ausencia" mayoritariamente utilizados por féminas ha sufrido un replanteamiento, comenzando a asumirse que, para conseguir un buen punto de equilibrio, procede adoptar medidas que permitan la asunción de responsabilidades familiares tanto por hombres como por mujeres, así como promulgar normas tendentes a equiparar las obligaciones entre los dos sexos, con el objetivo último de facilitar que las actuaciones previstas puedan ser solicitadas en igual medida por ambos ${ }^{207}$. Los derechos legales de conciliación han pasado, así, progresivamente a encontrar su razón de ser en el reparto ecuánime de los tiempos de trabajo y vida (personal y, sobre todo, familiar) de las personas trabajadoras y en la lógica de la corresponsabilidad entre los sexos para terminar con el denostado papel tradicional de la mujer y del hombre en la sociedad y en la familia ${ }^{208}$. Se trata de que varones y féminas compartan su tiempo de trabajo con su tiempo de cuidados familiares y de necesidades vitales, rompiendo la tradicional separación del "mundo remunerado masculino" frente al "mundo no productivo femenino", en el que la organización social patriarcal ha situado las tareas reproductivas y de cuidados familiares y domésticos ${ }^{209}$. De ahí que se vaya avanzando en la consecución de la efectiva igualdad, implantando derechos de titularidad indistinta y compartida por mujeres y hombres, a

\footnotetext{
${ }^{203}$ MOLERO MARAÑÓN, M.L.: "La necesaria reorientación de la conciliación de la vida profesional y familiar y la negociación colectiva", Relaciones Laborales, núm. 19, 2011, p. 23.

${ }^{204}$ CABEZA PEREIRO, J.: "Las políticas de conciliación al servicio de la igualdad entre hombres y mujeres”, en VV.AA (CABEZA PEREIRO, J. y FERNÁNDEZ DO CAMPO, B., Dirs.): Conciliación de la vida familiar y laboral y corresponsabilidad entre sexos, Tirant Lo Blanch, Valencia, 2011, p. 85.

205 INSTITUTO DE LA MUJER Y PARA LA IGUALDAD DE OPORTUNIDADES: Mujeres en Cifras, https://www.inmujeres.gob.es/gl/MujerCifras/Home.htm

${ }^{206}$ INE: Encuesta de Empleo del Tiempo (2009-2010)

${ }^{207}$ SSTJUE de 30 de septiembre de 2010, asunto Roca Álvarez, C- 104/09, y de 16 de julio de 2015, asunto Maistrellis, C-222/14.

208 GONZÁLEZ DE PATTO, M.R.: “Cuestiones básicas sobre las políticas de empleo y contratación de la mujer”, en VV.AA (MOYA AMADOR, R., Dir.): Estudios sobre los diversos aspectos jurídicos del trabajo de la mujer, Aranzadi, Pamplona, 2016, p. 82.

209 CASAS BAAMONDE, M.E.: "Soberanía sobre el tiempo de trabajo e igualdad de trato y de oportunidades de mujeres y hombres”, Derecho de las Relaciones Laborales, núm. 3, 2019, p. 236.
} 
excepción -lógicamente-- de aquellos relacionados con el embarazo y la maternidad biológica amparados bajo un claro hecho biológico diferencial ${ }^{210}$.

El progreso legislativo ha sido notorio, superando la inicial finalidad protectora de las normas dirigidas a la maternidad y al cuidado de los menores y mayores cuyo destinatario era la mujer trabajadora en exclusiva, para transitar, por influjo comunitario principalmente, hacia el reconocimiento de derechos de corresponsabilidad familiar a los trabajadores, hombres y mujeres, de forma indeterminada e individualizada ${ }^{211}$. Algunos han sido los pasos secuenciados en esta senda, pudiendo mencionar sin necesidad de remontarnos a antecedentes más lejanos: la Ley 39/1999, de 5 de noviembre, de conciliación de la vida laboral y familiar ${ }^{212}$; la Ley Orgánica 1/2004, de 28 de diciembre, de Protección Integral contra la violencia de género; la Ley Orgánica 3/2007, de 22 de marzo, de igualdad efectiva entre mujeres y hombres; la Ley 15/2005, de 8 de julio, que ha modificado el art. 68 del Código Civil para establecer que los cónyuges deberán "compartir las responsabilidades domésticas y el cuidado y atención de ascendientes y descendientes y otras personas dependientes a su cargo"; el Real Decreto Ley 6/2019, de 1 de marzo, de medidas urgentes para la garantía de la igualdad de trato y de oportunidades entre mujeres y hombres en el empleo y la ocupación, que ha atribuido permisos y prestaciones de la misma duración - 16 semanas - e intransferibles, por nacimiento y cuidado de menores de doce meses; y, como último eslabón hasta el momento, el Real Decreto Ley 8/2020, de 17 de marzo, por el que se aprueba el Plan Mecuida, prorrogado en su duración hasta el 31 de mayo de 2021, cuyo objetivo se centra en la atención de las necesidades familiares surgidas con motivo de la expansión de la pandemia por la covid-19.

Importante ha sido también la labor del Máximo Intérprete de la Norma Fundamental, pues ha dejado clara "la dimensión constitucional... de todas aquellas medidas tendentes a facilitar la compatibilidad de la vida laboral y familiar de los trabajadores, tanto desde la perspectiva del derecho a la no discriminación por razón de sexo (art. $14 \mathrm{CE}$ ), como desde el mandato de la protección a la familia y a la infancia (art. $39 \mathrm{CE}$ ), perspectiva que ha de prevalecer y servir de orientación para cualquier duda interpretativa",213.

Ahora bien, pese a que los pasos han sido de gigante, procede seguir avanzando en esta senda y abrir nuevas posibilidades más incisivas en relación con la configuración neutra en el diseño de facilidades intransferibles para el cumplimiento de las responsabilidades

210 LANTARÓN BARQUÍN, D.: "Transparencia salarial y otras reflexiones a propósito de la discriminación por razón de género”, en VV.AA (MONSALVE CUÉLLAR, M,E., Coord.): Género y no discriminación, Alderabán, Madrid, 2019, p. 118.

211 BALLESTER PASTOR, M.E.: "Del trabajo al trabajo de calidad: los nuevos retos de las políticas de empleo femeninos”, en VV.AA (MOYA AMADOR, R., Dir.): Estudios sobre diversos aspectos jurídicos del trabajo de la mujer, Aranzadi, Pamplona, 2016, p. 52.

212 LÓPEZ BALAGUER, M.: "Principio de igualdad en el acceso al empleo y en materia retributiva", en VV.AA (BALLESTER PASTOR, M.E., Coord.): La transposición del principio antidiscriminatorio contrario al ordenamiento jurídico laboral español, Tirant Lo Blanch, Valencia, 2010, p. 89.

${ }^{213}$ SSTCo 3/2007, de 15 de enero y 108/2019, de 30 de septiembre. 
familiares $^{214}$, tal y como se deduce de las nuevas estrategias diseñadas desde la Unión Europea, de las sucesivas decisiones del Tribunal de Justicia y, particularmente, de la nueva Directiva 2019/1158, de 20 de junio, relativa a la conciliación de la vida familiar y la profesional de los progenitores y cuidadores, que apuesta por el reparto equilibrado de los cuidados de los hijos y de otros familiares física o mentalmente dependientes adoptando una perspectiva individualizada para lograr una distribución equilibrada de la titularidad de los derechos $^{215}$. En definitiva, si mujeres y hombres asumieran con idéntica o similar intensidad las referidas obligaciones familiares, esta circunstancia ya no podría ser tomada en consideración por el empresario a la hora de tratar de un modo distinto a ambos colectivos en relación con su integración, promoción y estabilidad laboral ${ }^{216}$.

Ahora bien, pese a todos los avances, no cabe de resaltar agudas sombras, pues el legislador siempre ha dado preferencia a los derechos de conciliación relacionados con el cuidado de hijos, marginando el cuidado de familiares y obviando las necesidades de atención derivadas de la edad, que componen uno de los colectivos más vulnerables tal y como se ha podido comprobar con la expansión de la pandemia ${ }^{217}$.

En efecto, el factor del envejecimiento de familiares como necesidad específica de cuidado solo es mencionado tres veces de forma expresa por el legislador laboral, siendo además su atención de inferior intensidad frente al cuidado de hijo ${ }^{218}$ :

En primer lugar, en el art. 37.6 ET que reconoce el derecho a "la reducción de la jornada de trabajo diaria, con la disminución proporcional del salario entre, al menos, un octavo y un máximo de la mitad de la duración de aquella... (a quienes tienen que) encargarse del cuidado directo de un familiar, hasta el segundo grado de consanguinidad o afinidad, que por razones de edad, accidente o enfermedad no pueda valerse por sí mismo, y que no desempeñe actividad retribuida". Esta prerrogativa atribuye un incremento ficticio de las cotizaciones hasta un 100, esto es, como si no se hubiera producido tal reducción (art. 237 Real Decreto Legislativo 8/2015, de 30 de octubre, por el que se aprueba el texto

\footnotetext{
${ }^{214}$ MARTÍNEZ MORENO, C.: "Vida privada y relación de trabajo. A propósito de la posibilidad de pactar individualmente las condiciones de ejercicio de los derechos de conciliación de la vida familiar y laboral", Tribuna Social, núm. 97, 2007, pp. 20 y 22.

${ }^{215}$ NUÑEZ-CORTÉS CONTRERAS, P.: "Avances en corresponsabilidad y flexibilidad en cuidado del lactante y adaptación de jornada por motivos familiares", Revista General de Derecho del Trabajo y de la Seguridad Social, núm. 55, 2020, p. 110.

216 CASAS BAAMONDE, M.E.: "Igualdad, conciliación de la vida personal, familiar y laboral y Seguridad Social", en VV.AA (MONEREO PÉREZ, J.L.; MOLINA NAVARRETE, C. y MORENO VIDA, M.N., Dirs.): Homenaje al Profesor José Vida Soria con motivo de su jubilación. La Seguridad Social a la luz de sus reformas pasadas, presentes y futuras, Comares, Granada, 2008, p. 999.

217 DE VICENTE PACHÉS, F.: "Servicios sociales, envejecimiento activo y aprendizaje a lo largo de la vida", en VV.AA: Por una pensión de jubilación, adecuada, segura y sostenible, Tomo II. III Congreso Internacional y XVI Congreso Nacional de la Asociación Española de Salud y Seguridad Social, Laborum, Madrid, 2019, p. 308.

${ }^{218}$ VADILLO RUÍZ, J.J.: "Respuestas a los nuevos retos de envejecimiento, protección a la salud y cuidados: la perspectiva médica", en VV.AA.: Por una pensión de jubilación, adecuada, segura y sostenible, III Congreso Internacional y XVI Congreso Nacional de la Asociación Española de Salud y Seguridad Social, Laborum, Murcia, 2019, p. 64.
} 
refundido de la Ley General de la Seguridad Social -LGSS--) pero con una extensión temporal ceñida a un año frente a los dos atribuidos cuando la reducción de jornada obedezca al cuidado de menor de 12 años.

En segundo término, en el art. 46.3 ET, en virtud del cual "tendrán derecho a un periodo de excedencia, de duración no superior a dos años, salvo que se establezca una duración mayor por negociación colectiva, los trabajadores para atender al cuidado de un familiar hasta el segundo grado de consanguinidad o afinidad, que por razones de edad, accidente, enfermedad o discapacidad no pueda valerse por sí mismo, y no desempeñe actividad retribuida". Si el disfrute de la excedencia se destinara al cuidado de hijo la duración máxima podría alcanzar tres años. En ambos casos, se trata de supuestos suspensivos del contrato de trabajo, de distinta duración, en los que se interrumpen las prestaciones recíprocas de la persona trabajadora y de la empresa, si bien se mantienen determinados derechos laborales (asistir a cursos de formación, reserva del puesto durante un tiempo, cómputo de la excedencia a efectos de antigüedad). La mayor tutela de la excedencia por cuidado de hijos se proyecta también a efectos de protección social, pues el efecto de la falta de atribución de prestaciones sustitutorias de la Seguridad Social, se suaviza en el art. 237.1 LGSS de modo distinto, a saber: los "períodos de hasta tres años de excedencia que los trabajadores, de acuerdo con el art. 46.3 ET, disfrutados en razón del cuidado de cada hijo o menor en régimen de acogimiento permanente o de guarda con fines de adopción, tendrán la consideración de período de cotización efectiva a efectos de las correspondientes prestaciones de la Seguridad Social por jubilación, incapacidad permanente, muerte y supervivencia, maternidad y paternidad". En cambio, el art. 237.2 LGSS considera "efectivamente cotizado (solo) el primer año del período de excedencia para el cuidado de familiares".

En tercer lugar, en el art. 6 Real Decreto Ley 8/2020, que reconoce derechos de conciliación (medidas de flexibilidad en el tiempo y lugar de trabajo y reducciones de jornada) asociados a la propagación de la pandemia, fundados en los siguientes motivos: "cuando sea necesaria la presencia de la persona trabajadora para la atención del cónyuge o pareja de hecho, así como familiares de consanguinidad hasta el segundo grado, que, por razones de edad, enfermedad o discapacidad, necesiten de cuidado personal y directo como consecuencia del covid-19. Asimismo, se considerará que concurren circunstancias excepcionales cuando existan decisiones adoptadas por las autoridades gubernativas relacionadas con el covid-19 que impliquen cierre de centros educativos o de cualquier otra naturaleza que dispensaran cuidado o atención a la persona necesitada de los mismos. También se considerará que concurren circunstancias excepcionales que requieren la presencia de la persona trabajadora, cuando la persona que hasta el momento se hubiera encargado del cuidado o asistencia directos de cónyuge o familiar hasta segundo grado de la persona trabajadora no pudiera seguir haciéndolo por causas justificadas relacionadas con el covid-19"219.

${ }^{219}$ RODRÍGUEZ ESCANCIANO, S.: "Medidas para la conciliación de la vida laboral y familiar ante la emergencia sanitaria por covid-19", Derecho de las Relaciones Laborales, núm. 4, 2020, p. 457. 
A mayor abundamiento, manifestación señera de la falta de sensibilidad del legislador con las necesidades de cuidado de las personas de mayor edad puede encontrarse en el art. 34.8 ET, modificado por el Real Decreto Ley 6/2019, que reconoce una especie de una modificación sustancial de condiciones de trabajo a la inversa ${ }^{220}$, pues concede el derecho a solicitar por la persona trabajadora medidas de flexibilidad sin restar dedicación a la actividad laboral, esto es, "adaptaciones de la duración y distribución de la jornada de trabajo, en la ordenación del tiempo de trabajo y en la forma de prestación, incluida la prestación de su trabajo a distancia, para hacer efectivo su derecho a la conciliación de la vida familiar y laboral" 221 . Este precepto aclara que el mencionado derecho queda limitado, "si se trata de cuidado de hijo, hasta que el menor cumpla los 12 años ${ }^{222}$. Cierto es que este tenor no implica la desprotección de otras necesidades de atención de familiares, bien descendientes de mayor edad, bien personas dependientes ${ }^{223}$, no en vano, atendiendo al aforismo "quien puede lo más (minorar la dedicación), puede lo menos (adaptarla)", se entienden incluidos en el ámbito subjetivo de aplicación del art. 34.8 ET, a quienes pueden reducir la jornada por motivos familiares o de cuidados por mor del art. $37.6 \mathrm{ET}^{224}$. No menos verdad resulta, sin embargo, que la falta de referencia expresa no deja de ser criticable.

Como fácilmente puede comprobarse, los derechos de conciliación para el cuidado de las personas mayores se muestran como "de segundo grado" tanto desde el punto de vista cuantitativo como cualitativo si se comparan los establecidos para la atención de los hijos. Sin duda, esta tendencia debe corregirse, no en vano la propia evolución demográfica va a provocar que en un futuro próximo se va a invertir la pirámide del cuidado, siendo cada vez menor el número de hijos a atender y mayor el número de personas de edad avanzada

\footnotetext{
${ }^{220}$ MORALES ORTEGA, J.M.: "Tiempo de trabajo y crisis sanitaria: adaptación y reducción de jornada y permiso obligatorio recuperable", Trabajo, Persona, Derecho, Mercado, núm. 1, 2020, p. 24.

221 MOLINA NAVARRETE, C.: "Autodeterminación (soberanía) sobre el tiempo y adaptación de la jornada a la carta por razones conciliatorias: entre utopías", Revista Trabajo y Seguridad Social (Centro de Estudios Financieros), núm. 441, 2019, p. 15. Además de supeditar el ejercicio del derecho a una previa petición por parte del trabajador a modo de mera expectativa, el art. 34.8 ET sigue condicionando la adaptación de las condiciones de trabajo: primero, a que se trate de cambios "razonables" y proporcionados a las necesidades de las personas y a las demandas organizativas o productivas, quedando incólume la facultad de oposición empresarial; segundo, la solicitud se realizará conforme a lo que haya dispuesto al efecto el convenio colectivo, al que se le hace un llamamiento para que, de modo obligatorio, establezca "los términos de ejercicio, que se acomodarán a criterios y sistemas que garanticen la ausencia de discriminación, tanto directa como indirecta, entre las personas trabajadoras de uno y otro sexo", pero tal exigencia no se considera contenido mínimo del convenio colectivo y sólo se vincula tangencialmente al plan de igualdad; tercero, ante el silencio convencional, habrá de abrirse un procedimiento de negociación individualizada (sin intervención de terceros que intenten mediar o conciliar las posturas enfrentadas, ni posibilidad de resolución arbitral), durante un período máximo de 30 días, concluido el cual la empresa es quien habrá de comunicar si acepta la posición, plantea una alternativa o deniega el ejercicio del derecho indicando las "razones objetivas" en que se sustenta su postura. GORELLI HERNÁNDEZ, J. "La nueva regulación de la adaptación de la jornada: de la melancolía a una esperanza contenida“, Derecho de las Relaciones Laborales, núm. 2, 2020, p. 118.

${ }^{222}$ MARTÍNEZ MORENO, C.: Brecha salarial de género y discriminación retributiva: causas y vías para combatirlas, Bomarzo, Albacete, 2019, p. 125.

${ }^{223}$ NUNEEZ-CORTÉS CONTREAS, P.: Novedades en relación con la jornada de trabajo y los derechos de conciliación (tras la aprobación del RD 6/2019, de 1 de marzo), Dykinson, Madrid, 2019, p. 103.

${ }^{224}$ SSTSJ, Social, Madrid 10 mayo y 19 junio 2019 (núm. 191/2019 y 292/2019).
} 
a asistir ${ }^{225}$. Como con acierto se ha dicho, al mismo tiempo que disminuye en su conjunto la carga de cuidado de niños por el descenso de los nacimientos, crece la de personas de mayor edad por efecto del envejecimiento en la estructura de la población, la mayor longevidad y la cronificación de algunas patologías que antiguamente llevaban directamente a la muerte ${ }^{226}$. Nuevas perspectivas abre en este contexto la necesaria transposición de la Directiva 2019/1158, de 20 de junio, relativa a la conciliación de la vida familiar y la vida profesional de los progenitores y cuidadores, que reconoce dos nuevos derechos destinados, entre otros objetivos, a atender las necesidades de cuidado de las personas mayores, que deben ser incorporados al ordenamiento jurídico español ${ }^{227}$ :

En primer lugar, el art. 6 regula un asueto de cinco días laborales, introduciendo dos conceptos básicos justificativos del permiso. Por un lado, el de "cuidador", que comprende a aquel sujeto que "dispensa cuidados o presta ayuda en caso de enfermedad grave o dependencia a un familiar o a una persona que viva en el mismo hogar que el trabajador y que necesite asistencia o cuidados importantes por un motivo médico grave, conforme a lo definido por cada Estado miembro". Por otro, el de "familiar", que incluye al "hijo, hija, padre, madre o cónyuge del trabajador o pareja de hecho de este cuando las uniones de hecho están contempladas en el derecho nacional"228. Los términos son, pues, más generosos desde el punto de vista cuantitativo y cualitativo que los utilizados por el art. 37.3 b) ET, que, en su versión actual, se ciñe al reconocimiento de dos días de permiso por "el fallecimiento, accidente o enfermedad graves, hospitalización o intervención quirúrgica sin hospitalización que precise reposo domiciliario, de parientes hasta el segundo grado de consanguinidad o afinidad. Cuando con tal motivo la persona trabajadora necesite hacer un desplazamiento al efecto, el plazo será de cuatro días".

En segundo término, el art. 7 atribuye el derecho de los trabajadores a ausentarse del trabajo por motivos familiares urgentes en caso de enfermedad o accidente, que hagan indispensable la inmediata presencia del trabajador. Cierto es que este precepto no menciona la edad o la dependencia como causa justificativa, pero su redactado permitirá atender circunstancias sobrevenidas directamente relacionadas con estas dos contingencias aunque la enfermedad no sea grave o no se produzca un accidente (como

\footnotetext{
${ }^{225}$ MOERO MARAÑÓN, M.L.: "Los desafíos de una genuina conciliación de la vida profesional y familiar en la sociedad española del siglo XXI”, Revista del Ministerio de Trabajo, Migraciones y Seguridad Social, núm. Extraordinario, 2019, p. 164.

${ }^{226}$ CES: Informe 3/2020. El sistema de promoción de la autonomía personal y atención a las personas en situación de dependencia, cit., p. 28.

${ }^{227}$ BALLESTER PASTOR, M.A.: De los permisos parentales a la conciliación: expectativas creadas por la Directiva 2019/1158 y su transposición al ordenamiento español, Derecho de las Relaciones Laborales, núm. 11, 2019, p. 1122

${ }^{228}$ LOUSADA AROCHENA, J.F.: "La construcción de los derechos de conciliación de la vida personal, familiar y laboral como derechos fundamentales”, Derecho de las Relaciones Laborales, núm. 9, 2019, p. 783 y ss.
} 
exige el actual art. 37.3 ET) sino que se trate de una dolencia crónica o degenerativa propia de la senectud que exige atenciones urgentes ${ }^{229}$.

\section{Conclusión: el respeto del derecho a decidir}

El progresivo envejecimiento de la población incide en el agravamiento del problema social de la dependencia y sus necesidades de atención, no en vano se estima que en el año 2050 alrededor del 12 por 100 de la población española tendrá más de 80 años $^{230}$. La relación directa entre las variables mayor edad y vulnerabilidad no plantea duda alguna ante la progresiva pérdida de autonomía física, mental, intelectual, cognitiva o sensorial que conlleva la senectud, haciendo imprescindible la atención o ayuda de otra persona para la realización de las actividades básicas de la vida diaria ${ }^{231}$. El Estado de Bienestar debe de dar adecuado soporte a un entramado público de atenciones técnicas e infraestructuras que garanticen la calidad de vida de estas personas mayores, al tiempo que debe procurar la probidad de las condiciones de trabajo de los empleados en tal sector de la actividad.

Pieza esencial en este sistema de cuidados ha de ser su libertad de elección" sobre el tipo de servicio deseado, entre los posibles, y el lugar de preferencia para recibir asistencia. Teniendo en cuenta que la elección mayoritaria de los ancianos radica en la permanencia en su entorno, deviene imprescindible promover la profesionalización del sector cuidados en el hogar a través del desarrollo del servicio de ayuda a domicilio o de la figura del asistente personal, en condiciones dignas, debidamente combinados con la atención familiar informal dotada de una renta garantizada o con el reclutamiento subvencionado de un empleado doméstico que también debe quedar ubicado dentro del sector del empleo asociado a la LD, así como alternativamente con la posibilidad de acudir a un centro de día o de noche, sin olvidar, en todas las combinaciones posibles, la disposición de una verdadera teleasistencia avanzada, previa adaptación arquitectónica y digital de la vivienda con auxilio de la domótica. Todas estas atenciones deben de resultar compatibles entre sí con mayor o menor intensidad en sus distintas variables en función de las circunstancias subjetivas del dependiente, configurando un auténtico "traje a medida" que proporcione la pertinente calidad de vida a las personas ancianas independientemente de su lugar de residencia, sea en los núcleos urbanos o en los alejados territorios rurales ${ }^{232}$, sin olvidar la pertinente coordinación con el sistema de salud al objeto de que el anciano

${ }^{229}$ IGARTÚA MIRÓ, M.T.: "Conciliación y ordenación flexible del tiempo de trabajo. La nueva regulación del derecho de adaptación de jornada ex art. 34.8 ET”, Revista General de Derecho del Trabajo y de la Seguridad Social, núm. 53, 2019, p. 81.

${ }^{230}$ HERAS HERNÁNDEZ, M.M.: "Políticas públicas para el fomento de la financiación privada de la dependencia”, en VV.AA (MOLERO MARAÑÓN, M.L., Coord.): Retos para una implantación efectiva del sistema para la autonomía y atención a la dependencia, Cinca, Madrid, 2012, p. 2014.

${ }^{231}$ MOLERO MARAÑÓN, M.L.: "Un replanteamiento del modelo español de atención a la dependencia (long term care) en el contexto europeo", en VV.AA (MOLERO MARAÑÓN, M.L., Dir.): Dependencia (long term care) y empleo en el Estado del Bienestar, Aranzadi, Pamplona, 2017, p. 77.

${ }^{232}$ GARCÍA HERRERO, G.: "El servicio de ayuda a domicilio en la encrucijada", Revista de Derechos Sociales, núm. 49, 2011, pp. 56-57 
reciba la atención médica adecuada ante el deterioro físico y mental propio de la edad y las posibles circunstancias sobrevenidas derivadas de caídas, fracturas, traumatismos cardiovasculares u otro tipo de accidentes o empeoramientos súbitos en dolencias crónicas $^{233}$, incluyendo tratamientos paliativos, psicológicos y rehabilitadores ${ }^{234}$.

No obstante, para aquellos casos en los que proceda el internamiento en un centro residencial, bien por la voluntad del afectado, o bien porque su situación personal hiciese inviable la permanencia en su domicilio, teniendo en cuenta la edad y pluripatologías de las personas que requieren los servicios de las instituciones de carácter social, éstas deben estar debidamente equipadas y contar con personal cualificado, debiendo proporcionar no sólo acompañamiento, alojamiento y manutención, sino también una adecuada asistencia sanitaria. Esta doble configuración del modelo de residencias, propiamente sociosanitario, ayudará a reducir los ingresos de dilatada extensión temporal en hospitales de enfermos crónicos y la sobrehospitalización al final de la vida, así como a retrasar la entrada en las situaciones más severas de dependencia ${ }^{235}$.

Todo ello sin olvidar la necesidad de que la legislación laboral, convenientemente complementada y suplementada por la negociación colectiva, favorezca la conciliación o, mejor, la corresponsabilidad en los cuidados de la senectud, otorgando a las personas trabajadoras derechos de igual intensidad que los concebidos para el cuidado de hijos, sin dejar de descender a las situaciones particulares que plantean los cuidados de larga duración de las personas de mayor edad, aquejadas progresivamente de deterioros físicos, psíquicos y sensoriales y de enfermedades crónicas degenerativas, todo ello con el fin de no desincentivar la participación laboral y el desarrollo profesional de las personas cuidadoras, a su vez, asalariadas en el mercado de trabajo ordinario ${ }^{236}$.

En fin, el renovado planteamiento de la asistencia social al "sobre-envejecimiento" viene a aconsejar, a la postre, no sólo la puesta en marcha de un plan concertado entre las distintas Administraciones ${ }^{237}$, sino la elaboración y aprobación de una futura Ley Básica de Servicios Sociales que sirva para articular la actuación política en este campo, debiendo el IMSERSO liderar este loable objetivo de coordinación ${ }^{238}$, contando a tal fin

\footnotetext{
233 PRADOS, C.: "Prevención y mantenimiento de la autonomía de los mayores: la ayuda a domicilio", Cuadernos de Trabajo Social, núm. 14, 2001, pp. 291 y ss.

${ }^{234}$ SANCHO CASTIELLO, M. y DÍAZ MARTÍN, R.: “Atención a las personas mayores en su entorno: teleasistencia, ayuda a domicilio y centros de día, Sociedad y Utopía. Revista de Ciencias Sociales, núm. 30, 2007, p. 163.

${ }^{235}$ CES: Informe 3/2020. El sistema de promoción de la autonomía personal y atención a las personas en situación de dependencia, cit., p. 96

${ }^{236}$ CES: Informe 3/2020. El sistema de promoción de la autonomía personal y atención a las personas en situación de dependencia, cit., p. 50.

${ }^{237}$ Que incluye un compromiso en cofinanciación, gestión, información, asistencia técnica, participación y evaluación de las tres Administraciones. MARTÍN-SERRANO JIMÉNEZ, E.: El principio de cooperación como solución del Estado Autonómico. Una propuesta para la reforma (constitucional, o no) del sistema público de protección social en España, cit., p. 75.

238 MOLINA NAVARRETE, C.: "Los nuevos estatutos de autonomía y el reparto constitucional de competencias en las materias de empleo, trabajo y protección social", Revista Trabajo y Seguridad Social (Centro de Estudios Financieros), núm. 283, 2006, p. 109.
} 
con el Consejo Territorial de Servicios Sociales.

\section{Bibliografía}

ANAUT-BRAVO, S.: "Servicios sociales: definición en el marco del Estado de Bienestar", en VV.AA (ANAUT-BRAVO, S., Coord.): El sistema de servicios sociales en España, Aranzadi, Pamplona, 2019.

AGRA VIFORCOS, B. y MEGINO FERNÁNDEZ, D.: ““'Los cuidados a la vejez en el entorno rural: asistencia y el domicilio y teleasistencia”, en VV.AA (RODRÍGUEZ ESCANCIANO, S. y ÁLVAREZ CUESTA, H., Dirs.): La economía social como palanca para la sostenibilidad de los territorios rurales, Tirant Lo Blanch, Valencia (Tirant Lo Blanch), 2020.

ALEMÁN BRACHO, C. y ALONSO SECO, J.M.: "Los servicios sociales: sistema público de protección social”, Revista Española de Derecho del Trabajo, núm. 151, 2011.

ALONSO SECO, J.M.: "Las nuevas Leyes autonómicas de servicios sociales: hacia un reconocimiento progresivo de los servicios sociales como derechos subjetivos", Revista General de Derecho Administrativo, núm. 45, 2017.

ALONSO SECO, J. M. ${ }^{\mathrm{a}}$ y GONZALO GONZÁLEZ, B.: La asistencia social y los servicios sociales en España, BOE, Madrid, 1997.

ÁLVAREZ CUESTA, H.: "Transición justa y lucha contra el cambio climático en el Pacto Verde europeo y en el Proyecto de Ley de Cambio Climático en España", Iuslabor, núm. 2, 2020.

ARIAS MARTÍNEZ, M.A.: "Las competencias locales en materia de servicios sociales tras la aprobación de la Ley 27/2013, de 27 de diciembre, de racionalización y sostenibilidad de la Administración Local", Revista de Administración Pública, núm. 194, 2014.

BALLESTER PASTOR, M.A.: Retos y perspectivas de la discriminación laboral por razón de sexo, Tirant Lo Blanch, Valencia, 2016.

BALLESTER PASTOR, M.A.: "Del trabajo al trabajo de calidad: los nuevos retos de las politicas de empleo femeninos”, en VV.AA (MOYA AMADOR, R., Dir.): Estudios sobre diversos aspectos jurídicos del trabajo de la mujer, Aranzadi, Pamplona, 2016.

BALLESTER PASTOR, M.A.: "De los permisos parentales a la conciliación: expectativas creadas por la Directiva 2019/1158 y su transposición al ordenamiento español”, Derecho de las Relaciones Laborales, núm. 11, 2019.

BARCELÓN COBEDO, S.: "Seguridad Social y prestaciones en favor de cuidadores no profesionales”, en VV.AA (GONZÁLEZ ORTEGA, S., Dir.): La aplicación de la Ley de Dependencia en España, CES, Madrid, 2013. 
BARRIOS BAUDOR, G.: "La dependencia y su valoración", en VV.AA (MOLERO MARAÑÓN, M.L., Coord.): Retos para una implantación efectiva del Sistema para la Autonomía y Atención a la Dependencia, Cinca, Madrid, 2012.

BARRIOS BAUDOR, G.: "Avances y disfunciones en el procedimiento de reconocimiento de la dependencia: la valoración de la dependencia", Documentación Laboral, núm. 102, 2014, Vol. III.

BARRIOS BAUDOR, G.: "Modalidades contractuales en el sector de la dependencia: una aproximación al tema a propósito del VI Convenio Colectivo marco Estatal", en VV.AA (MOLERO MARAÑÓN, M.L., Dir.): Dependencia (long term care) y empleo en el Estado de Bienestar, Aranzadi, Pamplona, 2017.

BARRIOS BAUDOR, G..; SEMPERE NAVARRO, A.V. y MEGINO FERNÁNDEZ, D.: “Art. 369”, en VV.AA (SEMPERE NAVARRO, A.V. y BARRIOS BAUDOR, G.L., Dirs.): Comentarios a la Ley General de la Seguridad Social, Aranzadi, Pamplona, 2017.

BAVIERA PUIG, I.: "Desarrollo sostenible, transformación digital y atención a las personas: oportunidades y riesgos del envejecimiento demográfico", Adapt. Revista Internacional y Comparada de Relaciones Laborales y Derecho del Empleo, vol. 8, núm. $1,2020$.

BAYLOS GRAU, A.: “A propósito del envejecimiento", Revista de Derecho Social, núm. 87, 2019.

BAYLOS GRAU, A.: "Protección jurídica de las personas mayores. Tutela del empleo y del envejecimiento activo", en VV.AA.: Por una pensión de jubilación, adecuada, segura y sostenible, III Congreso Internacional y XVI Congreso Nacional de la Asociación Española de Salud y Seguridad Social, Laborum, Murcia, 2019.

BERNAL BLAY, M.A.: "La contratación de servicios a personas", en VV.AA.: Tratado de Contratos del Sector Público, vol. 3, Tirant Lo Blanch, Valencia, 2018.

BURILLO SÁNCHEZ, F.J.: "Las entidades de economía social como principales beneficiarias de la innovación social en la contratación pública", en VV.AA (GARCÍA ROMERO, B. y PARDO LÓPEZ, M.M, Dirs.): Innovación social en la contratación administrativa: las cláusulas sociales, Aranzadi, Pamplona, 2018.

CABEZA PEREIRO, J.: "Las políticas de conciliación al servicio de la igualdad entre hombres y mujeres", en VV.AA (CABEZA PEREIRO, J. y FERNÁNDEZ DO CAMPO, B., Dirs.): Conciliación de la vida familiar y laboral y corresponsabilidad entre sexos, Tirant Lo Blanch, Valencia, 2011.

CABEZAS CASADO, J.L. y GONZÁLEZ MALDONADO, M.C.: "La importancia de la participación en la tercera edad", en VV.AA (MONEREO PÉREZ, J.L.; MALDONADO MOLINA, J.A. y RUBIO HERRERA, R., Dir.): Prevención y protección de la dependencia: un enfoque transdisciplinar, Comares, Granada, 2018. 
CARRIL VÁZQUEZ, J.M.: “Argumentos de Derecho Internacional justificadores de que la legislación española tenga que adaptarse al envejecimiento de la población para proteger a las personas mayores con un sistema de atención (o de cuidados) a largo plazo", en VV.AA.: Estudios sobre Seguridad Social. Libro homenaje al profesor José Ignacio García Ninet, Atelier, Barcelona, 2017.

CARRODEGUAS MÉNDEZ, R.: "Reflexión crítica sobre el 'outsourcing' de los servicios sociales dirigidos a nuestros mayores en tiempos de covid", El Consultor de los Ayuntamientos y de los Juzgados, 5349/2020.

CASAS BAAMONDE, M.E.: "Igualdad, conciliación de la vida personal, familiar y laboral y Seguridad Social”, en VV.AA (MONEREO PÉREZ, J.L.; MOLINA NAVARRETE, C. y MORENO VIDA, M.N., Dirs.): Homenaje al Profesor José Vida Soria con motivo de su jubilación. La Seguridad Social a la luz de sus reformas pasadas, presentes y futuras, Comares, Granada, 2008.

CASAS BAAMONDE, M.E.: "Soberanía sobre el tiempo de trabajo e igualdad de trato y de oportunidades de mujeres y hombres", Derecho de las Relaciones Laborales, núm. 3, 2019.

CAVAS MARTÍNEZ, F.: "Aspectos fundamentales de la Ley de promoción de la autonomía personal y atención a las personas en situación de dependencia”, Aranzadi Social, núm. 13, 2006.

CAVAS MARTÍNEZ, F.: "Prestaciones del sistema", en VV.AA (MONTOYA MELGAR, A., Dir.): La protección de las personas dependientes. Comentario a la Ley 39/2006, de promoción de la autonomía personal y atención a las situaciones en situación de dependencia, Civitas, Madrid, 2007.

CAVAS MARTÍNEZ, F.: "La apuesta por el catálogo de servicios en el sistema de atención y protección de la dependencia”, Documentación Laboral, núm. 102, 2014.

CHINCHILlA MARÍN, C.: "La nueva Ley de Contratos del Sector Público: ámbito de aplicación y otras cuestiones novedosas", Revista Vasca de Administración Pública, núm. 79, 2007.

CRISTOBAL RONCERO, R.: "Los cuidadores familiares y su visualización”, en VV.AA (AESSS): Protección a la familia y Seguridad Social: Hacia un nuevo modelo de protección sociolaboral, II Congreso Internacional y XV Congreso Nacional de la Asociación Española de Salud y Seguridad Social, Vol. 1, Laborum, Murcia, 2018.

CUETO PÉREZ, M.: "Incertidumbre en las modalidades de gestión de servicios sociosanitarios tras la LCSP”, en VV.AA (TOLIVAR ALAS, L. y CUETO PÉREZ, M., Dirs.): La prestación de servicios socio sanitarios, Tirant Lo Blanch, Valencia, 2020.

DE LA VILLA GIL, L.E.: “Asistencia social y crisis económica”, Revista Universitaria de Ciencias del Trabajo, núm. 15, 2014. 
DE LAS HERAS HERNÁNDEZ, M.M.: "Cambios sustanciales en la protección jurídicopública de la persona en situación de dependencia: la estrangulada voluntad del beneficiario y de su familia y el alcance de su contribución al sostenimiento del SAAD”, Documentación Laboral, núm. 102, 2014, Vol. III.

DE NIEVES NIETO, N.: "Voluntariado y empleo en el tercer sector", Revista del Ministerio de Trabajo e Inmigración, núm. 33, 2001.

DE VICENTE PACHES, F.: "Asistencia social y servicios sociales: régimen de distribución de competencias", Tribuna Social, núm. 138, 2002.

DE VICENTE PACHÉS, F.: "Servicios sociales, envejecimiento activo y aprendizaje a lo largo de la vida", en VV.AA.: Por una pensión de jubilación, adecuada, segura y sostenible, Tomo II. III Congreso Internacional y XVI Congreso Nacional de la Asociación Española de Salud y Seguridad Social, Laborum, Murcia, 2019.

DE VICENTE PACHES, F.: Asistencia social y servicios sociales. Régimen de distribución de competencias, Secretaría General del Senado, Madrid, 2003.

DÍAZ AZNARTE, M.T.: “El sistema nacional de salud y las carteras de servicios común y complementarias: una visión crítica de la descentralización territorial en materia de asistencia sanitaria", en VV.AA (MORENO VIDA, M.N. y DÍAZ AZNARTE, M.T, Dir.): La protección social de la salud en el marco del Estado de bienestar: una visión nacional y europea, Comares, Granada, 2019.

DÍAZ LEMA, J.M.: "El Anteproyecto de Ley de racionalización y sostenibilidad de la Administración local: ¿cambio de rumbo en la Administración local española?”, en Anuario del Gobierno Local 2012, Madrid, Fundación Democracia y Gobierno Local, 2013.

DÍEZ SASTRE, S.: "Las cláusulas sociales en la contratación pública", Anuario de la Facultad de Derecho de la Universidad Autónoma de Madrid, núm. 21, 2017.

DOMÍNGUEZ MARTÍN, M.: "Los contratos de prestación de servicios a las personas. Repensando las formas de gestión de los servicios sanitarios públicos tras las Directivas de contratos de 2014 y la Ley 9/2017”, Revista General de Derecho Administrativo, núm. $50,2019$.

DOMÍNGUEZ MARTÍN, M.: "La acción concertada de los servicios a las personas en la Ley de Contratos del Sector Público y en la legislación autonómica”, en VV.AA (TOLIVAR ALAS, L., Dir.): La prestación de servicios socio sanitarios, Valencia, Tirant Lo Blanch, 2020.

DURÁN BERNARDINO, M.: "La distribución constitucional y legal de competencias en el modelo de protección social a la dependencia”, Aranzadi Social, núm. 8, 2013 (BIB 2013/2373). 
DURÁN BERNARDINO, M.: "La prestación económica para cuidados en el entorno familiar y su carácter excepcional a la luz de las últimas reformas”, Temas Laborales, núm. 124, 2014.

DURÁN BERNARDINO, M.: "La evolución de la acción protectora de las prestaciones de servicios. Impacto de las últimas reformas", en VV.AA (MOLERO MARAÑÓN, M.L., Dir.): Dependencia (long term care) y empleo en el Estado del Bienestar, Aranzadi, Pamplona, 2017.

ESCUDERO RODRÍGUEZ, R.: "El empleo en el sector de la dependencia", Documentación Laboral, núm. 102, 2014.

ESCUDERO RODRÍGUEZ, R.: “La injustificable desconexión legal entre el trabajo de cuidados en el hogar familiar y la protección de la dependencia", en VV.AA (MOLERO MARAÑóN, M.L., Dir.): Dependencia (long term care) y empleo en el Estado de Bienestar, Aranzadi, Pamplona, 2017.

ESTEBAN LEGARRETA, R.: "El voluntariado corporativo en el marco de la responsabilidad social empresarial. Nuevas cuestiones sobre las fronteras entre la actividad voluntaria y el contrato de trabajo", Derecho de las Relaciones Laborales, núm. $1,2017$.

FERNÁNDEZ ACEVEDO, R.: "Negocios y contratos excluidos", en VV.AA.: Estudio sistemático de la Ley de Contratos del Sector Público, Aranzadi, Pamplona, 2018.

FERNÁNDEZ COLLADOS, $M^{\mathrm{a}}$.B.: "Los cuidados en el entorno familiar más de una década después: los vaivenes en su regulación, su aplicación por la doctrina judicial y sus efectos en materia de igualdad", Nueva Revista Española de Derecho del Trabajo, núm. $210,2018$.

FERNANDEZ ORRICO, F.J.: “Art. 53”, en VV.AA (SEMPERE NAVARRO, A.V., Dir.): Comentarios a la Ley General de Seguridad Social, Laborum, Murcia, 2003.

FERNÁNDEZ ORRICO, F.J.: "Prestación económica para cuidados en el entorno familiar y Seguridad Social de cuidadores no profesionales", Revista Ministerio Trabajo y Asuntos Sociales, núm. 74, 2008.

FERNÁNDEZ SCAGLIUSI, M.A.: "La integración ambiental en la contratación pública: el certificado de eficiencia energética de los edificios", Revista General de Derecho Administrativo, núm. 49, 2018.

FIGUERUELO BURRIEZA, A., DE LORENZO, R.: "Los servicios sociales en la Constitución Española”, Revista General de Derecho Administrativo, núm. 52, 2019.

FONT I LLOVET, T.: “Gestión de servicios sociales en el ámbito local. Nuevos planteamientos sobre la ciudad y la contratación pública", en VV.AA (TOLIVAR ALAS, L. y CUETO PÉREZ, M., Dirs.): La prestación de servicios sociosanitarios: nuevo marco de la contratación pública, Tirant Lo Blanch, Valencia, 2020. 
FONTECHA LÓPEZ, A.: "Empleo y sistema para la autonomía y atención a la dependencia”, Documentación Laboral, núm. 102, 2014, vol. III.

FORTES MARTÍN, A.: "El nuevo contrato de servicios que conlleva prestaciones directas a favor de la ciudadanía ¿consolidación o disrupción del contrato de servicios públicos?", Revista General de Derecho Administrativo, núm. 52, 2019.

FORTES MARTÍN, A.: "La movilidad urbana sostenible como fenómeno jurídico: El derecho de la movilidad sostenible", en VV.AA (FORTES MARTÍN, A., Dir.): Movilidad urbana sostenible y acción administrativa. Perspectiva social, estrategias jurídicas y políticas públicas de movilidad en el medio urbano, Aranzadi, Pamplona, 2019.

GARCÉS SANAGUSTÍN, A.: La acción social: delimitación conceptual y régimen jurídico, Diputación General de Aragón, Zaragoza, 1988.

GARCÍA BLASCO, J.: "La experiencia aplicativa de las nuevas vertientes de protección social”, en VV.AA.: Estudios sobre Seguridad Social. Libro Homenaje al Profesor José Ignacio García Ninet, Atelier, Barcelona, 2017.

GARCÍA HERRERO, G.: "El servicio de ayuda a domicilio en la encrucijada", Revista de Derechos Sociales, núm. 49, 2011.

GARCÍA LUPIOLA, A.: "Normativa para el desarrollo sostenible: los paquetes legislativos 'economía circular' y ‘energía limpia”, Revista General de Derecho Europeo, núm. 50, 2020.

GARCÍA NINET, J.I.; DE VICENTE PACHÉS, F. y GARRIGUES GIMÉNEZ, A.: "Configuración técnica de los servicios sociales y régimen jurídico", en VV.AA (MONEREO PÉREZ, J.L.; MOLINA NAVARRETE, C. y MORENO VIDA, M.N., Coords.): La Seguridad Social a la luz de sus reformas pasadas, presentes y futuras, Comares, Granada, 2008.

GARRIDO JUNCAL, A.: Los servicios sociales en el siglo XXI. Nuevas tipologías y nuevas formas de prestación, Aranzadi, Pamplona, 2020.

GIMENO FELIÚ, J.M.: "Las condiciones sociales en la contratación pública: posibilidades y límites", Anuario del Gobierno Local, núm. 1, 2017.

GIMENO FELIÚ, J.M.: "La colaboración público-privada en el ámbito de los servicios sociales y sanitarios dirigidos a personas. Condicionantes europeos y constitucionales", Revista Aragonesa de Administración Pública, núm. 52, 2018.

GIMENO FELIÚ, J.M.: La Ley de Contratos de Sector Público 9/2017. Sus principales novedades, los problemas interpretativos y las posibles soluciones, Aranzadi, Pamplona, 2019.

GÓMEZ JIMÉNEZ, M.L.: "Vivienda domótica adaptada a la emergencia sanitaria: ideas preliminares, retos y propuestas normativas para la sociedad post covid-19", Revista de Derecho Urbanístico y medio ambiente, núm. 337-338, 2020. 
GONZÁLEZ DE PATTO, M.R.: “Cuestiones básicas sobre las políticas de empleo y contratación de la mujer”, en VV.AA (MOYA AMADOR, R., Dir.): Estudios sobre los diversos aspectos jurídicos del trabajo de la mujer, Aranzadi, Pamplona, 2016.

GONZÁLEZ ORTEGA, S.: "El cuidador no profesional de las personas en situación de dependencia de los mayores en la Ley 39/2006”, Temas Laborales, núm. 89, 2007.

GORELLI HERNÁNDEZ, J. "La nueva regulación de la adaptación de la jornada: de la melancolía a una esperanza contenida“, Derecho de las Relaciones Laborales, núm. 2, 2020 .

HERAS HERNÁNDEZ, M.L.: "Beneficiarios directos e indirectos de la protección social de la dependencia”, en VV.AA (MOLERO MARAÑÓN, M.L., Coord.): Retos para una implantación efectiva del sistema para la autonomía y atención a la dependencia, Cinca, Madrid, 2012.

HERAS HERNÁNDEZ, M.M.: “Cambios sustanciales en la protección jurídico pública de la persona en situación de dependencia: la estrangulada voluntad del beneficiario y su familia y el alance de su contribución al sostenimiento del SAAD”, Documentación Laboral, núm. 102, 2014, Vol. III.

HERRERA GÓMEZ, M.: El tercer sector en los sistemas de bienestar, Tirant Lo Blanch, Valencia, 1998.

HUETI-GARCÍA, A.; CHAVERRI-CARVAJAL, A. y MORALES-ROMO, N.: "El sistema para la autonomía y atención a la dependencia en España (SAAD). Memoria de debilidades desde su implantación”, Prisma Social, enero, 2021.

IGARTÚA MIRÓ, M.T.: “Conciliación y ordenación flexible del tiempo de trabajo. La nueva regulación del derecho de adaptación de jornada ex art. 34.8 ET", Revista General de Derecho del Trabajo y de la Seguridad Social, núm. 53, 2019.

LAGUNA DE PAZ, J.C.: "Regulación, externalización de actividades administrativas y autorregulación”, Revista de Administración Pública, núm. 185, 2011.

LANTARÓN BARQUÍN, D.: “Transparencia salarial y otras reflexiones a propósito de la discriminación por razón de género”, en VV.AA (MONSALVE CUÉLLAR, M,E., Coord.): Género y no discriminación, Alderabán, Madrid, 2019.

LLANO SÁNCHEZ, M.: "El marco procedimental del sistema de atención a la dependencia: balance crítico de los desarrollos normativos y de la práctica administrativa", Documentación Laboral, núm. 102, 2014, vol. III.

LLANO SÁNCHEZ, M.: "Los cuidados informales tras diez años de aplicación de la Ley de Dependencia: puntos críticos y algunas propuestas de mejora”, en VV.AA (MOLERO MARAÑÓN, M.L., Dir.): Dependencia (Long term care) y empleo en el Estado del Bienestar, Aranzadi, Pamplona, 2017.

LÓPEZ ANIORTE, M.C. y FERRANDO GARCÍA, M.C.: "Precariedad y desprotección social del trabajo de limpieza y cuidados ante la situación de crisis sanitaria provocada 
por la Covid-19", Adapt. Revista Internacional y Comparada de Relaciones Laborales y Derecho del Empleo, vol. 9, núm. 1, 2021.

LÓPEZ BALAGUER, M.: "Principio de igualdad en el acceso al empleo y en materia retributiva”, en VV.AA (BALLESTER PASTOR, M.A., Coord.): La transposición del principio antidiscriminatorio contrario al ordenamiento jurídico laboral español, Tirant Lo Blanch, Valencia, 2010.

LÓPEZ CUMBRE, L.: “La pensión de jubilación”, en VV.AA.: Derecho de la Seguridad Social, Tirant Lo Blanch, Valencia, 1997.

LÓPEZ-VEIGA BREA, J.: "Novedades relacionadas con la contratación pública socialmente responsable. Especial referencia a la discapacidad en el texto refundido de la Ley de Contratos del Sector Público en España”, en VV.AA: Contratación, ordenación del territorio y buena administración, Diputación, La Coruña, 2018.

LOUSADA AROCHENA, J.F.: "La construcción de los derechos de conciliación de la vida personal, familiar y laboral como derechos fundamentales", Derecho de las Relaciones Laborales, núm. 9, 2019.

LOZANO LARES, F.: "Los déficits de protección social del trabajo femenino", Revista General de Derecho del Trabajo y Seguridad Social, núm. 58, 2021.

MALDONADO MOLINA, J.A.: Génesis y evolución de la protección social por vejez en España, MTAS, Madrid, 2002.

MALDONADO MOLINA, J.A.: El seguro de dependencia. Presente y proyecciones de futuro, Tirant Lo Blanch, Valencia, 2003.

MARTÍN VALVERDE, A.: "Asistencia social: propuesta de reconstrucción de un concepto constitucional”, en VV.AA (MONEREO PEREZ, J.L.; MOLINA NAVARRETE, C. y MORENO VIDA, M.N., Coords.): La Seguridad Social a la luz de sus reformas pasadas, presentes o futuras. Homenaje al Profesor José Vida Soria con motivo de la jubilación, Comares, Granada, 2008.

MARTÍN VALVERDE, A.: "Asistencia social: propuesta de reconstrucción de un concepto constitucional", Anuario de la Facultad de Derecho de la Universidad de Oviedo, núm. 2, 2017.

MARTÍNEZ BARROSO, M.R.: "La atención a la dependencia en el mundo rural", en VV.AA (RODRÍGUEZ ESCANCIANO, S. y ÁLVAREZ CUESTA, H., Dirs.): La economía social como palanca para la sostenibilidad de los territorios rurales, Tirant Lo Blanch, Valencia, 2020 (en prensa).

MARTÍNEZ FONS, D.: "La contratación pública como instrumento de la política de empleo y la libre competencia", en VV.AA.: Los mercados laborales y las políticas sociales en Europa, XX Congreso Nacional de Derecho del Trabajo y de la Seguridad Social, Vol. II, MTSS, Madrid, 2010. 
MARTÍNEZ MORENO, C.: "Vida privada y relación de trabajo. A propósito de la posibilidad de pactar individualmente las condiciones de ejercicio de los derechos de conciliación de la vida familiar y laboral”, Tribuna Social, núm. 97, 2007.

MARTÍNEZ MORENO, C.: Brecha salarial de género y discriminación retributiva: causas y vías para combatirlas, Bomarzo, Albacete, 2019.

MARTÍN-SERRANO JIMÉNEZ, E.: El principio de cooperación como solución del Estado Autonómico. Una propuesta para la reforma (constitucional o no) del sistema público de protección social en España, Comares, Granada, 2018.

MENDOZA JIMÉNEZ, J.; ROMÁN CERVANTES, C.A. y HERNÁNDEZ LÓPEZ, M.: "Los contratos reservados: una herramienta para el fortalecimiento de las entidades sociales", Ciriec: Revista Jurídica de Economía Social y Cooperativa, núm 83, 2018.

MENÉNDEZ REXACH, A.: "Los objetivos económicos de la regulación del suelo (1956-2015)”, Revista de Derecho Urbanístico y Medio Ambiente, núm. 311, 2017.

MERCADER UGUINA, J.R.: "Titularidad, valoración y reconocimiento de las situaciones de dependencia", Temas Laborales, núm. 89, 2007.

MIÑARRO YANINI, M.: El trabajo al servicio del hogar familiar: análisis de su nueva regulación, Reus, Madrid, 2013.

MIÑARRO YANINI, M.: "Innovación tecnológica, organización del trabajo y sostenibilidad ambiental: ¿es el teletrabajo una forma de empleo verde?”, Revista Trabajo y Seguridad Social (Centro de Estudios Financieros), núm. 454, 2021.

MOLERO MARAÑÓN, M.L.: "La necesaria reorientación de la conciliación de la vida profesional y familiar y la negociación colectiva”, Relaciones Laborales, núm. 19, 2011.

MOLERO MARAÑÓN, M.L.: "El espacio de las prestaciones económicas en la protección social de las personas dependientes: una reflexión sobre el sistema de cuidados deseable", Documentación Laboral, núm. 102, 2014, vol. III.

MOLERO MARAÑÓN, M.L.: "Un replanteamiento del modelo español de atención a la dependencia (long term care) en el contexto europeo", en VV.AA (MOLERO MARAÑÓN, M.L., Dir.): Dependencia (long term care) y empleo en el Estado del Bienestar, Aranzadi, Pamplona, 2017.

MOLERO MARAÑ́́N, M.L.: Bases, evolución y retos de la Ley de Dependencia a los diez años de su aprobación, Bomarzo, Albacete, 2017.

MOLERO MARAÑÓN, M.L.: "Los desafíos de una genuina conciliación de la vida profesional y familiar en la sociedad española del siglo XXI", Revista del Ministerio de Trabajo, Migraciones y Seguridad Social, núm. Extraordinario, 2019.

MOLERO MARAÑÓN, M.L.: "Las trabajadoras del cuidado. Por un futuro de trabajo decente”, Revista de Derecho Social, núm. 89, 2020. 
MOLINA GONZÁLEZ-PUMARIEGA, R.: "Los servicios del Sistema para la Autonomía y Atención a la Dependencia tras seis años de funcionamiento", en VV.AA (MOLERO MARAÑÓN, Ma.L., Coord.): Retos para una implantación efectiva del Sistema para la Autonomía y Atención a la Dependencia, Cinca, Madrid, 2012.

MOLINA NAVARRETE, C.: "Los nuevos estatutos de autonomía y el reparto constitucional de competencias en las materias de empleo, trabajo y protección social", Revista Trabajo y Seguridad Social (Centro de Estudios Financieros), núm. 283, 2006.

MOLINA NAVARRETE, C.: "El régimen cuasi-profesional de cuidados de las personas dependientes", Revista Trabajo y Seguridad Social (Centro Estudios Financieros), núm. 297, 2007.

MOLINA NAVARRETE, C.: "Autodeterminación (soberanía) sobre el tiempo y adaptación de la jornada a la carta por razones conciliatorias: entre utopías ”, Revista Trabajo y Seguridad Social (Centro de Estudios Financieros), núm. 441, 2019.

MONEREO PÉREZ, J.L. y FERNÁNDEZ BERNAT, J.A.: "La iniciativa privada en la protección de la dependencia. Instrumentos e instituciones privadas de aseguramiento y asistencia”, en VV.AA (MONEREO PÉREZ, J.L.; MALDONADO MOLINA, J.A. y RUBIO HERRERA, R., Dirs.): Prevención y protección de la dependencia: un enfoque transdisciplinar, Comares, Granada, 2014.

MORALES ORTEGA, J.M.: "Tiempo de trabajo y crisis sanitaria: adaptación y reducción de jornada y permiso obligatorio recuperable", Trabajo, Persona, Derecho, Mercado, núm. 1, 2020.

NICOLÁS MARTÍNEZ, C. y RIQUELME PEREA, P.: “Análisis y retos del sistema de autonomía y atención a la dependencia”, en VV.AA (LÓPEZ ANIORTE, M.C. y GARCÍA ROMERO, B.: Envejecimiento, cuidados y dependencia: hacia una protección social con perspectiva de género, Aranzadi, Pamplona, 2020.

NUÑEZ-CORTÉS CONTREAS, P.: Novedades en relación con la jornada de trabajo y los derechos de conciliación (tras la aprobación del RD 6/2019, de 1 de marzo), Dykinson, Madrid, 2019.

NUÑEZ-CORTÉS CONTRERAS, P.: "Avances en corresponsabilidad y flexibilidad en cuidado del lactante y adaptación de jornada por motivos familiares", Revista General de Derecho del Trabajo y de la Seguridad Social, núm. 55, 2020.

PÉREZ DÍAZ, J. y ABELLÁN GARCÍA, A.: "Envejecimiento demográfico y vejez en España", Panorama Social, núm. 28, 2018.

POQUET CATALÁ, R.: “Covid-19, crisis sanitaria, económica y laboral: ¿hacia un trabajo decente en el trabajo doméstico?", Adapt. Revista Internacional y Comparada de Relaciones Laborales y Empleo, Vol. 9, núm. 1, 2021.

PRADOS, C.: "Prevención y mantenimiento de la autonomía de los mayores: la ayuda a domicilio", Cuadernos de Trabajo Social, núm. 14, 2001. 
QUESADA SEGURA, R.: "De nuevo sobre el sistema especial de Seguridad Social de Personas Empleadas de Hogar. Puntos críticos", Revista de Derecho de la Seguridad Social, núm. 3, 2015.

QUINTANA LÓPEZ, T.: "Hacia un modelo de urbanismo sostenible", en VV.AA (QUINTANA LÓPEZ, T., Dir.): Urbanismo sostenible. Rehabilitación, regeneración y renovación urbanas, Tirant Lo Blanch, Valencia, 2015.

RAMOS QUINTANA, M.I.: "El futuro del trabajo y las mutaciones del empleo", Trabajo y Derecho, núm. 11, 2015.

REVUELTA ALONSO, M.L.: "La ayuda a domicilio como servicio de proximidad en el contexto social actual”, Humanismo y Trabajo Social, Vol. 15, 2015.

RODRÍGUEZ BEAS, M.: "El encaje de las reglas de mercado en la gestión de los servicios sociales y sanitarios", en VV.AA (FONS I FERNÁNDEZ, M.V., Ed.): La protección jurídica de la atención a las personas en materia de servicios sociales. Una perspectiva multidisciplinar, Atelier, Barcelona, 2020.

RODRÍGUEZ CARDO, I.A.: "El nuevo sistema especial de empleados de hogar: una revolución inconclusa", Nueva Revista Española de Derecho del Trabajo, núm. 158, 2013.

RODRÍGUEZ ESCANCIANO, S.: "La atención a las necesidades de las personas mayores desde los servicios sociales", en VV.AA.: Por una pensión de jubilación, adecuada, segura y sostenible, III Congreso Internacional y XVI Congreso Nacional de la Asociación Española de Salud y Seguridad Social, Vol. II, Laborum, Murcia, 2019.

RODRÍGUEZ ESCANCIANO, S.: "La vis expansiva de las cláusulas sociales en el sistema de contratación pública: un cauce para el fomento del empleo de los colectivos más desfavorecidos permitido por el Derecho Comunitario", en VV.AA.: Los mercados laborales y las políticas sociales en Europa, Vol. II, XX Congreso Nacional de Derecho del Trabajo y de la Seguridad Social, MTSS, Madrid, 2010.

RODRÍGUEZ ESCANCIANO, S.: "Los cuidados en la vejez como servicio social público esencial: hacia una cobertura integral”, Revista General de Derecho del Trabajo y de la Seguridad Social, núm. 57, 2020.

RODRÍGUEZ ESCANCIANO, S.: "Medidas para la conciliación de la vida laboral y familiar ante la emergencia sanitaria por covid-19", Derecho de las Relaciones Laborales, núm. 4, 2020.

RODRÍGUEZ ESCANCIANO, S.: "Sostenibilidad laboral en el sector de la construcción: la estabilidad en el empleo como premisa”, Temas Laborales, núm. 152, 2020 .

RODRÍGUEZ MARTÍN-RETORTILLO, M.C.: "Los contratos de teleasistencia en la doctrina de los Tribunales administrativos de contratación", Anuario de la Facultad de Derecho de la Universidad de La Coruña, núm. 23, 2019. 
RODRÍGUEZ RODRÍGUEZ, P.: "La atención integral centrada en la persona (Principios y criterios que fundamentan un modelo de intervención en discapacidad, envejecimiento y dependencia)", Informes Portal Mayores, núm. 106, 2010.

ROJO-PÉREZ, F. y FERNÁNDEZ-MAYORALAS, G.: "La calidad de vida en la población mayor", Panorama Social, núm. 28, 2018.

ROLDÁN AYUSO, S.: "La necesidad de un replanteamiento en la financiación de la dependencia. El endurecimiento del copago", en VV.AA (MOLERO MARAÑÓN, M.L., Dir.): Dependencia (long term care) y empleo en el Estado de Bienestar, Aranzadi, Pamplona, 2017.

ROQUETA BUJ, R.: “Las prestaciones económicas”, en VV.AA (ROQUETA BUJ, R., Coord.): La protección de la dependencia, Tirant Lo Blanch, Valencia, 2007.

ROQUETA BUJ, R.: "Principios básicos del sistema de protección social: el principio de igualdad territorial a debate”, Documentación Laboral, núm. 102, 2014, vol.III.

RUANO ALBERTOS, S.: "Integración del régimen especial de la Seguridad Social de los empleados de hogar en el régimen general de la Seguridad Social”, Revista General de Derecho del Trabajo y de la Seguridad Social, núm. 29-30, 2012.

RUBIO HERRERA, R. y CASTELLÓN SÁNCHEZ DEL PINO, A.: "Las situaciones de dependencia desde una perspectiva socio-sanitaria”, en VV.AA (MONEREO PÉREZ, J.L.; MALDONADO MOLINA, J.A. y RUBIO HERRERA, R., Dir.): Prevención y protección de la dependencia: un enfoque transdisciplinar, Comares, Granada, 2014.

RUBIO RUBIO, L. y DUMITRACHE, C.G.: "Salud y tercera edad", en VV.AA (MONEREO PÉREZ, J.L.; MALDONADO MOLINA, J.A. y RUBIO HERRERA, R., Dirs.): Prevención y protección de la dependencia: un enfoque transdisciplinar, Comares, Granada, 2014.

SALVADOR PÉREZ, F.: "La nueva pensión no contributiva de jubilación: objeto de la protección y régimen jurídico" (I), Actualidad Laboral, núm. 7, 1992.

SÁNCHEZ, V.: "Las implicaciones de la economía digital en el sector de la construcción”, Gaceta Sindical, núm. 27, 2016.

SÁNCHEZ-TERÁN HERNÁNDEZ, J.M.: "En las fronteras del contrato de trabajo: el cuidador no profesional de las personas en situación de dependencia", Revista Trabajo y Seguridad Social (Centro Estudios Financieros), núm. 70, 2008.

SANCHO CASTIELLO, M. y DÍAZ MARTÍN, R.: "Atención a las personas mayores en su entorno: teleasistencia, ayuda a domicilio y centros de día", Sociedad y Utopía. Revista de Ciencias Sociales, núm. 30, 2007.

SANTIAGO IGLESIAS, D.: "Iniciativas para un futuro urbano sostenible: las Smart cities”, en VV.AA (QUINTANA LÓPEZ, T., Dir.): Urbanismo sostenible. Rehabilitación, regeneración y renovación urbanas, Tirant Lo Blanch, Valencia, 2015. 
SANZ MERINO, A.R.: Manual básico del sistema de Seguridad Social, La Ley, Madrid, 2010 .

SELMA PENALVA, A.: "La (des)protección social de los cuidadores no profesionales", Revista de Derecho Social y Empresa, núm. 10, 2019.

SERRANO GARCÍA, M.J.: "La distribución constitucional de competencias en el ámbito de la dependencia”, en VV.AA (MOLERO MARAÑÓN, M.L., Dir.): Dependencia (long term care) y empleo en el Estado de Bienestar, Aranzadi, Pamplona, 2017.

TERRÓN SANTOS, D.: "Políticas de dependencia en el Estado de las Autonomías", Revista Noticias de la Unión Europea, núm. 303, 2010.

TORRES FERNÁNDEZ, J.J.: "Administración contratante y contratistas de las Administraciones Públicas", Revista Española de Control Exterior, 2007.

TRILLO GARCÍA, A.R.: “Art. 62 y Art. 63”, en VV.AA (SEMPERE NAVARRO, A.V. y BARRIOS BAUDOR, G.L., Dirs.): Comentarios a la ley General de la Seguridad Social, Volumen I, Aranzadi, Pamplona, 2017.

VADILLO RUÍZ, J.J.: "Respuestas a los nuevos retos de envejecimiento, protección a la salud y cuidados: la perspectiva médica", en VV.AA.: Por una pensión de jubilación, adecuada, segura y sostenible, III Congreso Internacional y XVI Congreso Nacional de la Asociación Española de Salud y Seguridad Social, Laborum, Murcia, 2019.

VALDÉS DAL-RE, F.: "Una aproximación constitucional a los problemas competenciales de la Ley de Dependencia”, Documentación Laboral, núm. 102, 2014.

VAN-HALEN RODRÍGUEZ, J., "Ciudades sostenibles: un reto inaplazable", Revista de Derecho Urbanístico y Medio Ambiente, núm. 300, 2015.

VELASCO CABALLERO, F.: "Nuevo régimen de competencias municipales en el Anteproyecto de Racionalización y Sostenibilidad de la Administración Local", Anuario de Derecho Municipal 2012, núm. 6, 2013.

VILLALTA REIXACH, M.: "Los convenios administrativos a la luz de la nueva Ley de Contratos del Sector Público", en VV.AA.: Estudio sistemático de la Ley de Contratos del Sector Público, Aranzadi, Pamplona, 2018.

ZAMORA ROSELLÓ, M.R.: “Administración local y ciudadanía: pilares de las políticas públicas en materia de servicios sociales", Adapt, Revista Internacional y Comparada de Relaciones Laborales y Derecho del Empleo, vol. 7, núm. 4, 2019.

ZAMORANO WISNES, J.: "El derecho a la ciudad sostenible", Revista de Estudios de la Administración Local y Autonómica, núm. 15, 2021. 